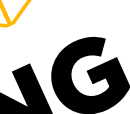

\section{Disability and Distress: \\ The Effect of Disability Programs on Financial Outcomes}

Manasi Deshpande

Tal Gross

Yalun Su

Working Paper

$2019-020$

$03 / 2019$
$Y$ HUMAN CAPITAL AND

ECONOMIC OPPORTUNITY

GLOBAL WORKING GROUP
The University of Chicago 1126 E. 59th Street Box 107 Chicago IL 60637 


\title{
Disability and Distress: The Effect of Disability Programs on Financial Outcomes*
}

\author{
Manasi Deshpande ${ }^{\dagger} \quad$ Tal Gross ${ }^{\ddagger} \quad$ Yalun $\mathrm{Su}^{\S}$
}

March 2019

\begin{abstract}
We provide the first evidence on the relationship between disability programs and markers of financial distress: bankruptcy, foreclosure, eviction, and home sale. Rates of these adverse financial events peak around the time of disability application and subsequently fall for both allowed and denied applicants. To estimate the causal effect of disability programs on these outcomes, we use variation induced by an age-based eligibility rule and find that disability allowance substantially reduces the likelihood of adverse financial events. Within three years of the decision, the likelihood of bankruptcy falls by 0.81 percentage point (30 percent), and the likelihood of foreclosure and home sale among homeowners falls by 1.7 percentage points (30 percent) and 2.5 percentage points (20 percent), respectively. We find suggestive evidence of reductions in eviction rates. Conversely, the likelihood of home purchases increases by 0.86 percentage point (20 percent) within three years. We present evidence that these changes reflect true reductions in financial distress. Considering these extreme events increases the optimal disability benefit amount and suggests a shorter optimal waiting time.
\end{abstract}

*We are grateful to Stephane Bonhomme, Michael Dinerstein, Keith Ericson, Amy Finkelstein, Andrey Fradkin, Peter Ganong, Mike Golosov, Michael Greenstone, Lars Hansen, Jeffrey Hemmeter, Greg Kaplan, Camille Landais, Jeffrey Liebman, Lee Lockwood, Neale Mahoney, Magne Mogstad, Tim Moore, Derek Neal, Matthew Notowidigdo, Jesse Shapiro, Alex Torgovitsky, Jialan Wang, Melanie Wasserman and workshop participants at the University of Chicago, the University of Virginia, the University of Michigan, NBER Public Economics, Boston University, RAND, and NBER Health Care for useful feedback. We thank John Phillips, Jason Brown, Natalie Lu, Ted Horan, Mark Sarney, Lynn Fisher, and Linda Martin of the Social Security Administration for making this work possible and providing access to data. The authors are grateful to the Washington Center for Equitable Growth and the Ronzetti Initiative for the Study of Labor Markets at the Becker-Friedman Institute for financial support. This research was supported by the U.S. Social Security Administration through grant \#5 DRC12000002-06 to the National Bureau of Economic Research as part of the SSA Disability Research Consortium. The findings and conclusions expressed are solely those of the authors and do not represent the views of the Social Security Administration, any agency of the Federal Government, or the NBER.

${ }^{\dagger}$ Kenneth C. Griffin Department of Economics, University of Chicago and NBER.

${ }^{\ddagger}$ Questrom School of Business, Boston University and NBER.

${ }^{\S}$ Kenneth C. Griffin Department of Economics, University of Chicago. 
More than 6 percent of working-age adults in the United States receive disability benefits through the Social Security Disability Insurance (SSDI) program or the Supplemental Security Income (SSI) program. The expansion of these programs over the past decades has prompted a public debate about their costs and benefits. On the cost side, disability programs can distort decisions about work and human-capital investment. On the benefits side, disability programs can provide protection against major consumption shocks such as disability.

Research on disability programs has focused mostly on the costs of these programs, especially on their labor-supply effects, which are often interpreted as moral-hazard costs. Several studies have found that allowance onto disability insurance reduces labor force participation by about 30 percentage points. ${ }^{1}$ If interpreted as moral hazard, these labor supply effects suggest that disability programs involve some disincentive costs.

Yet there is little evidence on the other side of the analysis, the benefits of disability programs. To our knowledge, there are no quasi-experimental studies that assess the effects of US disability programs on outcomes other than labor supply and mortality. ${ }^{2}$ In the absence of such studies, evidence on how disability programs affect quality of life, residential stability, and consumption is mostly anecdotal. In Evicted, Matthew Desmond writes of a recipient of the SSI program that "her $\$ 754$ monthly [SSI] check was more reliable than any job she could get," and explains that landlords seek out SSI recipients because their stable income makes them reliable tenants (Desmond, 2016). These hypotheses have yet to be tested in empirical research.

This paper presents the first evidence on the effect of disability programs on financial outcomes. We link administrative records from the Social Security Administration's (SSA) SSDI and SSI programs to records on bankruptcy, foreclosure, eviction, home purchases, and home sales. ${ }^{3}$ These financial outcomes are not direct measures of consumption or well-being.

\footnotetext{
${ }^{1}$ Bound (1989) uses the labor supply of denied disability-insurance applicants as an upper bound for allowed applicants, concluding that employment among disability-insurance recipients would be, at most, 30 percentage points higher had they been denied. Updating Bound's analysis, von Wachter et al. (2011) find similar effects for older cohorts and larger effects for younger cohorts. Chen and van der Klaauw (2008) find smaller employment effects for more-recent applicants. Maestas et al. (2013) and French and Song (2014) use examiner- and judge-based fixed-effects instruments to estimate labor-supply effects of around 30 percentage points. Moore (2015) estimates similar effects for disability recipients whose eligibility based on drug and alcohol addiction was terminated as part of the 1996 welfare reform law.

${ }^{2}$ Autor et al. (Forthcoming) study the effects of disability benefits receipt on consumption in Norway, and Gelber et al. (2018) study the effect of disability benefits on mortality in the US. Meyer and Mok (2018) study differences in the consumption drop surrounding disability for those who receive disability benefits and those who do not. Low and Pistaferri (2015) model the role of disability benefits and their interaction with other welfare programs in insuring the consumption of disability recipients.

${ }^{3}$ All of the non-SSA data we study exist in the public domain. Gross and Trenkamp (2015) were the first to link bankruptcy data to SSA administrative data.
} 
They are rather "tail events," events that occur infrequently and are associated with large drops in consumption. In the absence of administrative data on consumption, studying these extreme events sheds light on fluctuations in consumption that would otherwise be entirely unobservable.

Using this novel dataset, we document three descriptive facts. First, rates of bankruptcy, foreclosure, and eviction among applicants are higher than in the general population, suggesting that disability applicants are more likely to experience financial distress. Second, for disability applicants, rates of these adverse financial events increase leading up to the application date and peak around the application date. This trend indicates that disability applicants apply for disability programs when they are in relatively high financial distress. Third, these adverse financial events become less common after the disability decision, even for initially denied applicants, suggesting that applicants find other margins of adjustment.

This evidence of selection effects and time effects points to the need for causal identification of the effect of disability programs on financial outcomes. To identify the causal effect, we exploit an administrative rule that governs how the SSA evaluates applicants. During the fifth step of the initial determination process, SSA examiners decide whether an applicant can work in some capacity given his or her disability as well as vocational factors such as age, education, and experience. SSA guidelines require examiners to use more-lenient standards for older applicants. Applicants who are older than age 55 at the time of decision are judged using more-lenient standards than applicants between ages 50 and 55, who in turn are judged using more-lenient standards than applicants below age 50. These age-based rules, first used by Chen and van der Klaauw (2008) to estimate the effect of disability insurance on labor supply, allow us to isolate the causal effect of disability receipt on financial outcomes.

The results suggest that being allowed onto disability programs at the initial level (before appeals) results in large declines in rates of bankruptcy, foreclosure, and home sale. Initial allowance reduces the likelihood of filing for bankruptcy by a statistically significant 0.81 percentage point, or 30 percent, in the next three years. For homeowners, the likelihood of experiencing foreclosure in the three years after initial decision falls by 1.7 percentage points (30 percent) and the likelihood of selling a home falls by 2.5 percentage points (20 percent), both statistically significant at conventional levels. We find suggestive evidence that eviction rates also decline as a result of disability allowance, though the estimates are imprecise. Allowance onto disability programs also increases home purchases by 0.86 percentage point (20 percent). Most of the change in housing transactions is driven by allowed applicants becoming first-time homeowners or being less likely to sell their home overall, not by a change in the likelihood of moving from one home to another. These results suggest that some program recipients use their benefits to purchase homes or to stay in 
homes that they might otherwise have sold or lost to foreclosure.

Of course, these financial outcomes are not direct measures of recipient welfare. We outline the assumptions required to interpret the declines in adverse financial events as a "wealth effect:" true reductions in financial distress due to the transfer of cash and health insurance, and therefore improvements in recipient welfare. We consider alternative mechanisms, such as changes in access to credit and demand for credit. We conclude based on evidence from several sources that they are unlikely to drive the results and, if anything, would lead us to underestimate the wealth effect.

To consider the welfare implications of these results, we use our estimates to extend the standard calculations of optimal-benefit levels in two ways. First, we incorporate tail consumption risk into optimal-benefits calculations. Standard calculations of optimal-benefit levels use the difference between mean consumption in the good state of the world and mean consumption in the bad state of the world as a sufficient statistic for the welfare gains from insurance. However, risk-averse agents care about the likelihood of extreme losses in consumption in addition to mean consumption. We map the "tail events" that we observe into consumption changes using survey data. Foreclosure, for example, is associated with an annual \$6,300 drop in consumption, based on an event-study analysis using the Panel Study of Income Dynamics. We find that the optimal annual benefit increases by several hundred dollars when we use these estimates of tail consumption risk in optimal-benefits calculations. This increase would likely be even larger considering effects along the entire consumption distribution.

Second, we extend the standard calculations of optimal-benefit levels to consider spillovers to third parties from disability programs. We focus on higher property values for neighboring property owners from the reduction in foreclosures, though there could be other spillovers from disability programs. We find that the optimal annual benefit amount increases by approximately one hundred dollars when considering spillovers to neighboring property owners. Another way to put the property-related spillovers in context is to compare them to the effect of the disability programs on earnings. Disability allowance reduces labor market earnings by $\$ 3,300$ over three years; it increases housing values due to an averted foreclosure by roughly $\$ 2,400$, which is 70 percent of the decrease in earnings. ${ }^{4}$

Finally, we consider the implications of our results for the optimal timing of disability benefits. Descriptively, we find that disability applicants apply for the program when they are in high financial distress, both relative to the general population and relative to their own

\footnotetext{
${ }^{4}$ We quantify this positive externality and incorporate it into calculation of the marginal value of public funds (MVPF) for disability programs (Hendren, 2016). The positive spillovers due to reductions in bankruptcy and foreclosure increase the MVPF of disability programs from 0.99 to 1.04.
} 
histories. Causally, we find that disability benefits reduce financial distress substantially. All else equal, these facts together make the case for shorter wait times, though they must be weighed against the administrative costs and potential selection effects of shorter wait times.

The paper proceeds as follows. Section 1 describes the datasets and data-merge procedures. Section 2 presents descriptive facts on financial outcomes for the disability-applicant population. Section 3 describes the age-based eligibility rule, presents preliminary visual evidence of the causal effect, and presents IV estimates of the effect of disability programs on financial outcomes. Finally, Section 5 discusses the implications for recipient and social welfare and presents optimal benefit calculations, and Section 6 concludes.

\section{Institutional Background and Data}

\subsection{Background on Disability Programs and the Financial Outcomes We Study}

SSA administers the Social Security Disability Insurance (SSDI) and Supplemental Security Income (SSI) programs. SSDI and SSI have the same medical requirements but different non-medical requirements. SSDI requires an earnings history. ${ }^{5}$ SSI requires applicants to have low income and low assets. Individuals can apply for and receive benefits from both programs concurrently if they meet both sets of requirements. If applicants are allowed onto both programs, the SSI benefit is reduced by approximately the amount of the SSDI benefit.

The non-medical eligibility of both disability programs also requires applicants not to engage in substantial gainful activity (SGA). The SGA threshold for 2017 was $\$ 1,170$ per month, which means that applicants will be denied for benefits if they earn more than $\$ 1,170$ a month on average. The average monthly benefit for SSDI in 2017 was $\$ 1,197$ and the maximum monthly benefit for SSI for an individual was $\$ 735 .^{6}$ Program rules prohibit disability recipients from performing SGA and receiving disability benefits at the same time.

Bankruptcy is a legal procedure available to debtors overwhelmed by their debts. Bankruptcy filers can either file for Chapter 7 and have their debts discharged entirely, or file for Chapter 13 and commit to a repayment plan. The Bankruptcy Abuse Prevention and Consumer Protection Act (BAPCPA) of 2005 imposed a means test for Chapter 7 discharge, and the number of bankruptcy filings, particularly Chapter 7, plummeted after 2005 as a result of this reform. ${ }^{7}$ Filing for either type of bankruptcy is expensive; bankruptcy attorney fees

\footnotetext{
${ }^{5}$ The earnings history is usually the applicant's, though there are circumstances under which a widow or widower applies based on their spouse's earnings history.

${ }^{6}$ Annual Statistical Report on the Social Security Disability Insurance Program, 2017, Table 2; and Fast Facts and Figures about Social Security, 2018.

${ }^{7}$ Before 2005, consumers could choose under which chapter they wanted to file. Filers faced a tradeoff: under Chapter 7, their "non-exempt" assets would be divided among their creditors, while under Chapter 13,
} 
typically cost at least $\$ 1,000$, and many households must thus "save up" for bankruptcy (Gross et al., 2016).

In contrast to bankruptcy, the foreclosure process is initiated by a lender in response to a borrower who has become delinquent on a secured loan. The mortgage lender first issues a precaution notification and only then may choose to pursue a forced home sale in order to recover the remaining mortgage debt. Depending on state law, the time required to complete a foreclosure process varies from six months to eighteen months. In some cases, lenders and homeowners can reach an agreement or negotiate a settlement plan so that the debtors can keep the home.

Eviction is a legal process that landlords use to remove tenants for failing to pay rent or breaking other terms of the lease. ${ }^{8}$ After an initial grace period, a landlord can choose to file a request with the court and the tenant will be served. If the judge grants the landlords request, an order is placed with the sheriff and the sheriff evicts the tenant. Depending on jurisdiction and case backlogs, the entire eviction process varies from 30 days to more than six months.

\subsection{Merging Social Security Disability Records to Financial Records}

We link administrative records from the Social Security Administration to records on bankruptcies, foreclosures, evictions, and home transactions. Figure 1 summarizes the data merges. We start with an extract of the SSA 831 Disability File (F831) that includes the universe of disability applicants who received a disability decision between 2000 and 2014. The F831 files provide identifiers, including Social Security number (SSN), first name, last name, middle initial, and ZIP Code of residence; application history, including the dates of application and initial decision and the reason for the decision; and demographic information, including body system code, specific diagnosis, and, for those who are allowed, medical diary reason, which determines the frequency of continuing disability reviews. For the purposes of the quasi-experimental analysis, we use the classification of regulation basis codes in the F831 files developed by Wixon and Strand (2013). We then link the F831 extract to extracts of several other SSA datasets. The Master Beneficiary Record (MBR) provides the final

they would not lose their assets. Social Security benefits are excluded from the means test, and so allowance onto a disability program does not mechanically affect the choice of bankruptcy chapter (Social Security Rulings 79-4).

8 "Formal" eviction involves both removing the tenant and recovering back rent, while "summary" eviction involves only removing the tenant. Both processes involve legal filings with a court, but many landlords prefer summary eviction as it is relatively easy to file without the assistance of an attorney and the procedure is shorter. There are also "informal eviction" cases where tenants are forced to end their lease due to difficulties, such as large increases in rent, created by landlords. As these cases do not involve any court filing, we are not able to observe these cases in our data. 
disability decision and decision date for SSDI applicants, and the Supplemental Security Record (SSR) provides these variables for SSI applicants. The Master Earnings File (MEF) provides annual earnings for all workers. The Structured Data Repository (SDR) provides applicant ZIP Codes after 2010.

Figure 1: Merging Social Security Disability Records to Financial Records

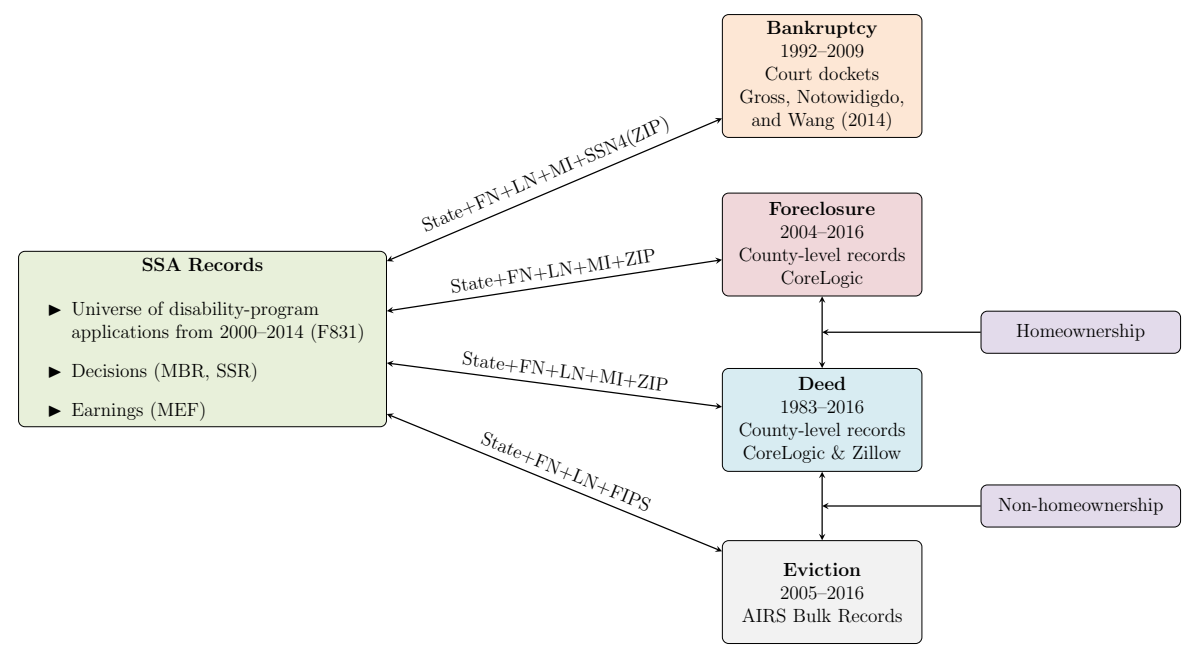

Notes: This figure describes the identifiers we use to link the administrative records. We start with Social Security Administration records: disability-program applications from 2000-2014 from the 831 Disability File (F831), disability-program decisions from the Master Beneficiary Record (MBR) and Supplemental Security Record (SSR), and earnings from the Master Earnings File (MEF). We then link the SSA data to bankruptcy records compiled by Gross et al. (2016), to foreclosure records from CoreLogic, to deeds records from CoreLogic and Zillow, and to eviction records obtained from AIRS. We use the CoreLogic and Zillow data to establish a sample of homeowners for the foreclosure sample and non-homeowners for the eviction sample. "SSN4" indicates the last four digits of Social Security number. "FN" indicates first name, "LN" indicates last name, and "MI" indicates middle initial.

We link the SSA data to public records on several financial outcomes: bankruptcies, foreclosures, evictions, and home deeds. We summarize the merge procedures here and provide more detail in Appendix A. Bankruptcy records, collected by Gross et al. (2016), consist of a near-census of personal bankruptcies for a majority of bankruptcy districts from the mid-1990s through 2009 (2011 for some districts). The bankruptcy records list the names and last four digits of SSN of the filers, date of filing, chapter, and address. We link SSA records to these bankruptcy records using primarily the last four digits of SSN, first name, last name, middle initial, and state. ${ }^{9}$

We combine records on home transactions from two sources, CoreLogic and Zillow, so as to ensure that the coverage is as comprehensive as possible. The combined data covers home

\footnotetext{
${ }^{9}$ To account for potential variations in the first name (such as "Tom" versus "Thomas"), we also use alternative merges based on the last four digits of SSN, last name, ZIP Code, and state.
} 
purchases and sales across the United States from 1983 to $2016 .{ }^{10}$ These records include seller and buyer names, transaction dates and amounts, property ZIP Code, and characteristics of the house. ${ }^{11}$ We remove blank entries, duplicate transaction records, commercial properties, and intra-family transfers.

The housing records do not include unique individual identifiers such as SSN. For that reason, we merge the SSA records to housing transactions based on first name, last name, middle initial, and ZIP Code. These merge variables could be problematic if different residents of the same ZIP Code have the same name. For that reason, we drop individuals with more than six transactions associated with their names and ZIP Codes, which consist of less than 1 percent of the sample population for most states. We use this merge to identify homeownership, home sales, and home purchases.

We use CoreLogic foreclosure records from 2004 to 2016. We remove blank entries, duplicate records, commercial properties, records with missing or invalid names, and records in which cases were settled without the properties being auctioned. In addition, we drop ZIP Codes from our initial record linkage process if defendant names are missing in more than 10 percent of the foreclosure records. Our main foreclosure sample comes from the population of homeowners identified in the CoreLogic-Zillow deeds data. As a validity check, we link the foreclosure records to the home deeds and find that 82 percent of the foreclosure records link to a deeds record. We link the SSA disability records to the foreclosure records using first name, last name, middle initial, and ZIP Code.

We use eviction records from American Information Research Services (AIRS), which collects public-record eviction court filings covering nearly 40 percent of the U.S. residential areas for various time periods. In addition, we collect eviction court filings in Harris County, Texas, from the county court's website. Each eviction court filing provides defendant names, filing date, and judgment information. We drop blank records and records with invalid names or ZIP Codes. In addition, we remove eviction filings that have been dismissed or settled. Our main eviction sample comes from the population of non-homeowners identified in the CoreLogic-Zillow deeds data. We map ZIP Code to FIPS county code to address high mobility among the renter population, and we merge eviction records from 2005 to 2016 to

\footnotetext{
${ }^{10}$ Data provided by Zillow through the Zillow Transaction and Assessment Dataset (ZTRAX). More information on accessing the Zillow data can be found at http://www.zillow.com/ztrax. The results and opinions are those of the authors and do not reflect the position of Zillow Group. Based on conversations with staff at CoreLogic and Zillow Research, the availability and quality of deeds varies across counties and time. To avoid analysis on small cells or areas with poor coverage, we keep ZIP Codes with an average of at least fifteen home purchases or fifteen home sales per year between 2000 and 2014.

${ }^{11}$ We observe sales dates in most cases and some other dates such as filing dates and signature dates. These dates are usually the same or within 10 days of each other. In our data harmonization process, we use the earliest dates as transaction dates. We provide more details on the construction of home transaction data in Appendix A.
} 
the SSA records based on first name, last name, FIPS county code, and middle initial when available. $^{12}$

Appendix A discusses the reliability of each merge. The bankruptcy merge is the most reliable because it involves full name and last four digits of SSN, a near-unique combination. Using the bankruptcy data, we simulate the foreclosure and deeds merges by dropping the last four digits of SSN as an identifier, and we simulate the eviction merge by additionally dropping middle name. Dropping those identifiers results in some attenuation of the causal estimate, but does not substantially reduce the quality of the merge.

With the exception of the bankruptcy data, each of the merges between the SSA records and financial records requires using ZIP Code or FIPS county code as a key linking variable. The SSA records provide the applicant's ZIP Code of residence at the time of application; if the applicant moved before or after applying, we do not observe the other ZIP Codes in which that applicant lived. Of course, not observing all ZIP Codes of residence will affect the number of financial events that we observe. Appendix B shows that this issue likely causes attenuation of the estimates of the causal effect of disability allowance on home purchases, eviction, and foreclosure. As long as disability allowance does not shift home purchases (or evictions or foreclosures) that would have occurred anyway (i.e., inframarginal home purchases) from the application ZIP Code to other ZIP Codes, then this data issue will solely bias us against finding an effect. However, if disability allowance does shift inframarginal home purchases from within- to outside-ZIP (or vice versa), then the sign of the bias cannot always be determined. The same conclusions apply to merges using FIPS county codes.

\subsection{Sample Statistics}

Table 1 presents summary statistics for the bankruptcy, foreclosure, and eviction samples. The first column for each outcome corresponds to the full sample, and the second column to the sample we use for the quasi-experimental analysis in Section 3. The bankruptcy sample includes disability-program applicants who have an initial decision date between 2000 and 2009 and reside in a ZIP Code with an average of at least five recorded bankruptcies per year over the 1992-2011 period covered by the bankruptcy data. The average applicant in this sample has less than a high school education (11.5 years) and annual earnings of $\$ 14,300$ prior to the initial decision. Thirty-five percent of the sample is allowed at the initial level and 54 percent is eventually allowed after all appeals. Bankruptcy rates are high: 12 percent ever file for bankruptcy between 1992 and 2011, with 10 percent ever filing for Chapter 7 and 2 percent ever filing for Chapter 13.

\footnotetext{
${ }^{12}$ The availability of middle names is substantially lower in the eviction data (15 percent) than in the deeds (70 percent) or foreclosure records ( 55 percent).
} 
Table 1: Summary Statistics for the Bankruptcy, Foreclosure, and Eviction Samples

\begin{tabular}{|c|c|c|c|c|c|c|c|c|c|c|c|c|}
\hline & \multicolumn{4}{|c|}{ Bankruptcy sample } & \multicolumn{4}{|c|}{ Foreclosure sample } & \multicolumn{4}{|c|}{ Eviction sample } \\
\hline & \multicolumn{2}{|c|}{ Full Sample } & \multicolumn{2}{|c|}{ Quasi-Exp. Sample } & \multicolumn{2}{|c|}{ Full Sample } & \multicolumn{2}{|c|}{ RD Sample } & \multicolumn{2}{|c|}{ Full Sample } & \multicolumn{2}{|c|}{ Quasi-Exp. Sample } \\
\hline & Mean & Std. Dev. & Mean & Std. Dev. & Mean & Std. Dev. & Mean & Std. Dev. & Mean & Std. Dev. & Mean & Std. Dev. \\
\hline Fraction SSI adults & 0.54 & 0.50 & 0.49 & 0.50 & 0.31 & 0.46 & 0.33 & 0.47 & 0.55 & 0.50 & 0.53 & 0.50 \\
\hline Fraction DI adults & 0.60 & 0.49 & 0.65 & 0.48 & 0.83 & 0.38 & 0.82 & 0.39 & 0.62 & 0.49 & 0.65 & 0.48 \\
\hline Fraction reaching step 5 & 0.68 & 0.47 & 1.00 & 0.00 & 0.70 & 0.46 & 1.00 & 0.00 & 0.69 & 0.46 & 1.00 & 0.00 \\
\hline Fraction initially allowed & 0.35 & 0.48 & 0.30 & 0.46 & 0.44 & 0.50 & 0.36 & 0.48 & 0.38 & 0.48 & 0.36 & 0.48 \\
\hline Fraction finally allowed & 0.54 & 0.50 & 0.60 & 0.49 & 0.64 & 0.48 & 0.65 & 0.48 & 0.51 & 0.50 & 0.57 & 0.49 \\
\hline Mental condition & 0.26 & 0.44 & 0.16 & 0.37 & 0.16 & 0.36 & 0.13 & 0.34 & 0.27 & 0.44 & 0.16 & 0.37 \\
\hline Musculoskeletal condition & 0.30 & 0.46 & 0.43 & 0.49 & 0.37 & 0.48 & 0.48 & 0.50 & 0.31 & 0.46 & 0.46 & 0.50 \\
\hline Age & 44.4 & 12.6 & 52.4 & 2.7 & 51.1 & 10.0 & 52.9 & 2.7 & 45.6 & 13.06 & 52.6 & 2.72 \\
\hline Male & 0.52 & 0.50 & 0.51 & 0.50 & 0.52 & 0.50 & 0.50 & 0.50 & 0.54 & 0.50 & 0.52 & 0.50 \\
\hline Pre-decision annual earnings & $\$ 14,349$ & $\$ 18,334$ & $\$ 16,791$ & $\$ 19,542$ & $\$ 20,831$ & $\$ 21,327$ & $\$ 20,477$ & $\$ 20,487$ & $\$ 12,182$ & $\$ 16,946$ & $\$ 13,590$ & $\$ 17,190$ \\
\hline Years of education & 11.5 & 2.53 & 11.5 & 2.61 & 12.3 & 2.40 & 12.2 & 2.32 & 11.8 & 2.55 & 11.7 & 2.61 \\
\hline Ever experience financial event & 0.12 & 0.32 & 0.15 & 0.36 & 0.13 & 0.33 & 0.13 & 0.34 & 0.18 & 0.38 & 0.18 & 0.39 \\
\hline Experience event before decision & 0.09 & 0.28 & 0.11 & 0.31 & 0.06 & 0.24 & 0.07 & 0.25 & 0.09 & 0.28 & 0.09 & 0.29 \\
\hline Experience event after decision & 0.04 & 0.19 & 0.04 & 0.20 & 0.07 & 0.26 & 0.08 & 0.26 & 0.10 & 0.30 & 0.10 & 0.30 \\
\hline Number of states & \multicolumn{2}{|r|}{47} & \multicolumn{2}{|r|}{47} & \multicolumn{2}{|r|}{48} & \multicolumn{2}{|r|}{48} & \multicolumn{2}{|r|}{16} & \multicolumn{2}{|r|}{16} \\
\hline Number of state-ZIP/FIPS & \multicolumn{2}{|c|}{20,973} & \multicolumn{2}{|c|}{20,973} & \multicolumn{2}{|c|}{14,422} & \multicolumn{2}{|c|}{14,422} & \multicolumn{2}{|c|}{319} & \multicolumn{2}{|c|}{319} \\
\hline Number of applicants (millions) & \multicolumn{2}{|c|}{18.7} & \multicolumn{2}{|c|}{3.1} & \multicolumn{2}{|c|}{3.6} & \multicolumn{2}{|c|}{0.81} & \multicolumn{2}{|c|}{5.8} & \multicolumn{2}{|r|}{1.1} \\
\hline
\end{tabular}

Notes: This table presents summary statistics for the bankruptcy, foreclosure (conditional on homeownership), and eviction (conditional on nonhomeownership) samples, and within each of these samples for the "full sample" and for the "quasi-experimental sample" used in Section 3. The "bankruptcy sample" consists of disability-program applicants who have an initial decision date in 2000-2009. The "foreclosure sample" consists of disability-program applicants who appear in the deeds records (homeowners) and who have an initial decision date in 2005-2014. The "eviction sample" consists of disability-program applicants who do not appear in the deeds records (non-homeowners) and who have an initial decision in 2005-2014. Samples involving "foreclosure" and "bankruptcy" outcomes exclude ZIP Codes of residence at application that have an average of fewer than five recorded events per year during the corresponding period; samples involving "eviction" outcomes exclude FIPS county codes of residence at application that have an average of fewer than fifteen recorded events per year during the corresponding period. "Reaching step 5 " denotes reaching step 5 of the disability determination process as depicted in Appendix Figure A.3. "Pre-decision annual earnings" are average annual earnings in the three years before the decision date. "Ever experience financial event" and "experience event before/after decision" are indicators for filing for bankruptcy, experiencing foreclosure, or experiencing eviction. "Number of states" includes the District of Columbia for the foreclosure sample. 
The foreclosure sample consists of applicants who have an initial decision date between 2005 and 2014 and reside in a ZIP Code with an average of at least five recorded foreclosures over the 2005-2014 period covered by the foreclosure data. Because we condition the foreclosure sample on homeownership, the applicants in the foreclosure sample are more-educated and higher-income than the applicants in the bankruptcy sample. The average applicant in

Table 2: Summary Statistics for the Home-Sale and Home-Purchase Samples

\begin{tabular}{|c|c|c|c|c|c|c|c|c|}
\hline & \multicolumn{4}{|c|}{ Home-sale sample } & \multicolumn{4}{|c|}{ Home-purchase sample } \\
\hline & \multicolumn{2}{|c|}{ Full Sample } & \multicolumn{2}{|c|}{ Quasi-Exp. Sample } & \multicolumn{2}{|c|}{ Full Sample } & \multicolumn{2}{|c|}{ Quasi-Exp. Sample } \\
\hline & Mean & Std. Dev. & Mean & Std. Dev. & Mean & Std. Dev. & Mean & Std. Dev. \\
\hline Fraction SSI adults & 0.31 & 0.46 & 0.31 & 0.46 & 0.55 & 0.50 & 0.51 & 0.50 \\
\hline Fraction DI adults & 0.81 & 0.40 & 0.81 & 0.39 & 0.63 & 0.48 & 0.67 & 0.47 \\
\hline Fraction reaching step 5 & 0.69 & 0.46 & 1.00 & 0.00 & 0.69 & 0.46 & 1.00 & 0.00 \\
\hline Fraction initially allowed & 0.43 & 0.50 & 0.35 & 0.48 & 0.35 & 0.48 & 0.32 & 0.46 \\
\hline Fraction finally allowed & 0.63 & 0.48 & 0.66 & 0.47 & 0.52 & 0.50 & 0.59 & 0.49 \\
\hline Mental condition & 0.16 & 0.37 & 0.13 & 0.34 & 0.26 & 0.44 & 0.16 & 0.37 \\
\hline Musculoskeletal condition & 0.37 & 0.48 & 0.48 & 0.50 & 0.31 & 0.46 & 0.44 & 0.50 \\
\hline Age & 50.42 & 10.15 & 52.81 & 2.73 & 44.8 & 12.8 & 52.5 & 2.7 \\
\hline Male & 0.52 & 0.50 & 0.50 & 0.50 & 0.53 & 0.50 & 0.51 & 0.50 \\
\hline Pre-decision annual earnings & $\$ 22,047$ & $\$ 22,227$ & $\$ 22,123$ & $\$ 21,755$ & $\$ 13,175$ & $\$ 17,244$ & $\$ 15,054$ & $\$ 17,965$ \\
\hline Years of education & 12.1 & 2.4 & 12.1 & 2.4 & 11.6 & 2.4 & 11.7 & 2.5 \\
\hline Ever experience event & 0.44 & 0.50 & 0.44 & 0.50 & 0.18 & 0.38 & 0.22 & 0.42 \\
\hline Experience event before decision & 0.17 & 0.38 & 0.18 & 0.38 & 0.14 & 0.35 & 0.18 & 0.38 \\
\hline Experience event after decision & 0.30 & 0.46 & 0.29 & 0.45 & 0.07 & 0.26 & 0.09 & 0.29 \\
\hline Number of states & \multicolumn{2}{|c|}{49} & \multicolumn{2}{|c|}{49} & \multicolumn{2}{|c|}{49} & \multicolumn{2}{|c|}{49} \\
\hline Number of state-ZIPs & \multicolumn{2}{|c|}{22,631} & \multicolumn{2}{|c|}{22,631} & \multicolumn{2}{|c|}{24,094} & \multicolumn{2}{|c|}{24,094} \\
\hline Number of applicants (millions) & \multicolumn{2}{|c|}{6.6} & \multicolumn{2}{|c|}{1.4} & \multicolumn{2}{|c|}{29.3} & \multicolumn{2}{|c|}{5.1} \\
\hline
\end{tabular}

Notes: This table presents summary statistics for the home-sale and home-purchase samples, and within each sample for the "full sample" and for the "quasi-experimental sample" used in Section 3. The homesale sample consists of disability-program applicants who appear in the deeds records (homeowners) and who have an initial decision date in 2000-2014. The home-purchase sample consist of disability-program applicants who have an initial decision date in 2000-2014. Each sample excludes ZIP Codes of residence at application that have an average of fewer than fifteen recorded events per year during 2000-2014. "Reaching step 5" denotes reaching step 5 of the disability determination process as depicted in Appendix Figure A.3. "Pre-decision annual earnings" are average annual earnings in the three years before the decision date. "Ever experience event" and "experience event before/after decision" are indicator functions for home purchases or sales. "Number of states" includes the District of Columbia.

this sample is a high school graduate (12.3 years of education) and average annual predecision earnings are $\$ 20,800$. SSDI applicants are disproportionately represented relative to SSI applicants, and applicants are less likely to have mental conditions and more likely to have musculoskeletal conditions compared to the bankruptcy sample. Foreclosure rates among these home-owning applicants are high: 13 percent of the sample ever experiences a foreclosure between 2004 and $2016 .^{13}$

\footnotetext{
${ }^{13}$ In the foreclosure sample that is unconditional on homeownership, roughly 3 percent applicants ever
} 
The eviction sample consists of applicants who do not appear in homeowner records and who apply from the 16 states for which we have eviction records. Average annual pre-decision earnings are lower than in the bankruptcy sample since the eviction sample is conditioned on non-homeownership. Eighteen percent of applicants ever experience eviction over the 2005-2014 period covered by the eviction data.

Table 2 presents summary statistics for the home-sale and home-purchase samples. The home-sale sample is conditioned on homeownership and therefore looks similar to the foreclosure sample. Nearly one-half of home-owning applicants sell a home over the 1986-2015

period for which we have deeds data. The home-purchase sample consists of applicants who have an initial decision date between 2005 and 2014 and reside in a ZIP Code with at least fifteen home purchases over the 2000-2015 period. Since it is not conditioned on homeownership, this sample looks more similar to the bankruptcy sample, with relatively low incomes and low education levels. Of this sample, 18 percent of applicants ever purchase a home between 1983 and 2016.

\section{Descriptive Facts on Disability Applicants and Financial Outcomes}

\section{Fact 1: Disability applicants have higher rates of adverse financial events than the general population.}

We first compare rates of adverse financial events in the disability-applicant population to rates of adverse financial events in the general population. Figure 2 plots annual bankruptcy rates, foreclosure rates, and eviction rates for disability-program applicants and the general population. Unconditional rates are given by the opaque bars, and rates conditional on homeownership (for foreclosure) and non-homeownership (for eviction) are given by the translucent bars.

Bankruptcy rates are slightly higher in the disability-applicant population relative to the general population in the year that applicants apply for disability benefits; they are slightly lower three years before application, which could be mechanical since bankruptcy is a rare event. For foreclosure, disability applicants have lower rates when we do not condition on homeownership, since disability applicants are less likely than the general population to be homeowners. Conditioning on homeownership, however, we find that foreclosure rates peak in the year of disability application at twice the rate of the general population. Eviction rates are much higher in the disability-applicant population than in the general population when we do not condition on non-homeownership, especially in the year of the disability

experience foreclosure. Foreclosure rates unconditional on homeownership are substantially lower, since applicants are less likely to be homeowners. 
application. Conditioning on non-homeowner (renter) status makes the eviction rate in the disability-applicant population and general population comparable.

The spike in adverse financial events in the year of disability application has several possible interpretations: disability applicants may apply for disability benefits in response to a financial shock, or a health shock or other type of shock may lead to both disability application and financial distress. To investigate the timing of financial shocks and disability application more closely, we next estimate event-study regressions around disability application and disability decision.

Figure 2: Rates of Adverse Financial Events in the General vs. Disability-Applicant Population

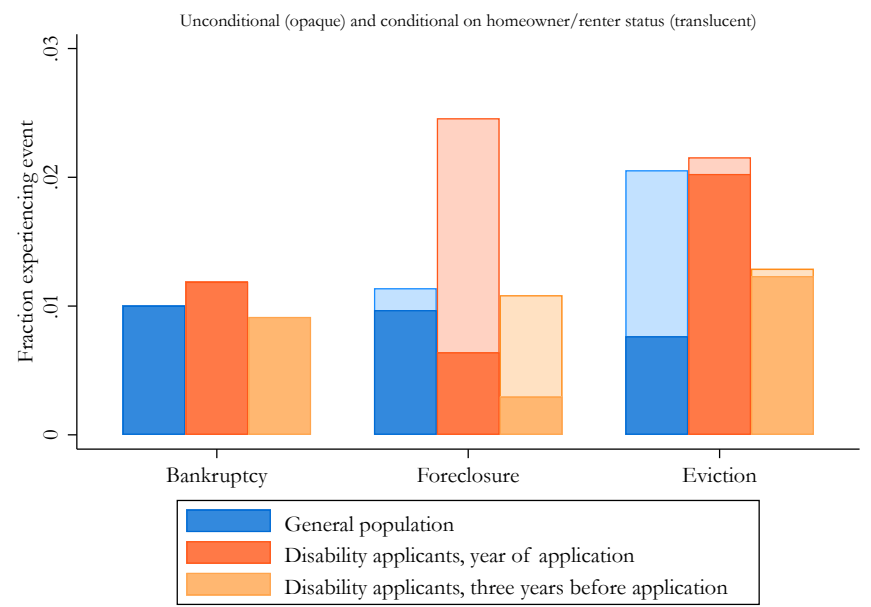

Notes: This figure presents bankruptcy, foreclosure, and eviction rates among the general population and the disability-program applicants across different application cohorts. Unconditional rates are in opaque bars, and conditional foreclosure (homeowners) and eviction (non-homeowners) rates are in translucent bars. The unconditional bankruptcy sample consists of disability-program applicants who have an initial decision date in 2000-2009. The unconditional foreclosure and eviction sample consists of disability-program applicants who have an initial decision date in 2005-2014. The conditional foreclosure sample consists of disability-program applicants who appear in the deeds records (homeowners) and who have an initial decision date in 2005-2014. The conditional eviction sample consists of disability-program applicants who are non-homeowners at the time of experiencing evictions and who have an initial decision in 2005-2014. Samples involving bankruptcy and foreclosure outcomes exclude ZIP Codes of residence at application that have an average of fewer than five recorded events per year during the corresponding period; samples involving eviction outcomes exclude FIPS county codes of residence at application that have an average of fewer than fifteen recorded events per year during 2005-2014. The denominator of the bankruptcy, foreclosure, and eviction rates for the general population is calculated using the 2010 Census population for individuals 18 years or older.

\section{Fact 2: Rates of adverse financial events exhibit an "Ashenfelter's peak" around the time of disability application.}

In Appendix Section C, we develop the following event-study specification to explore how the risk of bankruptcy, foreclosure, and eviction evolve around the time of disability application 
and decision:

$$
Y_{c t}=\alpha_{c}+\gamma_{t}+\sum_{\tau} \beta_{\tau}^{d}\left(\text { Allow }_{c} \times D_{c t}^{d}\right)+\sum_{\tau} \beta_{\tau}^{\prime d} D_{c t}^{d}+\sum_{\tau} \mu_{\tau}^{a}\left(\text { Allow }_{c} \times D_{c t}^{a}\right)+\sum_{\tau} \mu_{\tau}^{\prime a} D_{c t}^{a}+\varepsilon_{c t} .
$$

Here, $Y_{c t}$ is a financial outcome for cohort $c$ in month $t$, where cohort is defined by application month, decision month, and allowance status; $D_{c t}^{d}$ and $D_{c t}^{a}$ are event-month indicator functions relative to initial decision date and application date, respectively; and Allow $_{c}$ is an indicator functions for being approved for disability benefits at initial decision. The $\beta_{\tau}^{\prime d}$ coefficients give the financial outcome in initial-decision event time for the denied, controlling for application event time; the sum $\beta_{\tau}^{d}+\beta_{\tau}^{\prime d}$ gives this value for the allowed. Similarly, the $\mu_{\tau}^{\prime a}$ give the financial outcome in application event time for the denied and the sum $\mu_{\tau}^{a}+\mu_{\tau}^{\prime a}$ give this value for the allowed, controlling for initial-decision event time.

This specification is a standard event-study specification that we adapt to control for both application event time and decision event time. Since the initial decision usually occurs within a year of application, it is important to separate time trends around the two dates. If, for example, there is selection into the timing of application, we might mis-attribute a pattern that is associated with the application to the decision instead. This strategy exploits variation in examiner decision time to identify the patterns around application and decision separately.

Figure 3 presents the application-event-time coefficients and decision-event-time coefficients from equation (1), with the mean of the outcome at event month 0 added to all event months. For all three adverse events, the application-event-time coefficients (left-hand side of Figure 3) suggest that financial distress peaks around the time of application and then falls, even after controlling for decision event time. In other words, applicants apply for disability benefits after a period of increasing financial distress. It could be that a deterioration in health increases financial distress and drives disability-program application, or that high financial distress drives application. The peak in bankruptcy filings is just after the application date while the peak in foreclosures is a few months later, likely because there are multiple steps between default and foreclosure. ${ }^{14}$

\section{Fact 3: Rates of adverse financial events decline for both allowed and denied applicants after the initial disability decision.}

The decision-event-time coefficients (right-hand side of Figure 3) suggest a downward trend in bankruptcies, foreclosures, and evictions for both allowed and denied applicants preceding

\footnotetext{
${ }^{14}$ The fall in bankruptcies, foreclosures, and evictions after the application date could reflect households making other adjustments in consumption and saving. Or it could be a mechanical decline if most of the households at risk for these events have already experienced them.
} 
Figure 3: Trends in Adverse Financial Events Around Disability Application and Decision Dates
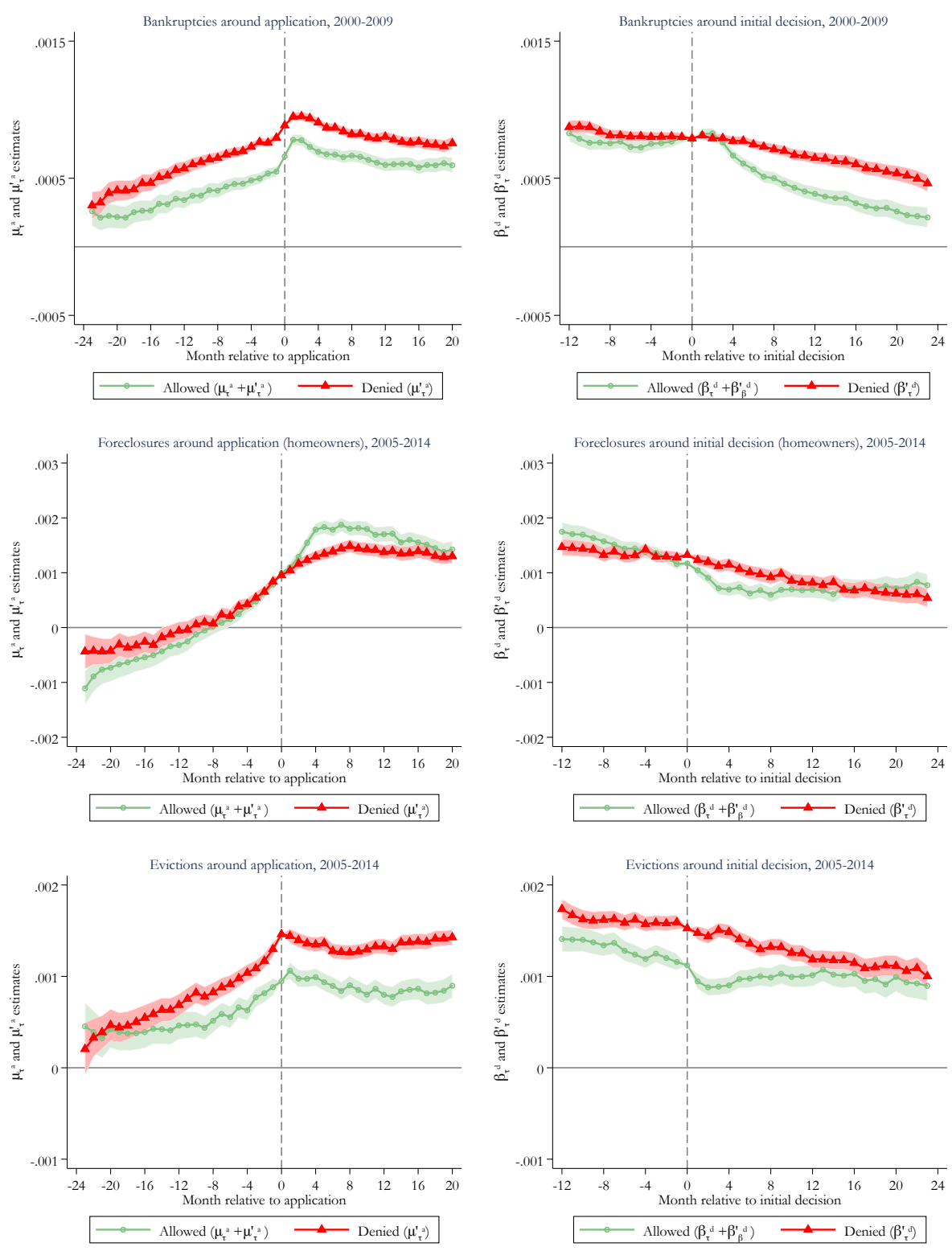

Notes: These figures plot estimates from the event-study specification in equation (1). The upper-left panel plots application event indicator functions for bankruptcy relative to the month of application, for allowed applicants $\left(\mu_{\tau}^{a}+\mu_{\tau}^{\prime a}\right)$ and denied applicants $\left(\mu_{\tau}^{\prime a}\right)$. Upper-right panel plots initial-decision event indicator functions for bankruptcy relative to the month of decision, for allowed applicants $\left(\beta_{\tau}^{d}+\beta_{\tau}^{\prime d}\right)$ and denied applicants $\left(\beta_{\tau}^{\prime} d\right)$. Middle-left and middle-right panels are analogous for foreclosure, and bottom-left and bottom-right graphs for eviction. The bankruptcy sample consists of disability-program applicants who have an initial decision date in 2000-2009. The foreclosure sample consists of disability-program applicants who appear in the deeds records (homeowners) and who have an initial decision date in 2005-2014. The eviction sample consists of disability-program applicants who do not appear in the deeds records (non-homeowners) and who have an initial decision in 2005-2014. Samples involving "foreclosure" and "bankruptcy" outcomes exclude ZIP Codes of residence at application that have an average of fewer than five recorded events per year during the corresponding period; samples involving "eviction" outcomes exclude FIPS county codes of residence at application that have an average of fewer than fifteen recorded events per year during 2005-2014. 
the decision, controlling for application date. After the initial decision, bankruptcy rates continue falling for the denied, but they decline further for the allowed. This is suggestive evidence that allowance onto disability programs reduces the risk of bankruptcy relative to denials. However, the graph also makes clear that considering only the trend for the allowed would lead to an overestimate of the decline in bankruptcies attributable to disability allowance, since bankruptcy risk also declines for the denied. ${ }^{15}$ Denied applicants may find other margins of adjustment that reduce their financial distress following their denial from the program. For foreclosures and evictions, the rates of these events exhibit a sharper drop for the allowed relative to the denied immediately after the initial decision, though the trends eventually converge.

\section{Interpreting the descriptive facts}

Where do these descriptive facts lead us? First, they suggest that applicants apply to disability programs when they are facing substantial financial distress, both relative to the general population and relative to their own histories. This peak in financial distress at application means that the cash transfer from disability benefits could potentially produce large reductions in financial distress. Indeed, the trends around disability decision provide suggestive, though not conclusive, evidence that disability programs reduce financial distress. Second, these facts indicate that application timing is non-random and that even denied applicants experience declines in financial distress following their initial decision. Given this evidence of selection and trends in event time, we conclude that estimating the causal effect of disability programs on financial outcomes requires a quasi-experimental strategy. We turn to such a strategy next.

\section{Quasi-Experimental Estimates of the Effect of Disability Receipt on Financial Outcomes}

To estimate the causal effect of disability programs on financial outcomes, we use age-based variation in eligibility for disability programs. ${ }^{16} \mathrm{SSA}$ evaluates disability applicants with a five-step process, described in Appendix Figure A.3. During the first two steps, examiners deny applicants if they have engaged in substantial gainful activity since onset of their disability (step 1) or if their impairment is not considered severe (step 2). During step 3,

\footnotetext{
${ }^{15}$ This is true even after controlling for final decision date, in which some of the initially denied are allowed on appeal.

${ }^{16}$ Chen and van der Klaauw (2008) originally used the age-55 threshold, along with data from the Survey of Income and Program Participation linked to SSA application and award data, to study the effect of receiving disability benefits on labor supply.
} 
applicants with listed medical impairments are allowed onto the program. During step 4, applicants are denied if the examiner deems that they could still do the work that they had done before the disability onset.

Finally, during step 5, examiners evaluate whether the applicants who cannot do past work can adjust to another type of work. Examiners first determine the individual's maximum work capability (e.g., sedentary, light, heavy, etc.) and then divide applicants in these groups into cells based on age, education, previous work experience, and the nature of their past work. ${ }^{17}$ We exploit SSA guidelines instructing disability examiners to use more-lenient standards for applicants who are above ages 50 and 55 relative to those below ages 50 and 55 at step $5 .^{18}$

Figure 4: Initial Allowance Rate at Step 5 By Age

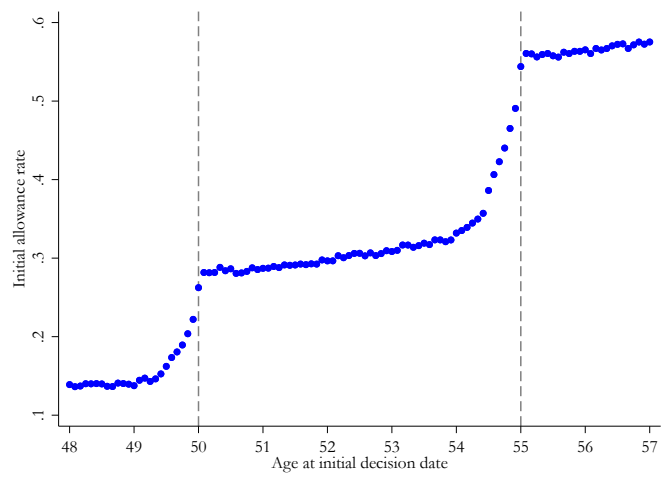

Notes: This figure plots the initial allowance rate by disability-program applicant age at step 5 of the disability determination process. This figure is based on the home-purchase sample: applicants who reach step 5 of the disability determination process, who have an initial decision date in 2000-2014, and whose ZIP Code of residence at application has an average of at least fifteen recorded home purchases per year during this period.

Figure 4 plots initial allowance rate by age at decision and so describes the age-based variation that we exploit to identify the effects of disability benefits. The initial allowance rate jumps at ages 50 and 55 because examiners are instructed to use the more-lenient standards at these cutoffs. ${ }^{19}$ There exists a trend break six months before the cutoff, with increasing initial allowance rates up to the threshold. This trend break is driven by the SSA's "borderline age rule," which allows examiners discretion in applying the more-lenient standards to applicants near the cutoff. The rule tells examiners: "If a claimant is within

\footnotetext{
${ }^{17}$ The full vocational grid used in this process is available here: http://policy.ssa.gov/poms.nsf/lnx/ 0425025035 (DI 25025.035).

${ }^{18}$ We use the classification of Wixon and Strand (2013) to map the "regulation basis code" in the F831 files into steps.

${ }^{19}$ There also exists a threshold at age 45 , but in practice the discontinuity in allowance rates at age 45 is close to zero.
} 
a few days to a few months of reaching a higher age category and using the chronological age results in a denial, consider using the higher age category if it results in a favorable determination, after you evaluate all factors." 20

The approximately 130 disability determination services (DDS) offices exercise discretion in implementing the borderline age rule. Some offices ignore the rule entirely and treat applicants in the "borderline" period the same as the other applicants below the cutoff. Other offices fully implement the borderline age rule such that an increasing fraction of applicants in the borderline period are allowed. Still others partially implement the borderline age rule such that there is an increasing fraction of applicants allowed in the borderline period but still a jump in allowance rates at the age cutoff. We take advantage of the variation across offices in the implementation of the borderline age rule in our estimation strategy.

Who are the applicants affected by this quasi-experiment? The least-severe applicants are denied in earlier steps of the process and the most-severe applicants are allowed in earlier steps of the process. As a result, the applicants who are evaluated in step 5 have conditions that do not meet the medical listings but are still potentially severe and often hard-to-verify. Tables 1 and 2 suggest that relative to the full samples, the quasi-experimental samples have higher earnings and are more likely to have a musculoskeletal condition and less likely to have a mental condition.

\subsection{Estimation Strategies}

The borderline age rule makes this age-based variation similar to but distinct from a standard regression discontinuity design. We deal with this unconventional feature of the quasiexperiment by using three alternative estimation strategies and we find that they lead to similar estimates. The first is a standard regression discontinuity design. We present estimates from a standard RD specification that stacks the age 50 and age 55 cutoffs:

$$
Y_{i}=\alpha+\beta \mathbb{1}\left\{\operatorname{Age}_{i}>0\right\}+\gamma \operatorname{Age}_{i}+\delta \mathbb{1}\left\{\operatorname{Age}_{i}>0\right\} \times \operatorname{Age}_{i}+\varepsilon_{i} .
$$

In this specification, $Y_{i}$ is an outcome for applicant $i$, Age $_{i}$ is the applicant's age at decision, and $\mathbb{1}\left\{\mathrm{Age}_{i}>0\right\}$ is an indicator for applicant's age at decision being greater than the age cutoff (either 50 or 55 years, normalized to zero).

The second estimation strategy is a "donut" regression discontinuity that excludes applicants with a borderline age. Since the applicants in the five months before the cutoff are partially treated, the donut specification drops them from the estimation of equation (2).

\footnotetext{
${ }^{20}$ SSA guidance (DI 25015.006) does not give a precise cutoff for what constitutes a borderline age, other than that the adjustment not exceed 6 months: "We do not have a more precise programmatic definition for the phrase 'within a few days to a few months.' We define the term 'a few' using its ordinary meaning, a small number. Consider a few days to a few months to mean a period not to exceed six months."
} 
The third estimation strategy, which is our preferred approach, exploits the heterogeneity across DDS offices in their implementation of the borderline age rule. We classify DDS offices into three types based on how they implement the borderline age rule. Figure 5 presents examples of each type. "RD offices" are offices that ignore the borderline age rule entirely; we name as such because a plot of initial allowance rates for those offices looks like a typical RD. "Spline offices" are offices that fully implement the borderline age rule such that there is no discontinuity at the cutoff at all, only trend breaks six months before the cutoff and at the cutoff. "Hybrid offices" are offices that partially implement the borderline age rule: there is a trend break in the initial allowance rate six months before the cutoff, but also a jump at the cutoff. ${ }^{21}$ Appendix E discusses different ways of classifying offices and demonstrates that the results are robust to alternative classification methods.

In Appendix D, we start with standard regression specifications for each type of office: RD, Spline, and Hybrid. We then develop the following main specification for the endogenous variable and financial outcome by combining the specifications for each office type:

$$
\begin{aligned}
Y_{i}=\beta_{0} & +\sum_{\substack{j \in\{\text { TypeRD, } \\
\text { TypeHybrid }\}}} \sum_{T \in\{50,55\}} \beta_{\mathrm{RD}_{j, T}} \mathbb{1}\left\{\text { Age }_{i}>T\right\} \times \text { Type }_{i}+\sum_{T \in\{50,55\}} \beta_{2, T} \text { Age }_{i} \\
& +\sum_{\substack{j \in\{\text { TypeSpline, } \\
\text { TypeHybrid }\}}} \sum_{T \in\{50,55\}} \beta_{\text {Spline }_{j, T}} \text { Age }_{i} \times \mathbb{1}\left\{\text { Age }_{i}>T-6\right\} \times \text { Type } j_{i} \\
& +\sum_{\substack{j \in\{\text { TypeSpline, } \\
\text { TypeHybrid }\}}} \sum_{T \in\{50,55\}} \beta_{\text {Spline }_{j, T}} \text { Age }_{i} \times \mathbb{1}\left\{\text { Age }_{i}>T\right\} \times \text { Type } j_{i} \\
& +\sum_{T \in\{50,55\}} \beta_{5, T} \text { Age }_{i} \times \mathbb{1}\left\{\text { Age }_{i}>T\right\} \times \text { TypeRD }_{i}+\varepsilon_{i},
\end{aligned}
$$

where $Y_{i}$ is a financial outcome for applicant $i$, Age $_{i}$ is the applicant's age at decision relative to age $T \in\{50,55\}, \mathbb{1}\left\{\right.$ Age $\left._{i}>T\right\}$ is an indicator for being above than the age cutoff at the decision date, and $\mathbb{1}\left\{\mathrm{Age}_{i}>T-6\right\}$ is an indicator for being above the threshold six months before the age cutoff. The coefficients $\beta_{\mathrm{RD}_{j, T}}$ give the effect on financial outcomes of being above the age $T$ cutoff for type $j \in\{$ TypeRD, TypeHybrid\}, like standard RD coefficients of interest. The coefficients $\beta_{\text {Spline }{ }_{j, T}}$ give the effect on the trend in financial outcomes of being above the age $T$ cutoff for office type $j \in\{$ TypeSpline, TypeHybrid $\}$, like standard regression kink coefficients of interest. The coefficients $\beta_{\text {Spline }_{j, T}}$ measure the kink at the minus-six-month cutoff. We use the variables corresponding to the coefficients $\beta_{\mathrm{RD}_{j, T}}$, $\beta_{\text {Spline }_{j, T}}$, and $\beta_{\text {Spline }_{j, T}}$ as instruments in the IV estimation.

\footnotetext{
21 "RD offices" make up 20 percent of total offices, and so RD estimates based solely on those offices are imprecise.
} 
Figure 5: Examples of RD, Spline, and Hybrid Offices
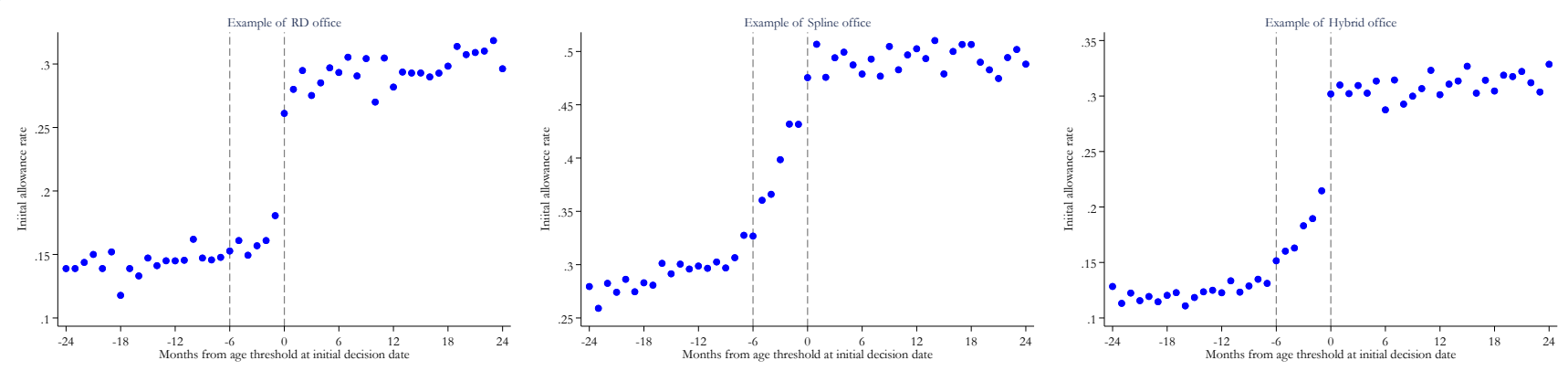

Notes: These figures plot initial allowance rates at step 5 of the disability determination process relative to the disability-program applicant's age at the initial decision date for specific DDS offices. The lefthand-side graph is an example of an RD office; the middle graph is an example of a Spline office; and the right-hand-side graph is an example of a Hybrid office. Age is calculated as months from age 50 or age 55, whichever threshold is closer. These figures are based on all disability-program applicants who reach step 5 of the disability determination process and who have an initial decision date in 2000-2014.

\subsection{Tests of Validity}

In a standard RD design, the identifying assumption requires that assignment to treatment is as good as random around the threshold. This assumption could be violated if some applicants strategically wait until age 50 or 55 to apply, or if there is differential sorting for other reasons. We follow the standard approach and test for a discontinuity in the density of applicants and in applicant covariates across the age thresholds (McCrary, 2008).

Figure 6: Histogram of Age at Decision at Step 5

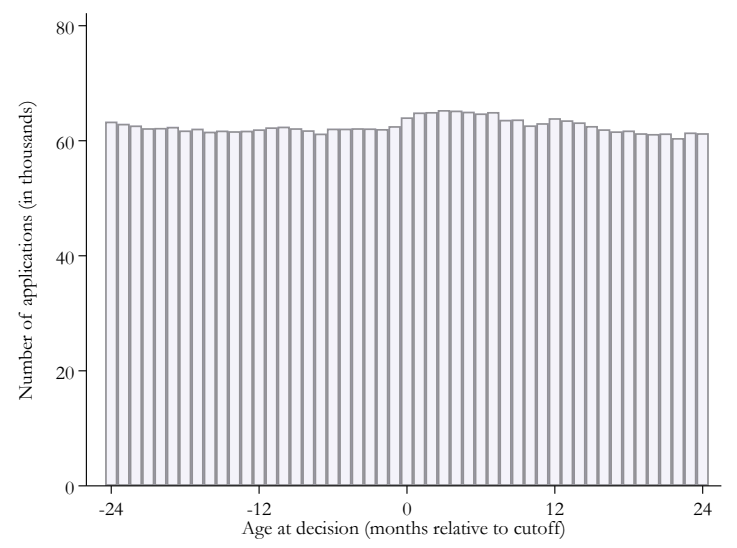

Notes: This figure presents a histogram of age at initial decision for disability-program applicants in the bankruptcy sample: applicants who reach step 5 of the disability determination process, who have an initial decision date in 2000-2009, and whose ZIP Code of residence at application has an average of at least five recorded bankruptcies per year during this period. Age is calculated as months from age 50 or age 55 , whichever threshold is closer. 
Figure 6 plots the number of applicants by age relative to the nearest age threshold. The number of applicants jumps by 4 percent at the threshold. ${ }^{22}$ Although this discontinuity in the density of applicants is not large relative to changes in the density at other ages, it is statistically significant and suggests that some applicants defer their application until they reach age 50 or 55. Public SSA documents, including the vocational grid, discuss the age thresholds and it is possible that some applicants understand that they are more likely to be allowed onto the program if they wait to apply until they are older.

Manipulation is a concern to the extent that different types of applicants end up on either side of the cutoff. We test for discontinuities in applicant covariates using equation (2) for the combined age-50 and age-55 samples. Table 3 reports discontinuities in applicant characteristics across the age-50 and age-55 cutoffs for the bankruptcy and foreclosure samples. ${ }^{23}$ The discontinuities are statistically significant, with a joint $F$-test rejecting random assignment across the cutoff. However, the discontinuities are small. Applicants above age 55 have annual earnings $\$ 215$ higher (1.3 percent) than those below age 55 , have 0.02 fewer (0.2 percent) years of education, and are 0.5 percentage points ( 1.3 percent) more likely to apply with a musculoskeletal condition and 0.5 percentage points (3.0 percent) less likely to apply with a mental condition. These estimates suggest that applicants who knowingly defer their applications until ages 50 or 55 are not a random sample, but they differ only slightly on observable dimensions compared to those who do not defer their applications.

In principle, differences in unobservables could bias RD estimates of the effect of disability benefits on financial outcomes: discontinuities in financial outcomes at the age thresholds might be driven not by disability benefits but by selection into which applicants defer their application past the age thresholds. Although the magnitude of the discontinuities is small, we probe the direction and magnitude of the potential bias by predicting bankruptcy and foreclosure for each applicant based on pre-determined characteristics. We then test for a discontinuity in predicted bankruptcy and foreclosure at the age thresholds, with the results at the bottom of Table 3. For both the bankruptcy and foreclosure sample, we find that the discontinuities in the predicted outcomes are statistically significant but economically small estimates, at just 0.2 and 0.1 percent of the means, respectively, and go in opposite directions.

Another potential confounder is differential mortality. If individuals on one side of the

\footnotetext{
${ }^{22}$ Chen and van der Klaauw (2008) study a sample of approximately 1,000 applicants from the 1990s and find that the standard RD assumptions are satisfied - they estimate no discontinuous change in the density of applicants or applicants' covariates in their sample. By contrast, we detect violations of the standard RD assumptions in our sample, which includes the several million applicants that reach step 5 between 2000 and 2014.

${ }^{23}$ Appendix Table A.4 and A.5 present covariate-balance tests for the eviction, net-home-sale and nethome-purchase samples.
} 
Table 3: Covariate Balance Test - Bankruptcy and Foreclosure Samples

\begin{tabular}{|c|c|c|c|c|c|c|}
\hline & \multicolumn{3}{|c|}{ Bankruptcy sample } & \multicolumn{3}{|c|}{ Foreclosure sample } \\
\hline & $\begin{array}{l}\text { Pt. Est. } \\
\text { (Std. Err.) }\end{array}$ & Mean & $\%$ of mean & $\begin{array}{l}\text { Pt. Est. } \\
\text { (Std. Err.) }\end{array}$ & Mean & $\%$ of mean \\
\hline \multicolumn{7}{|l|}{ Covariate } \\
\hline Pre-application adverse financial event & $\begin{array}{l}-0.000626 \\
(0.000784)\end{array}$ & 0.112 & $-0.6 \%$ & $\begin{array}{l}-0.00132 \\
(0.00117)\end{array}$ & 0.070 & $-1.9 \%$ \\
\hline Pre-app earnings & $\begin{array}{c}215.6^{* * *} \\
(46.45)\end{array}$ & $\$ 16,542$ & $1.3 \%$ & $\begin{array}{c}215.5^{* *} \\
(92.09)\end{array}$ & $\$ 20,057$ & $1.1 \%$ \\
\hline Years of education & $\begin{array}{c}-0.0201^{* * *} \\
(0.00673)\end{array}$ & 11.5 & $-0.2 \%$ & $\begin{array}{l}4.56 \mathrm{e}-05 \\
(0.0108)\end{array}$ & 12.2 & $0.0 \%$ \\
\hline Musculoskeletal & $\begin{array}{c}0.00543^{* * *} * \\
(0.00123)\end{array}$ & 0.428 & $1.3 \%$ & $\begin{array}{c}0.00795^{* * *} \\
(0.00229)\end{array}$ & 0.483 & $1.6 \%$ \\
\hline Respiratory & $\begin{array}{l}0.00104^{* *} \\
(0.000507)\end{array}$ & 0.042 & $2.5 \%$ & $\begin{array}{c}0.000309 \\
(0.000871)\end{array}$ & 0.036 & $0.9 \%$ \\
\hline Cardiovascular & $\begin{array}{c}0.000408 \\
(0.000801)\end{array}$ & 0.114 & $0.4 \%$ & $\begin{array}{l}0.000320 \\
(0.00133)\end{array}$ & 0.088 & $0.4 \%$ \\
\hline Endocrine & $\begin{array}{c}-0.000969^{*} \\
(0.000567)\end{array}$ & 0.053 & $-1.8 \%$ & $\begin{array}{c}-0.00288^{* * *} * \\
(0.000915)\end{array}$ & 0.041 & $-7.1 \%$ \\
\hline Neurological & $\begin{array}{c}0.000495 \\
(0.000605)\end{array}$ & 0.063 & $0.8 \%$ & $\begin{array}{l}0.000562 \\
(0.00121)\end{array}$ & 0.074 & $0.8 \%$ \\
\hline Mental & $\begin{array}{c}-0.00490 * * * \\
(0.000918)\end{array}$ & 0.162 & $-3.0 \%$ & $\begin{array}{c}-0.00475^{* * *} * \\
(0.00157)\end{array}$ & 0.141 & $-3.4 \%$ \\
\hline Special/other & $\begin{array}{c}-0.00133^{* *} \\
(0.000540)\end{array}$ & 0.050 & $-2.6 \%$ & $\begin{array}{c}0.000338 \\
(0.000952)\end{array}$ & 0.045 & $0.8 \%$ \\
\hline$p$-value on joint $F$-test & & 0.000 & & & 0.000 & \\
\hline Predicted adverse financial event occurs & $\begin{array}{c}0.000253^{* * *} \\
(6.56 \mathrm{e}-05)\end{array}$ & 0.109 & $0.2 \%$ & $\begin{array}{c}-8.71 \mathrm{e}-05^{*} \\
(4.76 \mathrm{e}-05)\end{array}$ & 0.069 & $-0.1 \%$ \\
\hline$N$ (in millions) & & 3.07 & & & 0.81 & \\
\hline
\end{tabular}

Notes: This table reports reduced-form estimates for the listed covariates for the bankruptcy and foreclosure samples, where we put the covariate on the left-hand-side of the RD specification in equation (2) and report $\beta$ with standard errors in parentheses. The table reports the $p$-value on the $F$ test for the joint significance of all covariates. Pre-application earnings are average annual applicant earnings in the three years prior to the year of application, from the Master Earnings File. Years of education is self-reported years of education from the 831 Disability File. Body system codes (musculoskeletal, respiratory, cardiovascular, endocrine, neurological, mental, special/other) come from the 831 Disability File. "\% of mean" denotes point estimate as a percent of control mean, where control means are the average value of the variable for applicants who are under age 50 or 55 by 6 to 10 months. For "predicted adverse financial outcome," we first regress an indicator for having the adverse financial outcome prior to the initial decision date on a set of covariates (pre-application earnings, years of education, male, body system code dummies, and ZIP dummies). We then put "predicted adverse financial outcome" on the left-hand-side of the RD specification in equation (2) and report estimates of $\beta$. The bankruptcy sample consists of disability-program applicants who reach step 5 of the disability determination process and who have an initial decision date in 2000-2009. The foreclosure sample consists of disability-program applicants who reach step 5 of the disability determination process, who appear in the deeds records (homeowners), and who have an initial decision date in 2005-2014. Each sample excludes ZIP Codes of residence at application that have an average of fewer than five recorded events per year during the corresponding period. Standard errors in parentheses. ${ }^{* * *} p<0.01,{ }^{* *} p<0.05,{ }^{*} p<0.1$. 
cutoff are more likely to die, then they are mechanically less likely to appear in financial records. This might lead us to conclude, erroneously, that rates of financial distress are lower on the side of the cutoff with higher mortality. Gelber et al. (2018) find that disability income reduces mortality. If true for this population, then their finding implies that individuals just above the age threshold are less likely to die than those just below. This would bias us in the direction of finding a positive effect of disability allowance on adverse financial outcomes. We instead find a negative effect, implying that our estimate is a lower bound for the true effect.

\subsection{Visual Evidence Based on the Standard and Donut RD Strategies}

We first present visual evidence based on the standard and donut RD strategies, starting with initial allowance and moving to the financial outcomes of interest. Figure 7 combines the age-50 and age-55 thresholds and plots the average initial-allowance rate against age in months relative to the nearest age threshold. The share of applicants initially allowed onto disability programs jumps by about 15 percentage points from 6 months before the cutoff to immediately after the cutoff. The six months leading up to the cutoff, shown in hollow markers, reflect the borderline age rule. The jump in final allowance rate, shown in Appendix Figure A.4, is smaller, about 7 percentage points.

Figure 7: Initial Allowance Rate at Step 5 Relative to Applicant Age

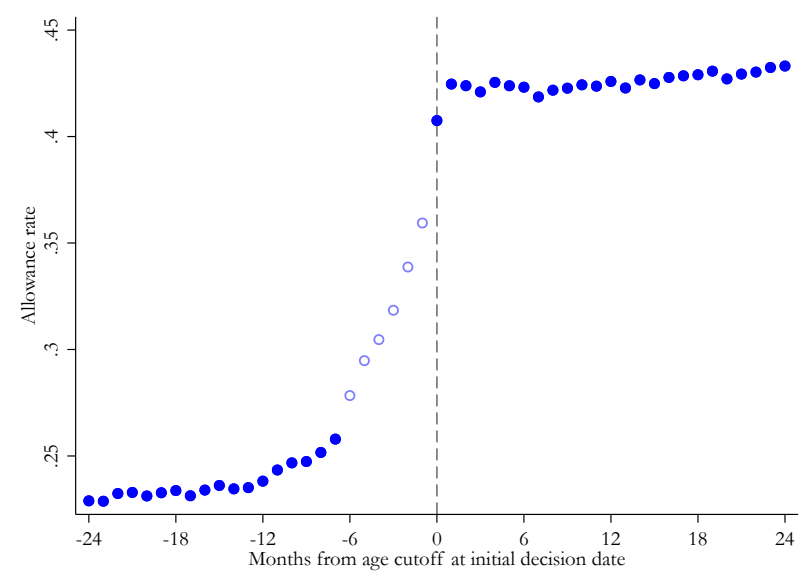

Notes: Figure plots initial allowance rate at step 5 of the disability determination process relative to the disability-program applicant's age at the initial decision date for applicants in the home-purchase sample: applicants who reach step 5 of the disability determination process, who have an initial decision date in 2000-2014, and whose ZIP Code of residence at application has an average of at least fifteen recorded home purchases per year during this period. Age is calculated as months from age 50 or age 55 , whichever threshold is closer.

Figure 8 presents the reduced-form pattern for bankruptcy, foreclosure, and eviction 
within the three years after the decision (left-hand side) and, as a falsification test, within the three years before the decision (right-hand side). The lines are fitted using a "donut" strategy, excluding the hollow markers that correspond to the borderline age period. For bankruptcy, the pattern three years after the decision looks similar to the first-stage initial allowance pattern. Bankruptcy risk increases in age up to six months before the cutoff, falls over those six months, and falls further at the cutoff. Rates of foreclosure display a similar pattern in the three years after the initial decision: they increase up to six months before the cutoff, fall in those six months, and fall further at the cutoff. For eviction, the graph is noisy and there does not appear to be a drop at the cutoff. Turning to the falsification figures on the right-hand side, there is no discontinuity for any of the outcomes in the three years before the decision.

Figure 9 shows the reduced-form pattern for "net" home sales and home purchases. We define a "net" home sale as a home sale that is not accompanied by a home purchase within six months before or after the sale, and analogously for net home purchase. By limiting to "net" home sales, we are less likely to pick up moves, which are difficult to interpret normatively, and more likely to pick up distressed sales. ${ }^{24}$ As described by Lusardi et al. (2011), the sale of a home is one of the main coping mechanisms to which households turn when facing a financial shortfall. Although the graph for home sales is noisier than those for bankruptcy and foreclosure, the same pattern is evident: increasing up to the six months before the cutoff, falling for those six months, and falling at the cutoff. There is no discontinuity for net home sale at the cutoff prior to the initial decision.

Conversely, there is a clear jump in the likelihood of net home purchase at the cutoff in the three years after the initial decision. This means that some disability applicants use their disability benefits to purchase a home. As with the other outcomes, there is no jump in the three years before the decision.

Appendix Figure A.6 presents the reduced-form pattern for earnings in the three years after the initial decision. The graph is a mirror image of the first stage, with earnings declining before the cutoff, dropping at six months before the cutoff, and falling further at the cutoff. This pattern is consistent with the findings of Chen and van der Klaauw (2008), who find that labor supply decreases at the age thresholds. There is no apparent discontinuity in earnings at the cutoff before the initial decision.

\footnotetext{
${ }^{24}$ A drawback to this approach is that "net" sales and purchases are more prone to bias than other outcomes as a result of unobserved transactions in ZIP Codes other than the application ZIP Code. Appendix B discusses this bias. Appendix Figure 9 shows the reduced-form pattern for "gross" home sales and home purchases.
} 
Figure 8: Bankruptcy, Foreclosure, and Eviction Rates Relative to Applicant Age
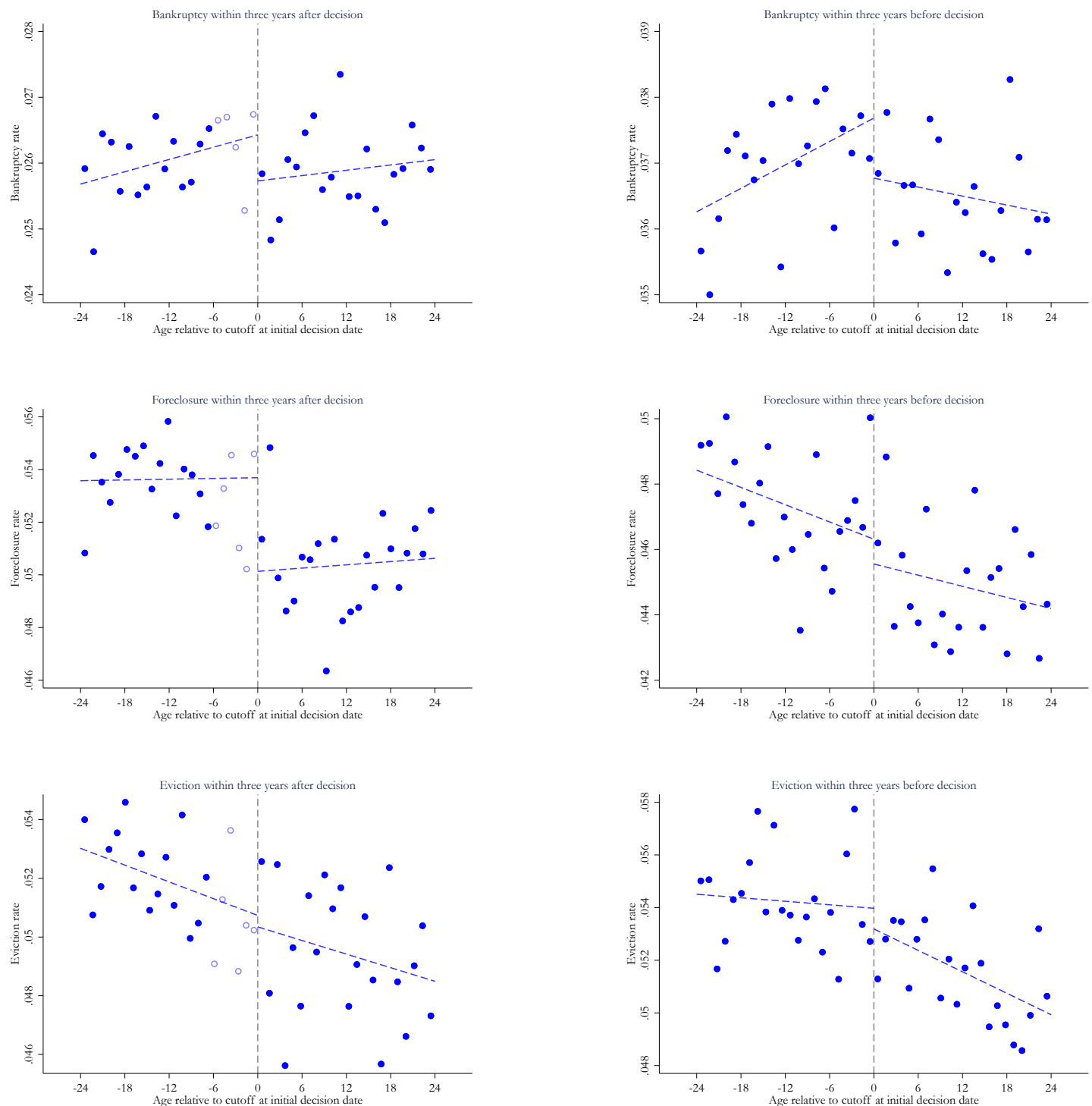

Notes: These figures plot the bankruptcy, foreclosure, and eviction rates within three years after initial decision (left-hand side panel) and before initial decision (right-hand side panel) relative to the disabilityprogram applicant's age at the initial decision date. Age is calculated as months from age 50 or age 55 , whichever threshold is closer. Figures are based on quantile spaced binning, allowing each bin to have the same number of observations. Dashed lines are fitted using a donut strategy, excluding the hollow markers that correspond to the borderline age period. The bankruptcy sample consists of disability-program applicants who reach step 5 of the disability determination process and who have an initial decision date in 2000-2009. The foreclosure sample consists of disability-program applicants who appear in the deeds records (homeowners), who reach step 5 of the disability determination process, and who have an initial decision date in 2005-2014. The eviction sample consists of disability-program applicants who do not appear in the deeds records (non-homeowners), who reach step 5 of the disability determination process, and who have an initial decision in 2005-2014. Samples involving "foreclosure" and "bankruptcy" outcomes exclude ZIP Codes of residence at application that have an average of fewer than five recorded events per year during the corresponding period; samples involving "eviction" outcomes exclude FIPS county codes of residence at application that have an average of fewer than fifteen recorded events per year during 2005-2014. 
Figure 9: Net Home-Sale and Net Home-Purchase Rates Relative to Applicant Age
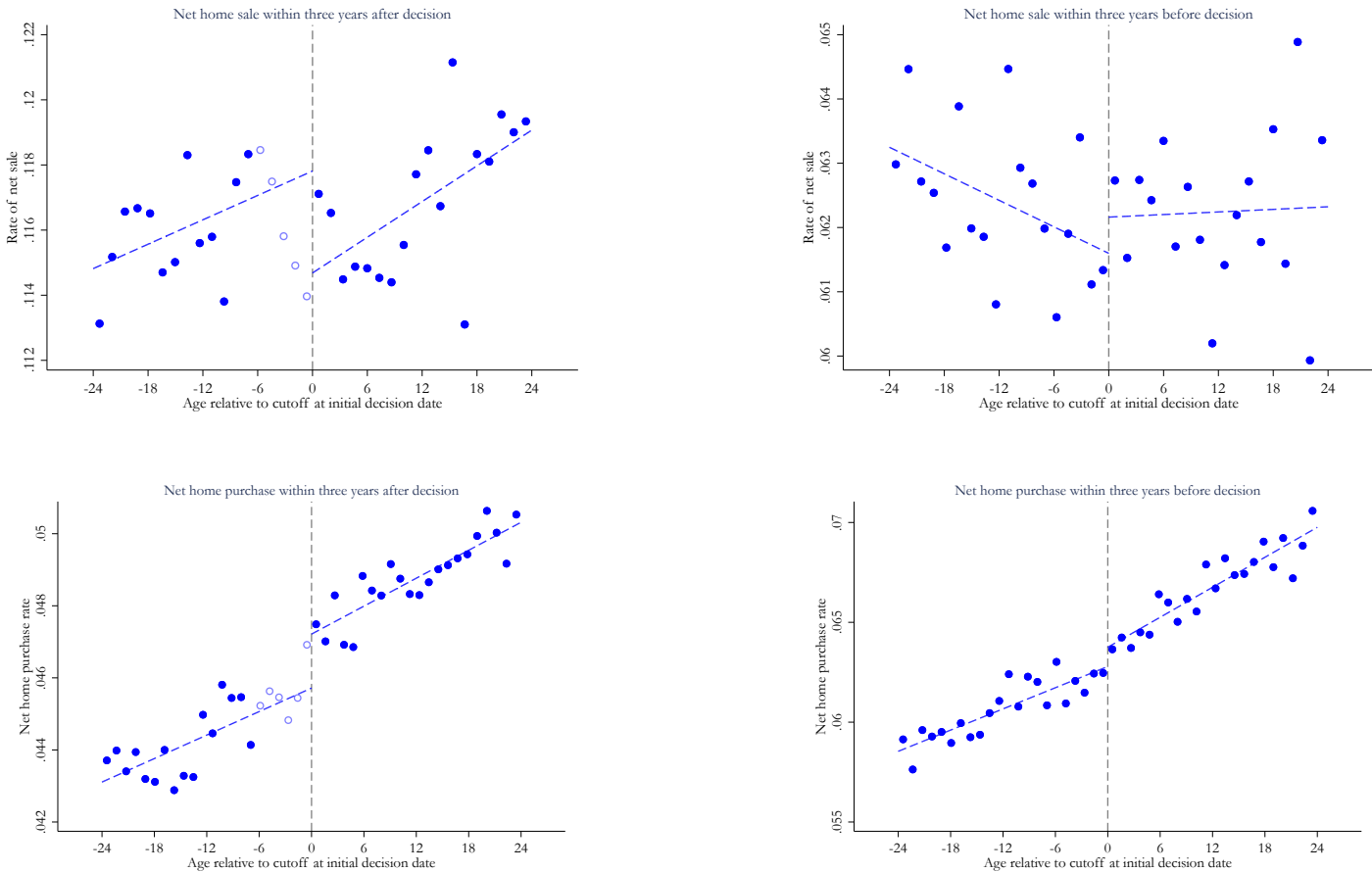

Notes: These figures plot the net home-sale and net home-purchase rates within three years after initial decision (left-hand side) and the net home-sale and the net home-purchase rates within three years before initial decision (right-hand side) relative to the disability-program applicant's age at the initial decision date. Age is calculated as months from age 50 or age 55, whichever threshold is closer. Figures are based on quantile spaced binning, allowing each bin to have the same number of observations. Dashed lines are fitted using a donut strategy, excluding the hollow markers that correspond to the borderline age period. A "net" home sale is defined as a home sale that is not accompanied by a home purchase within six months before or after the sale, and analogously for net home purchase. The "net home-sale sample" consists of disability-program applicants who appear in the deeds records (homeowners), who reach step 5 of the disability determination process, and who have an initial decision date in 2000-2014. The "net home-purchase sample" consists of disability-program applicants who reach step 5 of the disability determination process and who have an initial decision date in 2000-2014. Each sample excludes ZIP Codes of residence at application that have an average of fewer than fifteen recorded events per year during the corresponding period.

\subsection{Reduced-Form and IV Estimates Across Estimation Strategies}

We use the three estimation strategies discussed above - standard RD, donut RD, and the office classification strategy - and find that they produce similar estimates. In this section, we focus on the results from our preferred strategy, the office classification strategy. Appendix Tables A.9 and A.10 present estimates for the standard RD and donut RD strategies. Appendix Figure A.7 shows that the point estimates across the three estimation strategies are almost identical, though the estimates are less precise for the standard RD and donut RD strategies.

The first-stage and reduced-form estimates for the office classification strategy, equation 
(3), are presented in Appendix Tables A.6, A.7, and A.8. These results are consistent with the visual patterns in the corresponding graphs. The probability of initial allowance jumps by 7-12 percentage points for RD offices and 5-7 percentage points for Hybrid offices at the age-50 cutoff. The jumps are higher at age-55 cutoff: 12-14 percentage points for RD offices and 6-9 percentage points for Hybrid offices. For RD and Hybrid offices, the trend break at the minus-six-month cutoff is positive and at the zero cutoff is negative, as we would expect from the first stage figures. The estimates for final allowance have the same sign but are

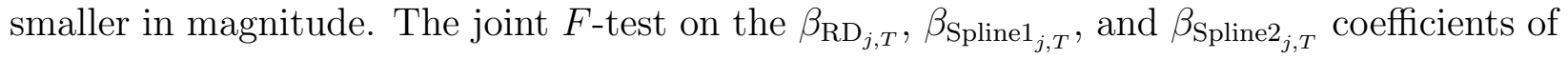
interest yields a $p$-value of less than 0.0001, indicating strong instruments.

For bankruptcy, foreclosure, eviction, and home sale, the reduced-form estimates largely have the expected sign, the opposite of the first-stage sign. For example, at both age cutoffs, bankruptcy rates decrease when the initial allowance rate jumps at the cutoff for RD and Hybrid offices; they decrease when the initial allowance rate trend increases at the minus-sixmonth cutoff for Spline and Hybrid offices; and they increase when the initial allowance rate trend drops at the zero cutoff for Spline and Hybrid offices. Although some reduced-form estimates are individually statistically significant at conventional levels, most are imprecise on their own.

Table 4 presents the IV estimates using the two-stage-least-squares estimator with initial allowance rate as the endogenous variable. ${ }^{25}$ We find that initial disability allowance reduces the bankruptcy rate by a statistically significant 0.81 percentage point (30 percent). Among homeowners, the likelihood of experiencing foreclosure falls by 1.7 percentage points (30 percent) and the likelihood of a net home sale falls by 2.5 percentage points (20 percent) within three years. These estimates are statistically significant. Net home purchases increase by 0.86 percentage point (20 percent) within three years. We also find suggestive evidence that initial disability allowance reduces eviction, though the estimates are imprecise. If taken at face value, they suggest that initial allowance reduces eviction rates by 0.49 percentage point (10 percent) within three years.

To verify that selection does not drive these results, Table 4 presents falsification tests for the the same outcomes in the years before the initial decision. As we would expect from the falsification graphs on the right-hand-side of Figures 8 and 9, none of the pre-decision estimates is significant.

In order to recover an IV estimate, we treat initial allowance as the endogenous variable of interest. There are, however, other ways in which we could specify the first stage. For instance, we could specify the endogenous variable as final allowance onto disability programs

\footnotetext{
${ }^{25}$ Appendix Table A.10 presents analogous estimates using the standard RD specification, equation (2). The estimates in that table are similar though less precise.
} 
Table 4: Instrumental Variable Estimates of the Effect of Initial Disability Allowance

\begin{tabular}{|c|c|c|c|c|c|c|c|}
\hline & \multicolumn{3}{|c|}{ After initial decision } & \multicolumn{3}{|c|}{ Before initial decision } & \multirow[b]{2}{*}{$\begin{array}{c}N \\
\text { (in millions) }\end{array}$} \\
\hline & $\begin{array}{l}\text { Within } 1 \text { year } \\
\text { Pt. Est. } \\
\text { (Std. Err.) } \\
\text { [Cntrl. Mean] }\end{array}$ & $\begin{array}{c}\text { Within } 3 \text { years } \\
\text { Pt. Est. } \\
\text { (Std. Err.) } \\
\text { [Cntrl. Mean] }\end{array}$ & $\begin{array}{c}\text { Within } 5 \text { years } \\
\text { Pt. Est. } \\
\text { (Std. Err.) } \\
\text { [Cntrl. Mean] }\end{array}$ & $\begin{array}{l}\text { Within } 1 \text { year } \\
\text { Pt. Est. } \\
\text { (Std. Err.) } \\
\text { [Cntrl. Mean] }\end{array}$ & $\begin{array}{l}\text { Within } 3 \text { years } \\
\text { Pt. Est. } \\
\text { (Std. Err.) } \\
\text { [Cntrl. Mean] }\end{array}$ & $\begin{array}{l}\text { Within } 5 \text { years } \\
\text { Pt. Est. } \\
\text { (Std. Err.) } \\
\text { [Cntrl. Mean] }\end{array}$ & \\
\hline Bankruptcy & $\begin{array}{c}-0.00654^{* * *} \\
(0.00233) \\
{[0.0126]}\end{array}$ & $\begin{array}{c}-0.00806^{* *} \\
(0.00332) \\
{[0.0262]}\end{array}$ & $\begin{array}{c}-0.0101^{* * *} \\
(0.00375) \\
{[0.0339]}\end{array}$ & $\begin{array}{c}0.000518 \\
(0.00250) \\
{[0.0139]}\end{array}$ & $\begin{array}{c}0.00210 \\
(0.00398) \\
{[0.0375]}\end{array}$ & $\begin{array}{c}0.00369 \\
(0.00492) \\
{[0.0590]}\end{array}$ & 3.07 \\
\hline Foreclosure & $\begin{array}{c}\text { onditional on l } \\
-0.0126^{* * *} \\
(0.00461) \\
{[0.0253]}\end{array}$ & $\begin{array}{c}\text { meownership) } \\
-0.0167^{* *} \\
(0.00650) \\
{[0.0530]}\end{array}$ & $\begin{array}{c}-0.0207^{* * *} \\
(0.00722) \\
{[0.0667]}\end{array}$ & $\begin{array}{c}-0.00230 \\
(0.00444) \\
{[0.0226]}\end{array}$ & $\begin{array}{c}0.00317 \\
(0.00615) \\
{[0.0456]}\end{array}$ & $\begin{array}{c}-0.00279 \\
(0.00689) \\
{[0.0587]}\end{array}$ & 0.81 \\
\hline Eviction (col & $\begin{array}{c}\text { ditional on non } \\
-0.00275 \\
-0.0046 \\
{[0.0206]}\end{array}$ & $\begin{array}{c}\text { omeownership) } \\
-0.00485 \\
-0.00725 \\
{[0.0512]}\end{array}$ & $\begin{array}{c}-0.00163 \\
-0.00859 \\
{[0.0742]}\end{array}$ & $\begin{array}{c}0.00515 \\
-0.005 \\
{[0.0232]}\end{array}$ & $\begin{array}{c}2.09 \mathrm{e}-05 \\
-0.00746 \\
{[0.0545]}\end{array}$ & $\begin{array}{c}0.00491 \\
-0.00871 \\
{[0.0754]}\end{array}$ & 0.83 \\
\hline Net home sa & $\begin{array}{c}\text { (conditional o } \\
-0.0111^{* *} \\
(0.00505) \\
{[0.0458]}\end{array}$ & $\begin{array}{c}\text { homeownership } \\
-0.0250^{* * *} \\
(0.00770) \\
{[0.117]}\end{array}$ & $\begin{array}{c}-0.0220^{* *} \\
(0.00893) \\
{[0.167]}\end{array}$ & $\begin{array}{c}-0.00191 \\
(0.00410) \\
{[0.0291]}\end{array}$ & $\begin{array}{c}0.000160 \\
(0.00583) \\
{[0.0621]}\end{array}$ & $\begin{array}{c}-0.000546 \\
(0.00677) \\
{[0.0873]}\end{array}$ & 1.45 \\
\hline Net home pr & $\begin{array}{l}\text { chase } \\
0.00572^{* * *} \\
(0.00192) \\
{[0.0183]}\end{array}$ & $\begin{array}{c}0.00859^{* * *} \\
(0.00296) \\
{[0.0451]} \\
\end{array}$ & $\begin{array}{c}0.00711^{* *} \\
(0.00341) \\
{[0.0615]}\end{array}$ & $\begin{array}{c}-0.000455 \\
(0.00206) \\
{[0.0210]} \\
\end{array}$ & $\begin{array}{c}-0.000316 \\
(0.00341) \\
{[0.0619]} \\
\end{array}$ & $\begin{array}{c}0.00245 \\
(0.00410) \\
{[0.0923]} \\
\end{array}$ & 5.12 \\
\hline
\end{tabular}

Notes: This table reports instrumental-variable estimates of the effect of disability benefits on financial outcomes. The "bankruptcy" regressions are based on the bankruptcy sample: disability-program applicants who reach step 5 of the disability determination process and who have an initial decision date in 2000-2009. The "foreclosure" regressions are based on the foreclosure sample: disability-program applicants who appear in the deeds records (homeowners), who reach step 5 of the disability determination process, and who have an initial decision date in 2005-2014. The "eviction" regressions are based on the eviction sample: disability-program applicants who do not appear in the deeds records (non-homeowners), who reach step 5 of the disability determination process, and who have an initial decision date in 20052014. The "net home-sale" regressions are based on the home-sale sample: disability-program applicants who appear in the deeds records (homeowners), who reach step 5 of the disability determination process, and who have an initial decision date in 2000-2014. The "net home-purchase" regressions are based on the home-purchase sample: disability-program applicants who reach step 5 of the disability determination process and who have an initial decision date in 2000-2014. A "net" home sale is defined as a home sale that is not accompanied by a home purchase within six months before or after the sale, and analogously for net home purchase. Samples involving "foreclosure" and "bankruptcy" outcomes exclude ZIP Codes of residence at application that have an average of fewer than five recorded events per year during the corresponding period; samples involving "eviction" outcomes exclude FIPS county codes of residence at application that have an average of fewer than fifteen recorded events per year during 2005-2014; samples involving "net home-sale" or "net home-purchase" outcomes exclude ZIP Codes of residence at application that have an average of fewer than fifteen recorded corresponding events per year during 2000-2014. Standard errors in parentheses; control means in square brackets are the average value of the variable for applicants who are under age 50 or 55 by 6 to 10 months. ${ }^{* * *} p<0.01,{ }^{* *} p<0.05,{ }^{*} p<0.1$. 
or the number of months on the program. We focus instead on initial allowance because it captures both the allowance itself and also the timing of allowance. Figure 3 suggests that the financial distress of applicants peaks very close to the date of their application. For applicants in severe financial distress, we would expect initial allowance to have a larger effect on consumption than allowance on appeal months later. ${ }^{26}$ Indeed, Table 4 suggests that most of the effect we observe appears in the first year after the initial decision.

We next evaluate the pattern of the IV estimates over time in Figure 10. The top graph shows the likelihood of receiving disability benefits in each event year. In addition to the extensive margin of allowance, the intensive margin - how many more months of disability benefits those applicants receive - is relevant for interpreting our findings. The top graph in Figure 10 plots the IV estimate of the likelihood of receiving disability benefits for each year relative to the initial decision year. As expected, there is minimal difference between control (below age threshold) and treatment (above age threshold) groups in the likelihood of receiving disability benefits before the initial decision. In the year of the decision, the initial disability allowance leads to an 80 percentage point difference in the likelihood of receiving disability benefits. The likelihood of receiving benefits then attenuates rapidly, falling to about 40 percentage points the year after the decision and then stabilizing around 20 percentage points. This attenuation is driven by two phenomena: denied applicants reapplying for benefits in later years and then being allowed onto the programs, and allowed applicants (particularly those receiving SSI) leaving the program in future years (see Appendix Figure A.8).

The pattern of attenuation in the top panel of Figure 10 is important in interpreting our main results. The figure reveals that the "treatment" coming from this quasi-experiment is not the effect of receiving disability benefits indefinitely, but rather the effect of receiving disability benefits earlier than the applicant otherwise would have. On average, including the zeros, applicants above the age cutoff receive disability benefits for 1.6 additional months relative to those just below the cutoff. The effects that we estimate may still reflect the belief on the part of the applicant that they will receive disability benefits indefinitely, but the effects are expected to dissipate mechanically over time as the first stage attenuates.

The remaining graphs in Figure 10 present IV estimates by event years for bankruptcy, foreclosure, net home sale, and net home purchase. Not surprisingly for uncommon events, the individual-year estimates have large confidence intervals. However, the time path of the treatment effects generally mirrors the first stage pattern: no treatment effect before

\footnotetext{
${ }^{26}$ Alternatively, we would focus on final allowance as the endogenous variable of interest if only allowance itself, and not the timing of the allowance, matter for outcomes. Scaling the reduced-form estimates by final allowance would result in IV estimates that are often larger than the control mean, though the confidence intervals include reductions smaller than the control mean.
} 


\section{Figure 10: Instrumental Variable Estimates by Event Year}
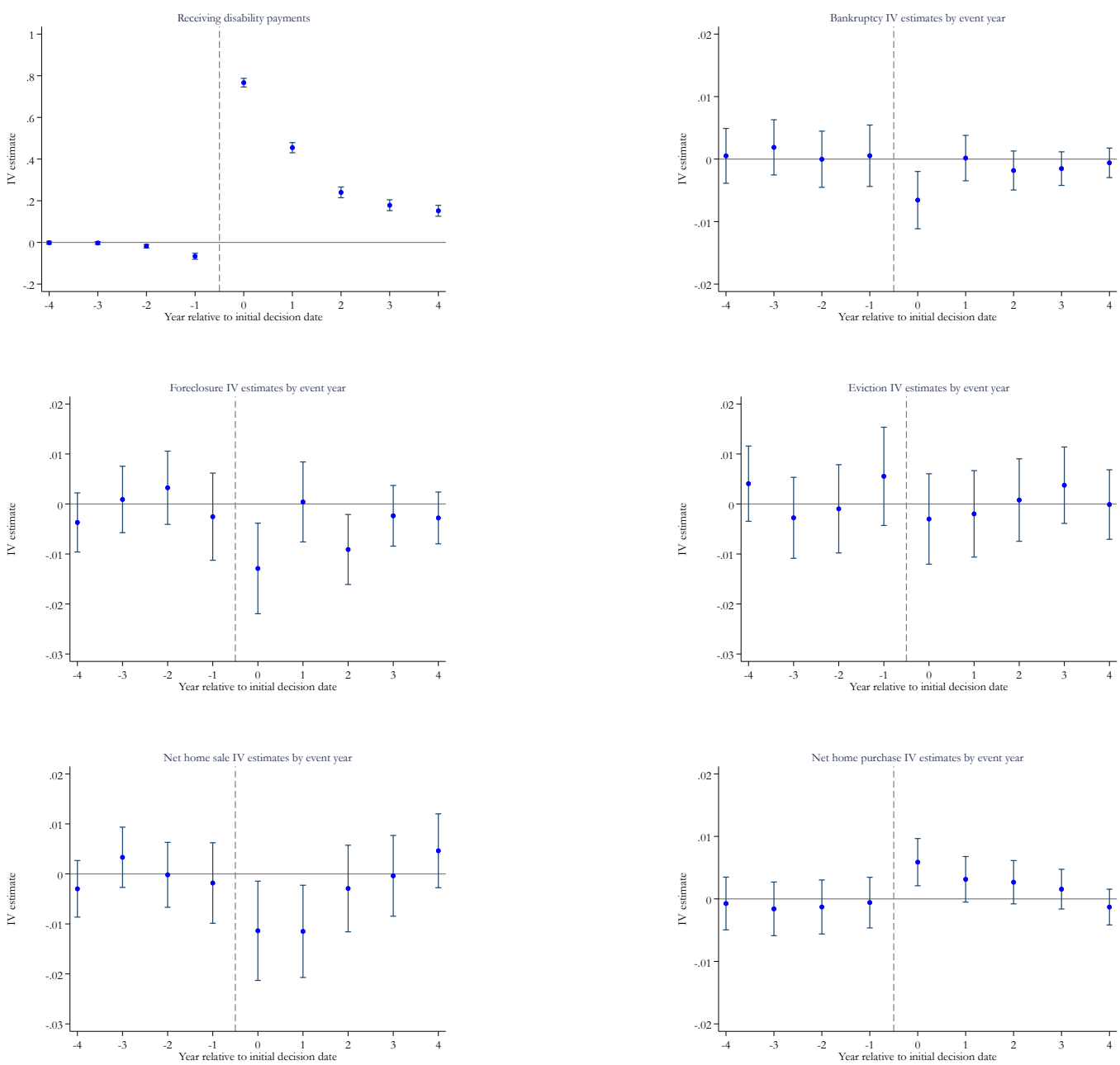

Notes: Figures present instrumental variable estimates of the effect of disability-program allowance on financial outcomes by event year around the initial decision date. The top graph plots estimates of the likelihood of receiving disability benefits in each event year. This sample is the same as the sample for "net home-purchase": disability-program applicants who reach step 5 of the disability determination process and who have an initial decision date in 2000-2014. The "bankruptcy" regressions are based on the bankruptcy sample: disability-program applicants who reach step 5 of the disability determination process and who have an initial decision date in 2000-2009. The "foreclosure" regressions are based on the foreclosure sample: disability-program applicants who appear in the deeds records (homeowners), who reach step 5 of the disability determination process, and who have an initial decision date in 2005-2014. The "eviction" regressions are based on the eviction sample: disability-program applicants who do not appear in the deeds records (non-homeowners), who reach step 5 of the disability determination process, and who have an initial decision date in 2005-2014. The "net home-sale" regressions are based on the home-sale sample: disability-program applicants who appear in the deeds records (homeowners), who reach step 5 of the disability determination process, and who have an initial decision date in 2000-2014. A "net" home sale is defined as a home sale that is not accompanied by a home purchase within six months before or after the sale, and analogously for net home purchase. Samples involving "foreclosure" or "bankruptcy" outcomes exclude ZIP Codes of residence at application that have an average of fewer than five recorded events per year during the corresponding period; samples involving "eviction" outcomes exclude FIPS county codes of residence at application that have an average of fewer than fifteen recorded corresponding events per year during 2005-2014; samples involving "net home-sale" or "net home-purchase" outcomes exclude ZIP Codes of residence at application that have an average of fewer than fifteen recorded corresponding events per year during 2000-2014. 
Table 5: Instrumental Variable Estimates by Subgroup

\begin{tabular}{|c|c|c|c|c|}
\hline & \multicolumn{4}{|c|}{ After initial decision - within 3 years } \\
\hline & Pt. Est. & (Std. Err.) & Cntrl. Mean & $\mathrm{N}$ (in millions) \\
\hline \multicolumn{5}{|l|}{ Bankruptcy } \\
\hline All & $-0.00806^{* *}$ & $(0.00332)$ & 0.0262 & 3.07 \\
\hline Less than high school education & -0.00788 & $(0.00480)$ & 0.0196 & 0.86 \\
\hline High school or more & -0.00544 & $(0.00461)$ & 0.0285 & 1.94 \\
\hline Male & -0.00184 & $(0.00411)$ & 0.0236 & 1.49 \\
\hline Female & $-0.0172^{* * *}$ & $(0.00580)$ & 0.0291 & 1.45 \\
\hline SSDI adults & $-0.00972^{* *}$ & $(0.00421)$ & 0.0313 & 2.00 \\
\hline SSI adults & -0.00573 & $(0.00380)$ & 0.0188 & 1.49 \\
\hline \multicolumn{5}{|c|}{ Foreclosure (conditional on homeownership) } \\
\hline All & $-0.0167 * *$ & $(0.00650)$ & 0.0530 & 0.81 \\
\hline Less than high school education & -0.00577 & $(0.0128)$ & 0.0498 & 0.16 \\
\hline High school or more & $-0.0189^{* *}$ & $(0.00764)$ & 0.0538 & 0.63 \\
\hline Male & $-0.0275^{* * *}$ & $(0.00802)$ & 0.0549 & 0.39 \\
\hline Female & 0.00230 & $(0.0113)$ & 0.0508 & 0.39 \\
\hline SSDI adults & $-0.0210^{* * *}$ & $(0.00699)$ & 0.0547 & 0.66 \\
\hline SSI adults & -0.0170 & $(0.0115)$ & 0.0538 & 0.27 \\
\hline \multicolumn{5}{|c|}{ Net home sale (conditional on homeownership) } \\
\hline All & $-0.0250 * * *$ & $(0.00770)$ & 0.117 & 1.45 \\
\hline Less than high school education & $-0.0254^{*}$ & $(0.0138)$ & 0.103 & 0.29 \\
\hline High school or more & $-0.0290^{* * *}$ & $(0.00933)$ & 0.120 & 1.06 \\
\hline Male & $-0.0374^{* * *}$ & $(0.00924)$ & 0.114 & 0.70 \\
\hline Female & -0.0106 & $(0.0138)$ & 0.121 & 0.70 \\
\hline SSDI adults & $-0.0290 * * *$ & $(0.00833)$ & 0.120 & 1.17 \\
\hline SSI adults & $-0.0272^{* *}$ & $(0.0127)$ & 0.105 & 0.44 \\
\hline \multicolumn{5}{|l|}{ Net home purchase } \\
\hline All & $0.00859^{* * *}$ & $(0.00296)$ & 0.0451 & 5.12 \\
\hline Less than high school education & $0.00950^{* *}$ & $(0.00407)$ & 0.0290 & 1.42 \\
\hline High school or more & $0.00825^{* *}$ & $(0.00402)$ & 0.0510 & 3.92 \\
\hline Male & $0.0119^{* * *}$ & $(0.00374)$ & 0.0442 & 2.51 \\
\hline Female & 0.00473 & $(0.00512)$ & 0.0473 & 2.40 \\
\hline SSDI adults & $0.0117^{* * *}$ & $(0.00401)$ & 0.0577 & 3.43 \\
\hline SSI adults & 0.00418 & $(0.00265)$ & 0.0203 & 2.63 \\
\hline
\end{tabular}

Notes: This table reports instrumental-variable estimates of the effect of being 50 years or older and 55 years or older at the initial decision date on reduced-form financial outcomes by subgroups. The "bankruptcy" regressions are based on the bankruptcy sample: disability-program applicants who reach step 5 of the disability determination process, and who have an initial decision date in 2000-2009. The "foreclosure" regressions are based on the foreclosure sample: disability-program applicants who appear in the deeds records (homeowners), who reach step 5 of the disability determination process, and who have an initial decision date in 2005-2014. The "net home-sale" regressions are based on the home-sale sample: disability-program applicants who appear in the deeds records (homeowners), who reach step 5 of the disability determination process, and who have an initial decision date in 2000-2014. The "net home-purchase" regressions are based on the home-purchase sample: disability-program applicants who reach step 5 of the disability determination process and who have an initial decision date in 2000-2014. A "net" home sale is defined as a home sale that is not accompanied by a home purchase within six months before or after the sale, and analogously for net home purchase. Samples involving foreclosure or bankruptcy exclude ZIP Codes of residence at application that have an average of fewer than five recorded events per year during the corresponding period; samples involving net home-sale or net home-purchase outcomes exclude ZIP Codes of residence at application that have an average of less than fifteen recorded corresponding events per year during 2000-2014. Control means are the average value of the variable for applicants who are under age 50 or 55 by 6 to 10 months. Standard errors in parentheses. ${ }^{* * *} p<0.01$, ** $p<0.05,{ }^{*} p<0.1$. 
the year of the initial decision, an immediate effect in the year of the initial decision, and then dissipating effects in future event years. The estimates are too imprecise to determine whether the effects dissipate because of first stage attenuation or because of actual changes in the treatment effect.

Finally, we consider heterogeneity in the IV estimates by subgroup. Table 5 presents IV estimates by education, gender, and program (SSDI or SSI). The table suggests strong bankruptcy effects for women: a decline of 1.7 percentage points, compared to 0.2 percentage points for men, within three years. By contrast, the effects for foreclosure, home sale, and home purchase are much stronger for men than women, and stronger for DI applicants as compared to SSI applicants. Since DI applicants have higher incomes than SSI applicants and are more likely to be homeowners, they may be more likely to be on the margin of experiencing foreclosure, selling a home, or purchasing a home.

\section{Understanding the Channels through which Disability Benefits Affect Financial Outcomes}

We find that initial disability allowance leads to large reductions in bankruptcies, foreclosures, and home sales. In order to assess the implications of these results for recipients' welfare, we must consider the mechanisms through which disability benefits affect household financial outcomes. One possible channel is a wealth effect: disability programs relax the recipient's budget constraint by increasing income, reducing income volatility, and providing access to health insurance. If the reduced-form results reflect primarily a wealth channel, then we can interpret the reductions in bankruptcy and foreclosure as reductions in financial distress and therefore as improvements in recipient welfare. ${ }^{27}$

There are, however, alternative mechanisms through which disability benefits might affect financial outcomes, and those mechanisms have more ambiguous implications for recipient welfare. For example, if disability benefits change access to credit or demand for credit, then benefits could affect bankruptcy rates and foreclosure rates mechanically by changing either the number of disability recipients who use credit or the amount of credit they use. We discuss these alternative mechanisms and the expected direction and magnitude of their effects. A combination of empirical evidence and institutional details suggests that a wealth effect is the most likely channel through which disability benefits affect financial outcomes.

\footnotetext{
${ }^{27}$ In the short term, the wealth channel could actually increase bankruptcy filings by providing households with enough money to pay bankruptcy fees. Bankruptcy attorney fees typically cost at least $\$ 1,000$, and many households must thus "save up" for bankruptcy (Gross et al., 2016), filing only when they have the funds to do so. If so, this would make our reduced-form estimates an under-estimate of the wealth effect operating through lower financial distress.
} 
If so, we can interpret the reduced-form results as a reduction in financial distress and an improvement in recipient welfare.

Credit access and credit demand. Disability benefits could affect either the supply of credit or demand for credit. On the supply side, benefits could increase access to credit, prompting lenders to offer more credit cards, bank loans, and mortgages in response to the higher incomes of disability recipients. This increase in access to credit could have two potential effects. First, it could mechanically increase bankruptcy and foreclosure rates since individuals can only default if they have access to credit. Indeed, we find that benefits increase home purchases, which likely means they increase mortgage underwriting. But overall we find that disability benefits lead to a decline in bankruptcies and foreclosures, so such an "access to credit" effect would lead us to under-estimate the wealth effect.

Second, greater access to credit could lead households to roll over debt onto credit cards or other new products and thus avoid default. If this were the case, we would expect the additional loans to postpone bankruptcy but not to eliminate it entirely. Yet the 5-year estimates in Table 4 do not suggest a reversal in the effects on bankruptcy, foreclosure, or home sale in later years. Although we cannot rule out a later increase in adverse financial events entirely, we think that is unlikely based on the long-term estimates of Table 4.

Disability benefits could also affect demand for credit through an income effect. We find that disability benefits increase recipient income (see Appendix Table A.11). If credit is a normal good, then disability benefits will increase demand for credit, which could mechanically increase bankruptcies and foreclosures. However, as with greater credit access, this mechanical increase would lead us to under-estimate the wealth effect. On the other hand, if credit is an inferior good, then disability benefits will decrease demand for credit, which could mechanically reduce bankruptcies and foreclosures. Although this is possible, we think it is unlikely that demand for credit is decreasing in income for households with such low levels of income - recall that average annual pre-decision earnings are less than $\$ 20,000$. Calculations based on the 2016 Survey of Consumer Finances indicate that, for the lower part of the income distribution, applications for credit are increasing in income.

Incentive Effects. Another way that disability benefits could mechanically affect financial outcomes is by changing the incentive to file for bankruptcy or repay debts. Suppose, for instance, that disability-program rules (e.g., income or asset tests) either impose restrictions on or encourage recipients to file for bankruptcy, default on a mortgage, or buy or sell a home. Or suppose that the bankruptcy process (or foreclosure or home-transaction process) treats disability recipients differently than other individuals. In either case, benefits could 
then affect the rates of these financial events.

To the best of our knowledge, however, disability program rules do not affect the incentives to file for bankruptcy or default on a mortgage. Disability benefits are not contingent on bankruptcy or foreclosure and adjudicators at the SSA are not supposed to consider financial markers like bankruptcy or foreclosure when deciding whether to continue a recipient's benefits. ${ }^{28}$ In terms of home transactions, the SSI asset test exempts one home, so one might hypothesize that some recipients purchase homes to shift assets from non-exempt to exempt categories in order to maintain eligibility. In practice, however, we find effects on home purchases only for the DI population, not for the SSI population.

Turning to bankruptcy, Social Security benefits are exempt from the Chapter 7 means test, meaning that allowance onto disability programs does not reduce the ability to file for Chapter 7. For Chapter 13, Social Security benefits may help recipients create a debt repayment plan that a court is more likely to approve, but we would consider this a wealth effect rather than an incentive effect. Federal disability benefits are protected in bankruptcy, which might increase the incentive to take on debt and file for bankruptcy, but this incentive would work in the opposite direction of the reduced-form results. ${ }^{29}$

Considering foreclosure, regulations prohibit lenders from garnishing disability benefits to cover mortgage debt not covered by the foreclosure sale, which could increase the incentive to default on a mortgage. But this too would lead to an increase in foreclosure rates after allowance, which would lead us to under-estimate the wealth effect. ${ }^{30}$

Finally, turning to home transactions, some public lending programs treat disability recipients differently than other potential homeowners. ${ }^{31}$ This could mean that SSI recipients get better loan terms and therefore are more likely to purchase a house than disability applicants who are denied. However, rates of homeownership among SSI applicants are low and these lending programs are small in scale.

Summary. Although we cannot rule out these alternative mechanisms, we conclude from the evidence and institutional details that, for the most part, they either work in the opposite direction of the results or would likely be small in magnitude. The most likely channel then is the wealth channel: allowance onto disability programs increases applicants' wealth and

\footnotetext{
${ }^{28}$ Initial examiners do not interact with the recipient in person during a continuing disability review. Administrative law judges do interact with disability applicants and recipients in person, so it is possible that they consider financial distress. Official agency guidelines require adjudicators to restrict their attention to only medical and vocational criteria.

${ }^{29}$ See, e.g., "Bankruptcy Can Help Seniors Protect Assets," New York Times, May 13, 2015.

${ }^{30}$ Section 207 of the Social Security Act, 42 U.S.C. $\$ 407$.

${ }^{31}$ For example, Connecticut's "Home of Your Own Program" offers better terms to recipients with disabilities and accepts SSI allowance as proof of disability. See https://mymortgageinsider.com/ qualify-mortgage-disability-income
} 
thus they become solvent. Newly allowed applicants can meet their financial obligations, and this wealth leads to a decrease in bankruptcies, foreclosures, and home sales.

Why does disability allowance have such a large effect on financial distress? One reason is that disability applicants are in severe financial distress at the time of application. Figure 2 suggests that applicants' risk of bankruptcy, foreclosure, and eviction is much higher than the general population, and Figure 3 shows that it is high relative to the applicants' lifetime risk, peaking just after they apply for benefits. For this population, then, it is perhaps unsurprising that a monthly disability check and health insurance has a large effect on financial outcomes. Indeed, the monthly disability check represents an increase in income for applicants. Appendix Table A.11 presents IV estimates for earnings and income. Disability allowance causes earnings to decline by $\$ 400$ and total observed income - earnings plus disability income - to increase by $\$ 1,300$ in the year after the decision.

Our results are consistent with previous studies showing that the social safety net can have a large effect on these same outcomes. Hsu et al. (2018) study unemployment insurance and foreclosure and find that increases in benefits drastically reduce foreclosures. Their estimates suggest that a one-standard-deviation increase in unemployment-insurance benefits cuts a layoff-related increase in foreclosures by more than half. Similarly, in studying the Oregon Health Insurance Lottery, Baicker et al. (2013) find that Medicaid "nearly eliminates" catastrophic medical debt, reducing its incidence by 81 percent. Gallagher et al. (2019) find that households eligible for Affordable Care Act marketplace subsidies experienced a 25 percent decline in mortgage delinquency rates.

\section{$5 \quad$ Welfare Implications}

In this section, we consider the welfare implications of our estimates of the effect of disability programs on financial distress. We incorporate our estimates into standard optimal-benefits calculations from the public finance literature. Typically, optimal-benefits calculations only consider mean consumption, and, in particular, the simple difference between mean consumption in the good state of the world and mean consumption in the bad state of the world. ${ }^{32}$ Such an approach is appropriate if mean consumption is a sufficient statistic for the welfare gains from insurance. In that case, one could simply turn to publicly available surveys to measure mean consumption and evaluate the welfare effects of the program.

But that approach would be problematic for two reasons. First, risk-averse disabilityprogram applicants care not only about mean consumption but also about the likelihood of

\footnotetext{
${ }^{32}$ For instance, Gruber (1997), Bronchetti (2012), and Lawson (2017) all approximate average marginal utility with the marginal utility of average consumption.
} 
extreme losses in consumption. Second, standard optimal-benefits calculations focus only on the transfer from individuals in the good state to individuals in the bad state, ignoring potential spillovers to those in the good state. For these reasons, we extend standard welfare calculations in two ways. First, we adapt optimal-benefits calculations to capture the effect of disability programs on tail consumption risk, under assumptions that we outline below. Second, we incorporate into optimal-benefits calculations our estimates combined with existing estimates of the spillover effects of foreclosure to neighboring property owners.

\subsection{Adapting Optimal-Benefit Calculations to Consider Tail Consumption Risk}

We use our estimates to illustrate that tail consumption risk, as proxied by the financial events we observe, can play an important role in the calculation of optimal benefits. We make several assumptions to illustrate this point. First, we assume that these tail eventsforeclosure, bankruptcy, eviction, and home sale - represent risk, which is uncertain from the agent's perspective, rather than heterogeneity, which is known to the agent. Second, we assume that there are no other forms of formal or informal insurance, such as spousal labor supply. Third, we consider only the ex-post value of disability benefits conditional on becoming disabled, not the ex-ante insurance value of the disability system prior to becoming disabled. We also abstract away from the ex-ante moral-hazard incentive problem that considering financial distress in the calculation of optimal benefits might encourage financial distress or applications from financially distressed individuals.

Consider the following adaptation of the Baily-Chetty (Baily, 1978; Chetty, 2006) framework, in which a social planner sets the benefit amount $b$ and tax $t$ to balance risk protection for the agent against the effect of moral hazard on the government budget. In this adaptation, agents face a small risk of a large consumption loss and the risk for disabled agents depends on $b$ :

$$
\begin{aligned}
\max _{c_{a}^{l}, c_{a}^{h}, c_{d}^{l}, c_{d}^{h}} & (1-p)\left[\left(1-q_{a}\right) u\left(c_{a}^{h}\right)+q_{a} u\left(c_{a}^{l}\right)\right]+p\left[\left(1-q_{d}(b)\right) u\left(c_{d}^{h}\right)+q_{d}(b) u\left(c_{d}^{l}\right)\right]+\Psi(p) \\
\text { s.t. } & c_{a}^{h}=A_{a}+w-t, \quad c_{a}^{l}=A_{a}+w-t-L, \\
& c_{d}^{h}=A_{d}+b, \quad c_{d}^{l}=A_{d}+b-L \\
& t(1-p)-p b \geq 0 .
\end{aligned}
$$

Here, $p$ is the likelihood of disability, $c_{a}^{l}\left(c_{a}^{h}\right)$ represents low (high) consumption in the ablebodied state (including assets $A_{a}$ and wages $\left.w\right), c_{d}^{l}\left(c_{d}^{h}\right)$ represents low (high) consumption in the disabled state, $q_{a}$ is the likelihood of a large consumption loss $L$ associated with an extreme financial event in the able-bodied state, and $\Psi(p)$ reflects the leisure value of not 
working. The parameter $q_{d}(b)$ is the likelihood of loss $L$ in the disabled state and depends on the benefit $b$. Making $q_{d}$ endogenous reflects the evidence from our IV estimates that disability programs not only increase consumption through the cash transfer but also make the worst states of the world (those with large consumption losses) less likely to arise.

Rewriting the problem in terms of $b$ yields the following first-order condition:

$$
\begin{aligned}
& (1-p)\left[-\left(1-q_{a}\right) u^{\prime}\left(c_{a}^{h}\right)-q_{a} u^{\prime}\left(c_{a}^{l}\right)\right] \frac{d t}{d b} \\
+ & p\left[\left(1-q_{d}(b)\right) u^{\prime}\left(c_{d}^{h}\right)+q_{d}(b) u^{\prime}\left(c_{d}^{l}\right)-q_{d}^{\prime}(b) u\left(c_{d}^{h}\right)+q_{d}^{\prime}(b) u\left(c_{d}^{l}\right)\right]=0 .
\end{aligned}
$$

Totally differentiating the balanced budget constraint yields

$$
(1-p) \frac{d t}{d b}=p\left[1+\varepsilon_{p, b} \frac{1}{1-p}\right]
$$

where $\varepsilon_{p, b}$ is the elasticity of the likelihood of disability with respect to the benefit $b$. Finally, substituting terms yields the following condition at the optimal $b^{*}$ :

$$
\frac{\varepsilon_{p, b}}{1-p}=\frac{E u^{\prime}\left(c_{d}^{*}\right)-E u^{\prime}\left(c_{a}^{*}\right)-q_{d}^{\prime}(b)\left[u\left(c_{d}^{* h}\right)-u\left(c_{d}^{* l}\right)\right]}{E u^{\prime}\left(c_{a}^{*}\right)} .
$$

We parameterize the probability of loss in the disabled state as follows:

$$
q_{d}(b)=a_{0}-a_{1} b
$$

where $a_{0}$ is the baseline probability of consumption loss for the disabled population from our descriptive estimates, and $a_{1}$ is the scaled causal effect of benefits on likelihood of an extreme consumption loss from our causal estimates. This parameterization assumes that the effect of disability benefits on the likelihood of the loss is linear - in other words, that the first dollar of benefits has the same effect as the ten-thousandth dollar.

We calculate $L$ from survey data. Note that $L$ need not be the causal effect of bankruptcy or foreclosure on consumption. Instead, we seek to measure the consumption drop associated with the financial distress for which these events are proxies. In order to estimate $L$, we calculate the average household food and housing expenses within three years of an adverse event based on households experiencing foreclosure or bankruptcy in the Panel Study of Income Dynamics (PSID). We find an annual drop of $\$ 6,300$ in average household food and housing expenses within three years of a foreclosure. ${ }^{33}$

\footnotetext{
${ }^{33}$ We use the PSID-provided measures on household expenses since 1999 and calculate annual household expenses using the sum of food and housing expenses. Due to data limitations, we apply the estimated consumption drop associated with foreclosure to all adverse financial events: foreclosure, bankruptcy, and distressed home sales. Questions on bankruptcy were only added to the survey in 1996, so we have insufficient power to estimate the consumption drop associated with bankruptcy alone. Appendix Figure A.9 presents the event-study plot.
} 
Baseline: $a_{0} \neq 0, a_{1}=0$, approximate average marginal utility with marginal utility of average consumption. We first establish a baseline in which $a_{0} \neq 0$ and $a_{1}=0$, meaning that we temporarily ignore the causal effect of $b$ on tail consumption risk $q_{d}$. This baseline corresponds to the standard Baily-Chetty condition, which is usually implemented by approximating average marginal utility with the marginal utility of average consumption. In our context, this approximation is:

$$
\frac{\varepsilon_{p, b}}{1-p}=\frac{E u^{\prime}\left(c_{d}^{*}\right)-E u^{\prime}\left(c_{a}^{*}\right)}{E u^{\prime}\left(c_{a}^{*}\right)} \approx \frac{u^{\prime}\left(\bar{c}_{d}^{*}\right)-u^{\prime}\left(\bar{c}_{a}^{*}\right)}{u^{\prime}\left(\bar{c}_{a}^{*}\right)}
$$

where

$$
\begin{aligned}
& \bar{c}_{d}=q_{d} c_{d}^{l}+\left(1-q_{d}\right) c_{d}^{h}=\bar{A}_{d}+b-q_{d} L, \\
& \bar{c}_{a}=q_{a} c_{a}^{l}+\left(1-q_{a}\right) c_{a}^{h}=\bar{A}_{a}+\bar{w}-t(b)-q_{a} L .
\end{aligned}
$$

To establish the baseline, we take the current average annual disability benefit of $\$ 13,000$ to be the optimal benefit amount, $b^{*}$, under a utility function with constant relative risk aversion (CRRA) and a coefficient of relative risk aversion, $\gamma$, of 2. Using our estimates of $\varepsilon_{p, b}, q_{a}$, and $q_{d}$ and an estimate of $\bar{A}_{a}+\bar{w}$ from survey data, we solve for the value of $\bar{A}_{d}$ that rationalizes the current benefit level as optimal. We use these parameters in our calculations. Table 6 reports the baseline optimal benefit amount for $\gamma=2$ and $\gamma=4$ using the empirical approximation in equation (5). Note that this column simply reflects the assumption that $\$ 13,000$ is optimal under $\gamma=2$. Using the parameter values that rationalize this assumption, the optimal benefit is slightly larger for $\gamma=4$.

Scenario 1: $a_{0} \neq 0, a_{1}=0$, use exact average marginal utility. The approximation in equation (5) is less accurate when agents are more prudent (i.e., non-linear marginal utility of consumption) and when they face larger consumption losses or a higher likelihood of consumption loss. The exact implementation of equation (4) when $a_{1}=0$ is

$$
\frac{\varepsilon_{p, b}}{1-p}=\frac{E u^{\prime}\left(c_{d}^{*}\right)-E u^{\prime}\left(c_{a}^{*}\right)}{E u^{\prime}\left(c_{a}^{*}\right)}=\frac{\left[\left(1-q_{d}\right) u^{\prime}\left(c_{d}^{h}\right)+q_{d} u^{\prime}\left(c_{d}^{l}\right)\right]-\left[\left(1-q_{a}\right) u^{\prime}\left(c_{a}^{h}\right)+q_{a} u^{\prime}\left(c_{a}^{l}\right)\right]}{\left(1-q_{a}\right) u^{\prime}\left(c_{a}^{h}\right)+q_{a} u^{\prime}\left(c_{d}^{l}\right)} .
$$

Scenario 1 in Table 6 shows optimal benefit calculations using this parameterization. Depending on the value of $\gamma$ and the baseline risk, the optimal benefit increases by $\$ 50$ to $\$ 170$ relative to the Baseline. ${ }^{34}$ The optimal benefit is higher using the exact formula because the increase in marginal utility from the consumption loss is larger than the decrease from

\footnotetext{
${ }^{34}$ We consider three scenarios for baseline risk: one based on foreclosure risk only (2 percent for the able-bodied, 5 percent for the disabled); one based on foreclosure plus bankruptcy risk (3 percent for the able-bodied, 8 percent for the disabled); and one based on foreclosure plus bankruptcy plus net-home-sale risk where we assume that 50 percent of net-home sales are distressed ( 5 percent for the able-bodied, 14 percent for the disabled).
} 
a comparable consumption gain. Note that this increase is likely an underestimate of the true increase in the optimal benefit amount we would obtain were we able to consider the full distribution of consumption. We observe only certain extreme events, but if disability benefits shift mass from bad states to good states more generally, then considering effects on the full distribution of consumption could increase the optimal benefit amount under Scenario 1 substantially.

Scenario 2: $a_{0} \neq 0, a_{1} \neq 0$, use exact average marginal utility. Finally, we consider the implementation of equation (4) when $a_{0} \neq 0$ and $a_{1} \neq 0$, so that $q_{d}(b)$ depends on $b$. Making $q_{d}$ endogenous has an ambiguous effect on optimal benefits. On the one hand, a higher benefit level has even more value to the agent than before, in that it reduces the likelihood of extreme consumption loss. This effect is reflected in the additional term in equation (4): $q_{d}^{\prime}(b)\left[u\left(c_{d}^{* h}\right)-u\left(c_{d}^{* l}\right)\right]$. On the other hand, by reducing the likelihood of extreme consumption loss, a higher benefit level means more equal consumption between the able and disabled states. This offsetting effect is reflected in the term $E u^{\prime}\left(c_{d}^{*}\right)=q_{d}(b) u^{\prime}\left(c_{d}^{l}\right)+$ $\left(1-q_{d}(b)\right) u^{\prime}\left(c_{d}^{h}\right)$, which is smaller, and therefore closer to $E u^{\prime}\left(c_{a}^{*}\right)$, when $b$ is larger. From Scenario 2 in Table 6, making $q_{d}$ endogenous increases the optimal benefit by about $\$ 100$ relative to Scenario 1 when $\gamma=2$ and decreases it by about $\$ 40$ when $\gamma=4$.

This exercise illustrates that incorporating the risk of an extreme consumption loss, as proxied by financial events like foreclosure, can change optimal benefit calculations substantially. In our calculations, the annual optimal benefit amount increases by up to $\$ 250$, or around 2 percent. This number is likely a lower bound for the true increase if we were to consider the entire distribution of consumption.

\subsection{Adapting Optimal-Benefit Calculations to Consider Spillovers}

In addition to tail risk, we adapt optimal-benefit calculations to consider the spillovers associated with allowance onto disability programs. Previous research on foreclosures, evictions, and bankruptcies suggests that these events impose negative externalities on third parties. For example, Campbell et al. (2011) extrapolate from their difference-in-difference estimates and forecasting models to calculate that each foreclosure during the Great Recession lowers neighborhood property values by $\$ 148,000$ to $\$ 477,000$.

Consider the Social Planner's problem in the previous subsection. We model the spillovers related to property values by assuming that the program benefit, $b$, produces some fraction $s \in[0,1]$ in aggregate spillovers to property values. In other words, benefits not only increase consumption in the disabled state, but also increase consumption in the able-bodied state, through the reduction in nearby foreclosures. The aggregate spillover amount, $s \times b$, is 
Table 6: Optimal Benefit Calculation

\begin{tabular}{ccccccc}
\multicolumn{5}{c}{ Baseline risk } & \multicolumn{5}{c}{ Optimal benefit } \\
$\gamma$ & $q_{a}$ & $a_{0}$ & Baseline & Scenario (1) & Scenario (2) & $\begin{array}{r}\text { Scenario (1) } \\
\text { w/ spillover }\end{array}$ \\
\hline 2 & 0.02 & 0.05 & $\$ 13,000$ & $\$ 13,050$ & $\$ 13,120$ & $\$ 13,170$ \\
4 & 0.02 & 0.05 & $\$ 13,230$ & $\$ 13,310$ & $\$ 13,280$ & $\$ 13,400$ \\
2 & 0.03 & 0.08 & $\$ 13,000$ & $\$ 13,060$ & $\$ 13,170$ & $\$ 13,190$ \\
4 & 0.03 & 0.08 & $\$ 13,220$ & $\$ 13,340$ & $\$ 13,300$ & $\$ 13,430$ \\
2 & 0.05 & 0.14 & $\$ 13,000$ & $\$ 13,100$ & $\$ 13,250$ & $\$ 13,230$ \\
4 & 0.05 & 0.14 & $\$ 13,220$ & $\$ 13,390$ & $\$ 13,330$ & $\$ 13,480$ \\
\hline
\end{tabular}

Notes: This table presents the optimal benefit in different scenarios, assuming a constant relative risk aversion (CRRA) utility function and a risk of becoming disabled of $p=0.06$. The parameter $q_{a}\left(a_{0}\right)$ denotes the baseline risk of experiencing an adverse event in the able-bodied (disabled) state. In the first two rows of both panels, we consider the probability of experiencing foreclosure only; in the next two rows, we consider the probability of experiencing foreclosure or filing for bankruptcy; in the last two rows, we consider the probability of experiencing foreclosure, filing for bankruptcy, or selling a home in distress (assuming 50 percent of net home sales are distressed). For the optimal benefit calculation, we assume $A_{a}+w=\$ 40,000$ based on the Health and Retirement Study (HRS). Under the assumption that the current disability benefit level $\$ 13,000$ is optimal based on equation (5) under CRRA with $\gamma=2$, we obtain $A_{d}=\$ 31,690$ under $q_{a}=0.02$ and $a_{0}=0.05, A_{d}=\$ 32,000$ under $q_{a}=0.03$ and $a_{0}=0.08$, and $A_{d}=\$ 32,225$ under $q_{a}=0.05$ and $a_{0}=0.14$. foreclosure. We estimate $L=\$ 6,300$ from the Panel Study of Income Dynamics (PSID), and we calculate the elasticity of non-employment with respect to the benefit amount $\varepsilon_{p, b}=0.02$ from our data. For Scenario (3), $q_{d}\left(b^{*}\right)$ denotes the endogenous probability of experiencing an adverse event in the disabled state under the optimal disability benefit. We use $b=\$ 13,000$ to scale the casual estimates.

divided among all able-bodied agents, which in the model is $\frac{1-p}{p}$. The only change in the Social Planner's problem from the previous subsection is the consumption of the able-bodied agent:

$$
c_{a}=A_{a}+w-t+\frac{s b}{\frac{1-p}{p}} .
$$

The Baily-Chetty condition under Scenario 1 with spillovers becomes

$$
\frac{\varepsilon_{p, b}}{1-p}=\frac{E u^{\prime}\left(c_{d}^{*}\right)-E u^{\prime}\left(c_{a}^{*}\right) \cdot[1-s p]}{E u^{\prime}\left(c_{a}^{*}\right)} .
$$

All else equal, a larger spillover $s$ increases the difference in the marginal utilities across states and therefore increases the optimal benefit, $b^{*}$.

To determine a reasonable value for $s$, we use our estimates of the effect of initial disability allowance on foreclosure combined with estimates from the literature of the decline in neighboring property values from foreclosure. We find that initial disability allowance reduces the likelihood of foreclosure by 1.7 percentage points. Campbell et al. (2011) estimate 
a decline of at least $\$ 148,000$ in neighboring property values for each foreclosure. Multiplying these two numbers, we approximate that 6.3 percent of the disability benefit amount accrues to neighboring property owners through the reduction in foreclosures.

We use this value of $s$ to determine how the optimal benefit changes. As shown in Table 6, considering property-value spillovers increases the optimal benefit by approximately $\$ 130$ for $\gamma=2$ and by $\$ 90$ for $\gamma=4$ relative to Scenario 1 . The increase is smaller for a larger degree of risk aversion because the consumption of able-bodied agents is valued less at higher levels of risk aversion. Disability programs may also create other spillovers that we do not consider here. $^{35}$

\subsection{Considering Optimal Benefit Timing}

In addition to the optimal benefit level, this analysis can also inform the optimal timing of disability benefits. Figure 3 suggests that applicants, on average, apply for disability benefits when they are in peak financial distress and have a high marginal utility of consumption relative to their lifetime average. In addition, our causal estimates suggest that initial disability allowance, which occurs several months after application, dramatically lowers rates of financial distress. Based on those two findings, it is likely that awarding disability benefits sooner would avert a substantial amount of financial distress among applicants. Of course, awarding benefits sooner also involves higher administrative costs and could change the composition of the applicant pool. Determining the optimal wait time requires weighing these considerations against the benefits suggested by our estimates.

\section{Conclusions}

This paper provides the first evidence of the effect of disability programs on financial outcomes. We merge the universe of Social Security disability applicants to nationwide records on bankruptcies, foreclosures, evictions, home sales, and home purchases to create the first sample of disability applicants linked to financial records. We produce three descriptive findings. First, rates of bankruptcy, foreclosure, and eviction are higher among disability

\footnotetext{
${ }^{35}$ Another way to put the real-estate-related spillovers in context is to compare it to the effect of the disability programs on earnings. We find that disability allowance reduces labor market earnings by $\$ 3,300$ over three years, and it increases housing values due to an averted foreclosure by roughly $\$ 2,400$, which is 70 percent of the decrease in earnings. We also calculate the marginal value of public funds (MVPF), which is the ratio of the marginal benefits of a policy to its marginal cost (see Jacobs (2018) for a review). In Appendix F, we use our estimates to calculate the MVPF, as derived by Hendren (2016) and Hendren (2017), incorporating spillovers to third parties and fiscal externalities. We calculate an MVPF of 1.04 for disability programs when considering effects on foreclosure and bankruptcy. The ratio is smaller, 0.99, when we ignore these effects because of the large positive spillovers to third parties and to the government from reductions in foreclosures and bankruptcies.
} 
applicants than the general population. Second, rates of these adverse financial events increase steadily and peak around the application date, suggesting that applicants apply for these programs after a period of increasing financial distress. Third, these financial events become less common, even for denied applicants, after the initial decision, suggesting that applicants find other margins of adjustment.

We use this data linkage in combination with a quasi-experiment created by the disability determination process to identify the impact of disability programs on bankruptcy, foreclosure, eviction, home sales, and home purchases. We find that allowance onto disability programs leads to large reductions in bankruptcies, foreclosures, and home sales, and to increases in home purchases. We consider the mechanisms through which disability programs can affect financial outcomes, including wealth, credit access, credit demand, and incentives from program rules. The evidence indicates that most of the reduction in adverse financial events reflects a true reduction in financial distress and an increase in recipient welfare.

Our findings inform both the optimal magnitude and the optimal timing of benefits. Regarding the magnitude of benefits, the estimates suggest that disability programs confer large welfare gains to recipients and to third parties. The reduction in the likelihood of an extreme consumption loss is more valuable than the increase in average consumption alone would suggest. Under certain assumptions regarding the relationship between financial events and consumption, incorporating the reduction in tail consumption risk increases the optimal benefit by at least several hundred dollars. The estimates also suggest sizable spillovers from disability programs to non-recipients, especially neighboring homeowners whose property values increase as a result of the reduction in foreclosures. Determining the optimal generosity of disability programs requires weighing these benefits against the moral-hazard costs of these programs.

Regarding the optimal timing of benefits, the findings suggest that disability programs could avert even more financial distress if awarded earlier. The argument for long wait times is that they reduce administrative costs and could, in theory, improve the targeting of disability programs. However, we find that applicants apply for disability programs when they are in peak financial distress, and that benefits reduce financial distress substantially when they are awarded several months later. These findings suggest that awarding benefits sooner could avert a substantial amount of financial distress. Determining the optimal wait time requires weighing these gains against potential administrative and targeting costs. 


\section{References}

Anenberg, Elliot and Edward Kung, "Estimates of the Size and Source of Price Declines Due to Nearby Foreclosures," American Economic Review, August 2014, 104 (8), 2527-51.

Apgar, William C., Mark Duda, and Rochelle Nawrocki Gorey, "The Municipal Cost of Foreclosures: A Chicago Case Study," Homeownership Preservation Foundation, 2005, pp. 1-57.

Autor, David, Andreas Ravndal Kostol, Magne Mogstad, and Bradley Setzler, "Disability Benefits, Consumption Insurance, and Household Labor Supply," American Economic Review, Forthcoming.

Baicker, Katherine, Sarah L. Taubman, Heidi L. Allen, Mira Bernstein, Jonathan H. Gruber, Joseph P. Newhouse, Eric C. Schneider, Bill J. Wright, Alan M. Zaslavsky, and Amy N. Finkelstein, "The Oregon experiment-Effects of Medicaid on clinical outcomes," New England Journal of Medicine, 2013, 368 (18), 1713-1722.

Baily, Martin Neil, "Some Aspects of Optimal Unemployment Insurance," Journal of Public Economics, 1978, 10 (3), 379-402.

Bound, John, "The Health and Earnings of Rejected Disability Insurance Applicants," American Economic Review, 1989, 79 (3), 482-503.

Bronchetti, Erin Todd, "Workers' compensation and consumption smoothing," Journal of Public Economics, 2012, 96 (5), 495 - 508.

Campbell, John Y., Stefano Giglio, and Parag Pathak, "Forced Sales and House prices," American Economic Review, 2011, 101 (5), 2108-2131.

Chen, Susan and Wilbert van der Klaauw, "The Work Disincentive Effects of the Disability Insurance Program in the 1990s," Journal of Econometrics, 2008, 142 (2), 757784.

Chetty, Raj, "A general formula for the optimal level of social insurance," Journal of Public Economics, 2006, 90 (10-11), 1879-1901.

Desmond, Matthew, Evicted: Poverty and Profit in the American City, New York: Crown, 2016.

Dobkin, Carlos, Amy Finkelstein, Raymond Kluender, and Matthew J. Notowidigdo, "The Economic Consequences of Hospital Admissions," American Economic Review, 2018, 108 (2), 308-52.

Finkelstein, Amy, Nathaniel Hendren, and Erzo F.P. Luttmer, "The Value of Medicaid: Interpreting Results from the Oregon Health Insurance Experiment," Journal of Political Economy, Forthcoming.

French, Eric and Jae Song, "The Effect of Disability Insurance Receipt on Labor Supply," American Economic Journal: Economic Policy, 2014, 6 (2), 291-337.

Gallagher, Emily A., Radhakrishnan Gopalan, and Michal Grinstein-Weiss, "The effect of health insurance on home payment delinquency: Evidence from ACA Marketplace subsidies," Journal of Public Economics, 2019, 172, 67 - 83.

Gelber, Alexander, Timothy Moore, and Alexander Strand, "Disability Insurance Income Saves Lives," Working Paper 18-005, Stanford Institute for Economic Policy Research March 2018. 
Gross, Tal and Brad Trenkamp, "Risk of Bankruptcy among Applicants to Disability Insurance," Journal of health care for the poor and underserved, 2015, 26 (4), 1149-1156.

_ , Matthew Notowidigdo, and Jialan Wang, "The Marginal Propensity to Consume Over the Business Cycle," Working Paper 22518, National Bureau of Economic Research August 2016.

Gruber, Jonathan, "The consumption smoothing benefits of unemployment insurance," American Economic Review, 1997, 87 (1), 192.

Hendren, Nathaniel, "The Policy Elasticity," Tax Policy and the Economy, 2016, 30 (1), $51-89$.

_, "Efficient Welfare Weights," Working Paper 20351, National Bureau of Economic Research October 2017.

Hsu, Joanne W., David A. Matsa, and Brian T. Melzer, "Unemployment Insurance as a Housing Market Stabilizer," American Economic Review, January 2018, 108 (1), 49-81.

Jacobs, Bas, "The marginal cost of public funds is one at the optimal tax system," International Tax and Public Finance, Aug 2018, 25 (4), 883-912.

Lawson, Nicholas, "Fiscal Externalities and Optimal Unemployment Insurance," American Economic Journal: Economic Policy, November 2017, 9 (4), 281-312.

Low, Hamish and Luigi Pistaferri, "Disability Insurance and the Dynamics of the Incentive Insurance Trade-Off," American Economic Review, October 2015, 105 (10), 29863029.

Lusardi, Annamaria, Daniel Schneider, and Peter Tufano, "Financially Fragile Households: Evidence and Implications," Brookings Papers on Economic Activity, 2011, p. 83.

Maestas, Nicole, Kathleen Mullen, and Alexander Strand, "Does Disability Insurance Receipt Discourage Work? Using Examiner Assignment to Estimate Causal Effects of SSDI Receipt," American Economic Review, 2013, 103 (5), 1797-1829.

McCrary, Justin, "Manipulation of the running variable in the regression discontinuity design: A density test," Journal of Econometrics, 2008, 142 (2), 698-714.

Meyer, Bruce D. and Wallace K.C. Mok, "Disability, earnings, income and consumption," Journal of Public Economics, 2018.

Moore, Timothy, "The employment effects of terminating disability benefits," Journal of Public Economics, 2015, 124, 30 - 43.

U.S. Department of Housing and Urban Development, "Economic Impact Analysis of the FHA Refinance Program for Borrowers in Negative Equity Positions," 2010.

von Wachter, Till, Jae Song, and Joyce Manchester, "Trends in Employment and Earnings of Allowed and Rejected Applicants to the Social Security Disability Insurance Program," American Economic Review, December 2011, 101 (7), 3308-29.

Wixon, Bernard and Alexander Strand, "Identifying SSA's Sequential Disability Determination Steps," Social Security Administration Research and Statistics Note, 2013, pp. 1-16. 


\title{
Disability and Distress:
}

\section{The Effect of Disability Programs on Financial Outcomes}

\author{
Manasi Deshpande Tal Gross $\quad$ Yalun Su
}

\section{Online Appendix}

\section{A Appendix: Data Sources and Record Linkage}

Home Transactions Data. In order to match disability-program applicants to home purchases or sales, we combine four separate datasets from two sources: CoreLogic Deeds records, CoreLogic Deeds History records, Zillow Transaction Data, and Zillow Assessment Data. CoreLogic provides extensive coverage of home deeds prior to 2000, though buyer and seller names are often missing in many counties. By contrast, buyer and seller names are rarely missing in the Zillow data, but the dataset contains few transactions prior to 1993. ${ }^{36}$ Given these data limitations, we "harmonize" the data collected by CoreLogic and Zillow, combining both datasets into one file that we merge to records on disability-program applicants. The CoreLogic datasets provide seller and buyer names, transaction dates and amounts, each property's address, and the latitude and longitude of property centroids. If the property's ZIP Code is missing in the CoreLogic record, we use GIS software and the 2017 ZIP Code boundaries shapefiles from the United States Postal Service (USPS) to impute ZIP Codes. ${ }^{37}$ Zillow Transaction Data provides similar information as CoreLogic except that the Zillow data does not include latitude-longitude coordinates for property centroids. In the cases where ZIP Code is missing, we link the property with Zillow Assessment Data and use the ZIP Code associated with the most-recent county record. As a last attempt to impute missing ZIP Codes, we use the property mailing ZIP Codes.

Administrative Record Linkage. The bankruptcy data we use was originally compiled by Gross et al. (2016) and is described in their paper. The data consist of names, addresses, the last four digits of each bankruptcy filer's Social Security number (SSN), and dates of

\footnotetext{
${ }^{36}$ According to staff at CoreLogic and Zillow Research, the heterogeneity across counties and years is driven by different data-collection protocols and changes in the information-release policies of each county's assessor's office.

${ }^{37}$ We obtain 2017 USPS ZIP Code shapefiles based on interpolation from ArcGIS. We validate the imputation procedure using CoreLogic records with non-missing ZIP Codes and find that ArcGIS boundary shapfiles outperform the 2010 Census ZCTA boundary shapefiles.
} 
bankruptcy for a majority of the bankruptcy courts in the United States from the late 1990s through 2009 (2011 for some districts). ${ }^{38}$ Since the data include both the last four digits of SSNs and filers' ZIP Codes, we perform the record linkage in the following five steps for each state. These steps are meant to address potential recording errors and name variations in administrative datasets. First, we link individuals in the bankruptcy records with disability records using first name, last name, middle initial, ZIP Code, and the last four digits of SSN. Second, for records that did not match in the first step, to account for the possibility that people might apply for disability-program benefits in a different ZIP Code than the one they used for bankruptcy filings, we use first name, last name, middle initial, and the last four digits of SSN as the merge identifier. Third, for records that did not match in the previous steps, we use first name, last name, and the last four digits of SSN as the merge identifiers to account for potential misreported middle names and location variations. Fourth, for records that did not match in the previous steps, we use last name, middle initial, and the last four digits of SSN as the merge identifiers to account for potential variations in the first name (e.g., "Tom" versus "Thomas") and allow flexibility in location. Finally, for records that did not match in previous steps, we use last name, the last four digits of SSN, and ZIP Code to allow the maximum flexibility in both first name and middle name.

For other merges between the SSA administrative records and the financial-outcome records, ZIP Code serves as a key linking variable in the absence of the last four digits of SSN. For foreclosures, we first link individuals in the foreclosure records who have middle names to the disability-program records using first name, last name, middle initial, and ZIP Code. We then link individuals in the foreclosure records who do not have middle names to the disability-program records using first name, last name, and ZIP Code. In cases where we observe complete middle names in both housing and SSA disability-program records, we exclude false-matched cases based on identical middle initials but different full middle names. To address the name ambiguity, we exclude individuals with more than six events associated under the same first name, last name, middle initial, and ZIP Code. ${ }^{39}$ We use the same protocol to merge the disability-program records with eviction and home-transaction records.

We probe the validity of the foreclosure, deeds, and eviction merges using simulations with the bankruptcy data, which contain the most accurate identifiers (particularly last four digits of SSN and full names) of any of the financial records. First, we merge the bankruptcy records to disability records using all of the identifiers in the bankruptcy data: first name,

\footnotetext{
${ }^{38}$ Depending on the bankruptcy district, other information is also included, such as the disposition of the case, the chapter, the judge, the bankruptcy trustee, whether the filing was pro se, and so on.

${ }^{39}$ For most states, this step drops less than 1 percent of records.
} 
middle initial, last name, last four digits of SSN, and ZIP Code. Next, we simulate the deeds and foreclosure merges by dropping last four digits of SSN and conducting the merge using only first name, last name, middle initial, and ZIP Code. Finally, we simulate the eviction merge by dropping both last four digits of SSN and middle initial and conducting the merge using only first name, last name, and ZIP Code.

Table A1: Bankruptcy Record Merge Simulation Comparison

\begin{tabular}{lccccc} 
& & \multicolumn{2}{c}{ Ever experienced bankruptcy } & \multicolumn{2}{c}{ "False-Positive" Merge } \\
& Merge identifiers & Count & Fraction & Count & Fraction \\
\hline \multirow{2}{*}{$\begin{array}{l}\text { Bankruptcy-type merge } \\
\text { Foreclosure/deeds-type merge }\end{array}$} & SSN4, FN, LN, MI, ZIP & 282,428 & $9.2 \%$ & - & - \\
Eviction-type merge & FN, LN, MI, ZIP & 300,136 & $9.8 \%$ & 18,820 & $6.3 \%$ \\
& FN, LN, ZIP & 333,555 & $10.9 \%$ & 52,496 & $15.7 \%$ \\
Number of applicants & & & & & \\
\hline
\end{tabular}

Notes: This table presents a comparison of merge results based on bankruptcy record linkages using three sets of merge identifiers. The sample includes disability-program applicants who reach step 5 of the disability determination process, who have an initial decision date in 2000-2009, and whose ZIP Code of residence at application has an average of at least five recorded bankruptcies per year during this period. "SSN4" indicates the last four digits of Social Security Number. "FN" indicates first name, "LN" indicates last name, and "MI" indicates middle initial. The "False-Positive Merge" columns presents the number and the fraction of applicants who are not merged under the "bankruptcy-type merge" but merged under weaker sets of merge identifiers.

Appendix Table A1 presents statistics for this simulation. When we simulate the deeds and foreclosure merges by dropping the last four digits of SSN, about 6 percent of the merges are "false positive" merges that do not occur using the more-accurate bankruptcy merge. When we simulate the eviction merge by dropping the last four digits of SSN and middle initial, the false positive rate increases to 16 percent.

Figure A1 plots the IV estimates for bankruptcy using the three merge simulations. Using all available identifiers in the bankruptcy data, we get a large and statistically significant IV estimate of the effect of disability allowance on bankruptcy rates. Dropping last four digits of SSN - to simulate the deeds and foreclosure merges - increases the confidence intervals slightly. Additionally dropping middle initial - to simulate the eviction merge - leads to a moderate amount of attenuation such that the 3-year and 5-year estimates are no longer statistically significant at conventional levels. Overall, this simulation exercise increases our confidence in the validity of the deeds, foreclosure, and eviction merges. It also explains why the eviction merge is less likely than the deeds, foreclosure, or bankruptcy merges to produce statistically significant causal estimates even if there is a true causal effect. 
Figure A1: Bankruptcy Record Merge Simulation with Different Identifiers

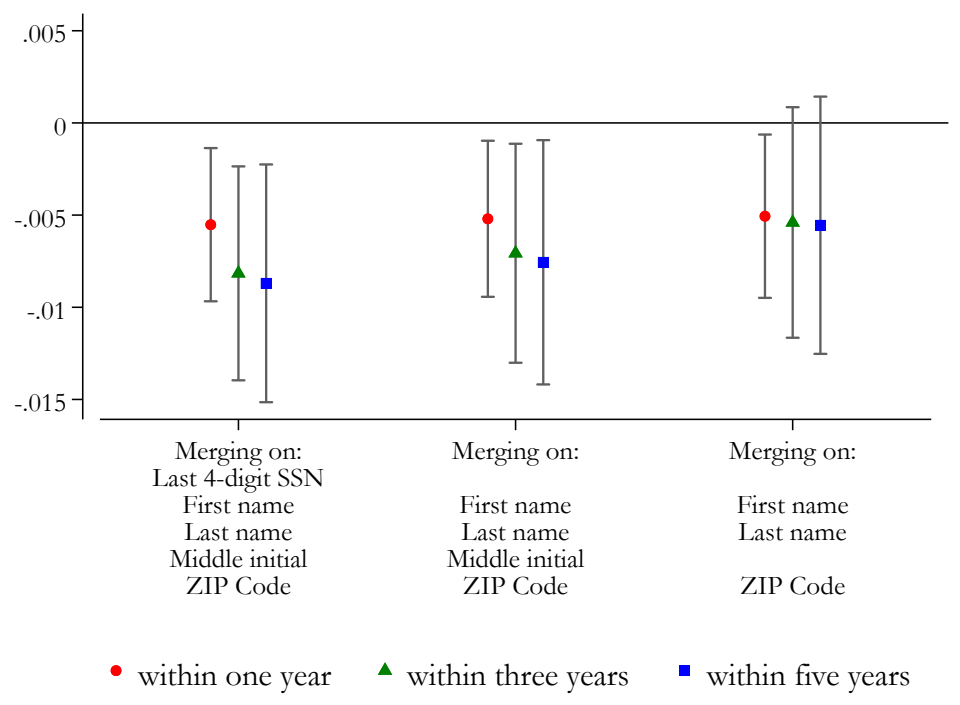

Notes: This figure presents a comparison of instrumental-variable estimates of effects based on bankruptcy records linkages using three sets of merge identifiers: those corresponding to the bankruptcy-type merge (last four digits of SSN, first name, last name, middle initial, ZIP Code); those corresponding to the deeds and foreclosure-type merges (first name, last name, middle initial, ZIP Code); and those corresponding to the eviction-type merge (first name, last name, ZIP Code). The sample includes disability-program applicants who reach step 5 of the disability determination process, who have an initial decision date in 2000-2009, and whose ZIP Code of residence at application has an average of at least five recorded bankruptcies per year during this period.

\section{B Appendix: Unobserved Events}

In this section, we analyze the potential bias created by purchases, sales, foreclosures, and evictions that occur in ZIP Codes other than the ZIP Code listed on the disability application and are therefore unobserved to us. We observe whether an applicant purchased or sold a home in the application ZIP Code in the years after their application. However, if the applicant were to purchase a home in a different ZIP Code, then we would not observe that purchase. We show in this section that in most cases this shortcoming in our data will simply bias us against finding an effect.

We consider the event of a home purchase, but the same analysis applies to foreclosures and evictions. Suppose that, in the absence of disability allowance, the share of applicants who would purchase a home is $x \in[0,1]$ and the share who would not purchase a home is $1-x$. Suppose further that a share $z \in[0, x]$ of the applicants purchase a home outside of their disability-application ZIP Code and the remaining share $x-z$ purchase a home in their 
application ZIP Code. In this case, the true fraction of applicants who purchase a home is $x$, but we only observe the fraction $x-z$ since we observe only purchases that occur within the application ZIP Code.

Assumption 1. Disability allowance does not shift the location of applicants' inframarginal home purchase decision (or eviction or foreclosure) from within the disability-application ZIP to outside the application ZIP Code, or vice versa.

Assumption A1 allows disability programs to affect the decision to purchase a home, but not to alter the ZIP Code in which the home is purchased conditional on the decision to purchase a home (that is, an inframarginal home purchase). This assumption will be violated if, for instance, an applicant would have purchased a home regardless of disability-program allowance, but because of the allowance, purchases the home in a wealthier neighborhood, and so a different ZIP Code, instead of his or her application ZIP Code.

Proposition 1. Under $\boldsymbol{A} 1$, the only bias in estimates of the causal effect of disability allowance on home purchases (or evictions or foreclosures) will be attenuation bias.

Proposition A1 states that under the assumption that disability allowance does not alter the location (within-ZIP versus outside-ZIP) of inframarginal home purchases, the estimates will be biased against finding a causal effect of disability allowance on home purchases. The estimated effect, then, will be an underestimate in magnitude of the true causal effect of disability-program allowance on home purchases.

Proof. Suppose that allowance onto a disability program increases the probability of home purchase by a fraction $y \in[0,1-x]$. Suppose that a fraction ay of the new home purchases occur within the disability-application ZIP Code and the remaining fraction $(1-a) y$ occur outside of the disability-application ZIP Code, where $a \in[0,1]$. By Assumption A1, program allowance does not change the likelihood that inframarginal home purchases occur within the application ZIP Code instead of outside the application ZIP Code, or vice versa. The econometrician observes a fraction of applicants $x-z+$ ay purchasing a home, compared to $x-z$ under the baseline assumption above. The observed effect of disability allowance on home purchases is therefore $a y$, which is attenuated relative to the true effect $y$, since $0 \leq a y \leq y$ under $a \in[0,1]$. This case corresponds to Scenario 1 in Table A2.

Analogously, if disability allowance decreases the probability of home purchase by $y \in$ $[0, x]$, then the observed fraction of applicants purchasing a home is $x-z-a y$ and the observed effect is $-a y$. Again, the observed effect is attenuated since $-y \leq-a y \leq 0$ under $a \in[0,1]$. This case corresponds to Scenario 2 in Table A2. 
Table A2: Bias of Unobserved Home Purchase Events

\begin{tabular}{|c|c|c|c|c|c|c|c|c|c|}
\hline Scenario & $\begin{array}{l}\text { Effect on } \\
\text { home purchase } \\
\text { decision }\end{array}$ & $\begin{array}{c}\text { Effect on } \\
\text { home purchase } \\
\text { outside ZIP }\end{array}$ & $\begin{array}{c}\text { Purchased } \\
\text { No }\end{array}$ & $\begin{array}{c}\text { Home? } \\
\text { Yes }\end{array}$ & $\begin{array}{l}\text { Purchased } \\
\text { within ZIP }\end{array}$ & $\begin{array}{l}\text { Purchased } \\
\text { outside ZIP }\end{array}$ & $\begin{array}{l}\text { True } \\
\text { effect }\end{array}$ & $\begin{array}{c}\text { Observed } \\
\text { effect }\end{array}$ & Bias \\
\hline Control & - & - & $1-x$ & $x$ & $x-z$ & $z$ & - & - & - \\
\hline 1 & Positive & No effect & $1-x-y$ & $x+y$ & $x-z+a y$ & $z+(1-a) y$ & $y$ & ay & Attenuation \\
\hline 2 & Negative & No effect & $1-x+y$ & $x-y$ & $x-z-a y$ & $z-(1-a) y$ & $-y$ & $-a y$ & Attenuation \\
\hline 3 & No effect & Positive & $1-x$ & $x$ & $x-z-b$ & $z+b$ & 0 & $-b$ & Downward \\
\hline 4 & No effect & Negative & $1-x$ & $x$ & $x-z+b$ & $z-b$ & 0 & $b$ & Upward \\
\hline 5 & Positive & Positive & $1-x-y$ & $x+y$ & $x-z+a y-b$ & $z+(1-a) y+b$ & $y$ & $a y-b$ & Indeterminate \\
\hline 6 & Negative & Negative & $1-x+y$ & $x-y$ & $x-z-a y+b$ & $z-(1-a) y-b$ & $-y$ & $-a y+b$ & Indeterminate \\
\hline 7 & Positive & Negative & $1-x-y$ & $x+y$ & $x-z+a y+b$ & $z+(1-a) y-b$ & $y$ & $a y+b$ & Indeterminate \\
\hline 8 & Negative & Positive & $1-x+y$ & $x-y$ & $x-z-a y-b$ & $z-(1-a) y+b$ & $-y$ & $-a y-b$ & Indeterminate \\
\hline
\end{tabular}

Notes: This table summarizes an exhaustive list of scenarios that lead to bias in the causal effect of disability-program allowance on home purchases. Assumption A1 is satisfied in Scenario 1 and 2, whereas it is violated in Scenario 3-8. "Effect on home purchase decision" means the effect of disability-program allowance on the probability of home purchase. "Effect on home purchase outside ZIP" means the effect of disability-program allowance on the fraction of inframarginal home purchases made outside of the disability-program application ZIP (rather than within-ZIP). "(Not) purchase home" indicates the fraction of people who decide (not) to purchase homes with the disability-program allowance. "Purchase within (outside) ZIP" indicates the fraction of people who decide to purchase homes within (outside) the disability-program application ZIP Code.

We discuss below the bias in the causal estimates when Assumption A1 is violated. We conclude that the direction of the bias varies based on the direction of the true causal effect and the direction of the shift of inframarginal home purchases between "within" and "outside" the application ZIP Code.

I. Suppose that disability-program allowance has no effect on overall home purchases, but increases the fraction of inframarginal home purchases made outside of the application ZIP Code (rather than within-ZIP) by a fraction $b \in[0, x-z]$. As shown in Table A2, Scenario 3, $x-z-b$ of home purchases occur within the application ZIP Code and $z+b$ occur outside the application ZIP Code. Then the observed effect is $-b$, which is smaller than the true effect of zero.

If instead disability allowance decreases the fraction of inframarginal home purchases made outside of the application ZIP Code (rather than within-ZIP) by $b \in[0, z]$, then $x-z+b$ home purchases occur within the application ZIP Code and $z-b$ occur outside the application ZIP Code. Then the observed effect is $b$, which is larger than the true effect of zero. This case corresponds to Scenario 4 in Table A2.

II. Suppose that disability-program allowance increases the likelihood of home purchases by $y$, where $y \in[0,1-x]$, and also increases the fraction of inframarginal home 
purchases made outside of the application ZIP Code (rather than within-ZIP) by $b \in$ $[0, x-z]$. As shown in Table A2, Scenario $5, x-z+a y-b$ of home purchases occur within the disability-application ZIP and $z+(1-a) y+b$ occur outside of the disability-application ZIP. Then the observed effect of disability allowance is $a y-b$, which is less than the true effect $y$ since $(a y-b)-y=-(1-a) y-b \leq 0$. However, without additional assumptions, the relationship between $a y$ and $b$ is unknown and the observed effect could have the wrong sign if $a y<b$.

Analogously, suppose that disability allowance decreases the likelihood of home purchases by $y \in[0, x]$ and also decreases the fraction of inframarginal home purchases made outside of the disability-application ZIP (rather than within-ZIP) by $b \in[0, z]$. Then the observed effect $-a y+b$ is greater than the true effect $-y$ as $(-a y+b)-(-y)=$ $(1-a) y+b \geq 0$, and might have the wrong sign if $a y<b$. This case corresponds to Scenario 6 in Table A2.

III. Suppose that disability allowance increases the likelihood of home purchases by $y \in$ $[0,1-x]$, but decreases the the fraction of inframarginal home purchases made outside of the disability-application ZIP (rather than within-ZIP) by $b \in[0, z]$. As shown in Table A2, Scenario 7, $x-z+a y+b$ of home purchases within the disability-application ZIP Code and $z+(1-a) y-b$ occur outside of the disability-application ZIP. The relationship between true effect $y$ and observed effect $a y+b$ is indeterminate without further assumptions about the values of $a, b$, and $y$.

Analogously, suppose that disability allowance decreases the likelihood of home purchases by $y \in[0, x]$, but increases the fraction of inframarginal home purchases made outside of the disability-application ZIP (rather than within-ZIP) by $b \in[0, x-z]$. The observed effect is then $-a y-b$, and the relationship between $-a y-b$ and true effect $-y$ is again indeterminate. This case corresponds to Scenario 8 in Table A2.

In general, home purchases (and likewise, evictions or foreclosures) that occur in other ZIP Codes will bias us against finding an effect if Assumption A1 holds. The likelihood that these events occur in other ZIP Codes may vary by event. For example, in a given amount of time, it is more likely that an applicant purchases a home in another ZIP Code than that an applicant purchases a home in another ZIP Code and experiences foreclosure in that home.

With respect to home sales, we assume disability applicants sell only their primary home. In this case, there is likely little or no bias in the estimate of the causal effect of disabilityprogram allowance on home sale in the initial years after the disability decision because all home sales must be in the application ZIP Code. In future years, applicants may purchase 
and then sell homes outside of their application ZIP Code, and the bias will be the same as in Proposition 1.

In contrast to "gross" home purchases and "gross" home sales, the bias for "net" home purchases (i.e., purchases not immediately followed or preceded by a sale) and "net" home sales is indeterminate even with Assumption A1. The reason is that some purchases (sales) that are part of a move (purchase followed by sale, or vice versa) will be misclassified as "net" purchases (sales) because the other transaction occurs in another ZIP Code and is unobserved. The attenuation bias will bias the estimate toward zero, but the misclassification bias will bias the estimate away from zero, making the net bias indeterminate.

\section{Appendix: Derivation of the Event-Study Specification}

Figure 3 shows that the risk of financial distress peaks during the year of application and then declines. To develop a more nuanced picture of how financial outcomes evolve around the date of application and decision, we use an event-study design at the month level. We define a cohort of applicants, $c$, by application month, decision month, and allowance status. We define event-time, $d$, as months until a cohort's initial decision date. We start with a simple event study design around the date of disability decision, similar to that used by Dobkin et al. (2018) to study the effect of hospitalizations on financial outcomes:

$$
Y_{c t}=\alpha_{c}+\gamma_{t}+\sum_{\tau} \beta_{\tau}^{d} D_{c t}^{d}+\varepsilon_{c t}
$$

Here, $D_{c t}^{d}$ is an indicator function equal to one if cohort $c$ reaches decision event-time $\tau$ on calendar-month $t$. Such a regression specification allows us to capture the average change in financial distress as it evolves before and after initial decision date. This simple regression includes a fixed effect for each cohort, $\alpha_{c}$; and a fixed effect for each calendar month, $\gamma_{t}$. The coefficients $\beta_{\tau}^{d}$ capture how the financial outcome, $Y$, evolves before and after the date of initial decision.

However, by focusing only on the initial decision date, this simple event-study design ignores applicants' choice of when to apply for disability benefits. If there is selection into the timing of application, then such an event-study design might mis-attribute trends that are associated with the timing of the application to the initial decision instead. Since SSA examiners vary in how long they take to decide a case, there is substantial variation in the time between application and decision. Because the application and decision dates are not perfectly co-linear, this variation helps us to separately identify trends associated with the application date versus the decision date. We add a second set of event-time indicators into 
the regression specification as follows:

$$
Y_{c t}=\alpha_{c}+\gamma_{t}+\sum_{\tau} \mu_{\tau}^{a} D_{c t}^{a}+\sum_{\tau} \beta_{\tau}^{d} D_{c t}^{d}+\varepsilon_{c t}
$$

Here, $D_{c t}^{a}\left(D_{c t}^{d}\right)$ indicate application (decision) event-time for cohort $c$ at calendar-month $t$. This regression now models financial distress as a function of time since application date and time since decision date, in addition to the effect of calendar time.

Finally, we consider the possibility that allowed and denied applicants differ in how their financial outcomes evolve around the application and decision dates. We allow for this possibility by interacting an indicator for allowed applicants with the application-event-time indicators and the decision-event-time indicators:

$Y_{c t}=\alpha_{c}+\gamma_{t}+\sum_{\tau} \beta_{\tau}^{d}\left(\right.$ Allow $\left._{c} \times D_{c t}^{d}\right)+\sum_{\tau} \beta_{\tau}^{\prime d} D_{c t}^{d}+\sum_{\tau} \mu_{\tau}^{a}\left(\right.$ Allow $\left._{c} \times D_{c t}^{a}\right)+\sum_{\tau} \mu_{\tau}^{\prime a} D_{c t}^{a}+\varepsilon_{c t}$. 


\section{Appendix: Derivation of the Main Quasi-Experimental Specification}

If all offices were RD offices, we would use a standard RD specification like the following:

$$
Y_{i}=\beta_{0}+\sum_{T \in\{50,55\}} \beta_{\mathrm{RD}_{T}} \mathbb{1}\left\{\mathrm{Age}_{i}>T\right\}+\sum_{T \in\{50,55\}} \beta_{2, T} \mathrm{Age}_{i}+\sum_{T \in\{50,55\}} \beta_{5, T} \mathrm{Age}_{i} \times \mathbb{1}\left\{\mathrm{Age}_{i}>T\right\}+\varepsilon_{i} .
$$

If all the offices were Spline offices, we would use a standard spline specification:

$$
\begin{aligned}
Y_{i}=\beta_{0}+\sum_{T \in\{50,55\}} \beta_{2, T} \mathrm{Age}_{i} & +\sum_{T \in\{50,55\}} \beta_{\text {Spline }_{T}} \operatorname{Age}_{i} \times \mathbb{1}\left\{\text { Age }_{i}>T-6\right\} \\
+ & \sum_{T \in\{50,55\}} \beta_{\text {Spline }_{T}} \text { Age }_{i} \times \mathbb{1}\left\{\text { Age }_{i}>T\right\}+\varepsilon_{i} .
\end{aligned}
$$

Finally, if all offices were Hybrid offices, we would use a combination of the RD and Spline specifications as follows:

$$
\begin{aligned}
Y_{i}=\beta_{0} & +\sum_{T \in\{50,55\}} \beta_{\mathrm{RD}_{T}} \mathbb{1}\left\{\mathrm{Age}_{i}>T\right\}+\sum_{T \in\{50,55\}} \beta_{2, T} \mathrm{Age}_{i} \\
& +\sum_{T \in\{50,55\}} \beta_{\mathrm{Spline}_{T}} \mathrm{Age}_{i} \times \mathbb{1}\left\{\mathrm{Age}_{i}>T-6\right\}+\sum_{T \in\{50,55\}} \beta_{\mathrm{Spline}_{T}} \mathrm{Age}_{i} \times \mathbb{1}\left\{\mathrm{Age}_{i}>T\right\}+\varepsilon_{i} .
\end{aligned}
$$

In the end, we rely on the following main specification, which combines multiple sources of variation created by the discretion of DDS offices and interacts instruments with office types:

$$
\begin{aligned}
& Y_{i}=\beta_{0}+\sum_{\substack{j \in\{\text { TypeRD, } \\
\text { TypeHybrid }\}}} \sum_{T \in\{50,55\}} \beta_{\mathrm{RD}_{j, T}} \mathbb{1}\left\{\mathrm{Age}_{i}>T\right\} \times \text { Type } j_{i}+\sum_{T \in\{50,55\}} \beta_{2, T} \mathrm{Age}_{i} \\
& +\sum_{\substack{j \in\{\text { TypeSpline, } \\
\text { TypeHybrid }\}}} \sum_{T \in\{50,55\}} \beta_{\text {Spline }_{j, T}} \operatorname{Age}_{i} \times \mathbb{1}\left\{\text { Age }_{i}>T-6\right\} \times \text { Type } j_{i} \\
& +\sum_{\substack{j \in\{\text { TypeSpline, } \\
\text { TypeHybrid }\}}} \sum_{T \in\{50,55\}} \beta_{\text {Sline }_{j, T}} \mathrm{Age}_{i} \times \mathbb{1}\left\{\mathrm{Age}_{i}>T\right\} \times \text { Type } j_{i} \\
& +\quad \sum_{T \in\{50,55\}} \beta_{5, T} \mathrm{Age}_{i} \times \mathbb{1}\left\{\mathrm{Age}_{i}>T\right\} \times \mathrm{TypeRD}_{i}+\varepsilon_{i} .
\end{aligned}
$$




\section{E Appendix: DDS Office Classification}

Figure 5 shows examples of the three DDS office types according to how they implement the borderline age rule: RD, Spline, and Hybrid. There are several potential ways to classify offices. In this section, we discuss different ways to classify offices and demonstrate that the results are robust to alternative classification methods.

Our primary classification method relies on the point estimates from a RD-spline regression. We refer to this as the "point estimates method" below. ${ }^{40}$ We start with the sample of applicants who reach step 5 in the disability determination process, combine the age-50 and age-55 thresholds, and run the following "Hybrid" specification for each office separately:

$$
\begin{aligned}
Y_{i}=\beta_{0}+\beta_{\mathrm{RD}} \mathbb{1}\left\{\mathrm{Age}_{i}>0\right\}+\beta_{2} \mathrm{Age}_{i} & +\beta_{\mathrm{Spline}} \mathrm{Age}_{i} \times \mathbb{1}\left\{\mathrm{Age}_{i}>-6\right\} \\
& +\beta_{\mathrm{Spline}_{2} \mathrm{Age}_{i}} \times \mathbb{1}\left\{\mathrm{Age}_{i}>0\right\}+\varepsilon_{i} .
\end{aligned}
$$

This specification allows for both a jump at the cutoff (corresponding to the RD office type) and kinks at the cutoff and six months before the cutoff (corresponding to the Spline office type). We then assign DDS office type as (i) "RD office" if there is at least a 0.05 percentagepoint increase in the initial allowance rate at the age thresholds $\left(\beta_{\mathrm{RD}} \geq 0.05\right)$ and the change in slope at age -6 does not exceed $0.001\left(\beta_{\text {Spline } 1}<0.001\right)$; (ii) "Hybrid office" if $\beta_{\mathrm{RD}} \geq 0.03$ and $\beta_{\text {Spline } 1} \geq 0.001$; and (iii) "Spline office" if $\beta_{\mathrm{RD}}<0.03$ and $\beta_{\text {Spline1 }}<0.001$.

As an alternative classification method, we classify offices based on goodness-of-fit using the Akaike Information Criterion (AIC). We first calculate for each DDS office the initial allowance rate by applicant age. We then run the three office-type specifications on the age cell means for each DDS office: "RD" (equation 2), "Spline" (equation 8, below), and "Hybrid" (equation 7). The "Spline" regression specification is:

$$
\begin{aligned}
Y_{i}=\beta_{0}+\beta_{1} \mathrm{Age}_{i} & +\beta_{\text {Spline1 }}\left(\operatorname{Age}_{i} \times \mathbb{1}\left\{\operatorname{Age}_{i}>-6\right\}\right) \\
& +\beta_{\text {Spline2 }}\left(\operatorname{Age}_{i} \times \mathbb{1}\left\{\operatorname{Age}_{i}>0\right\}\right)+\varepsilon_{i} .
\end{aligned}
$$

We assign the office type based on the specification which yields the minimum AIC. We refer to this below as the "AIC method."

As an alternative measure, we update the office type to a simpler specification if the difference in AIC values between the simpler specification and the AIC-minimum specification is less than 7. We refer to this as the "Alternative AIC method" below. The purpose of this alternative measure is to choose the simpler model in cases when the difference in goodnessof-fit across models is small. We consider "RD office" and "Spline office" specifications to be simpler than the "Hybrid office" specification, and the "RD office" specification to be

\footnotetext{
${ }^{40}$ Within the same DDS office, we find no discrepancy in how they implement the borderline age rule at age 50 versus age 55 .
} 
simpler than the "Spline office" specification.

Figure A2: Instrumental Variable (IV) Estimates by DDS Office Classification Method
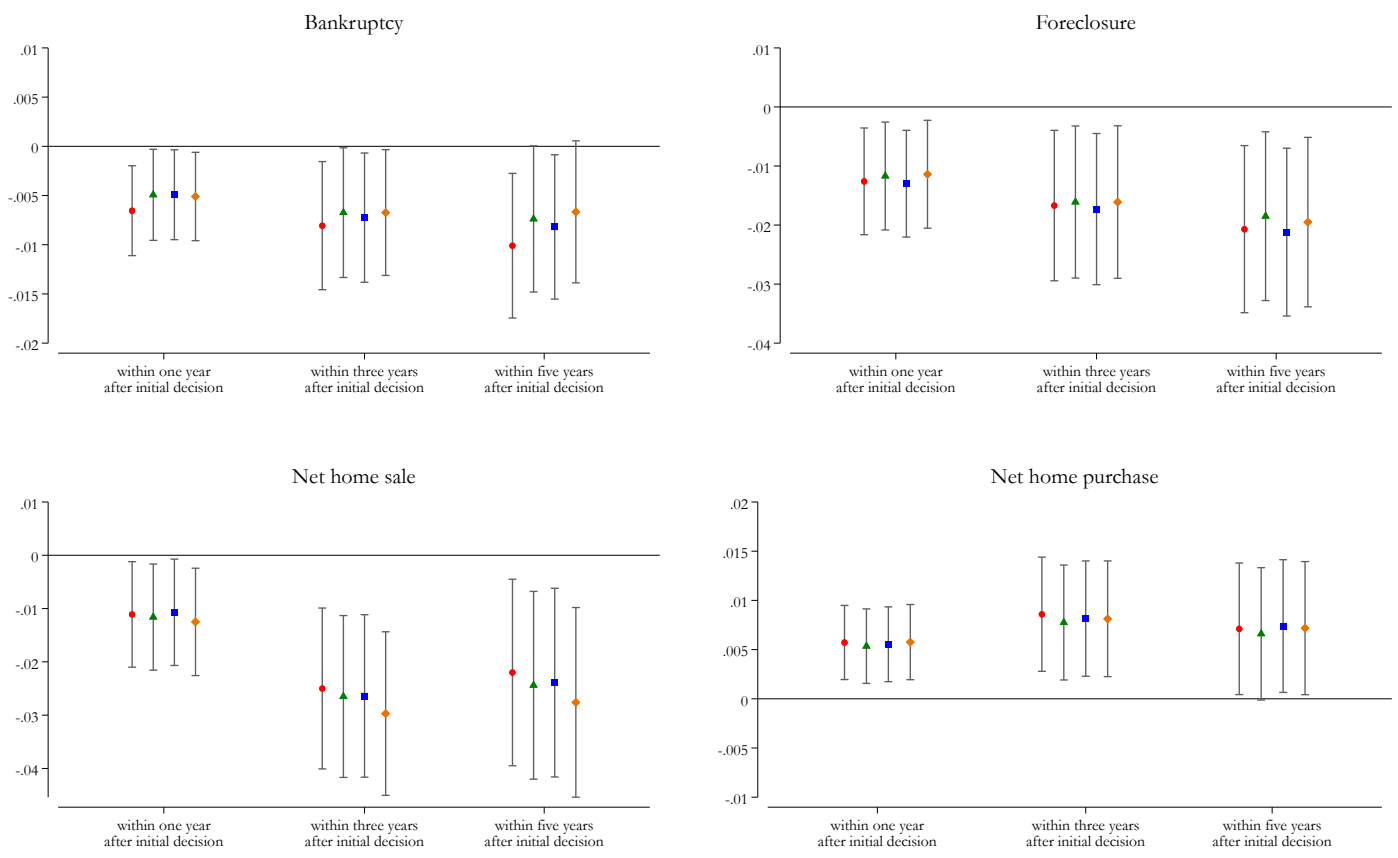

- Point estimates (main)

$\triangle \mathrm{AIC}$

- Alternative AIC

$\checkmark$ Visual inspection

Notes: These figures compare instrumental-variable estimates of the effect of disability-program benefits on financial outcomes using different DDS office classification methods. The outcomes include bankruptcy (top-left), foreclosure (top-right), net home sale (bottom-left), and net home purchase (bottom-right). A "net" home sale is defined as a home sale that is not accompanied by a home purchase within six months before or after the sale, and analogously for net home purchase. In the "Point Estimates" method, we run the "Hybrid office" specification (equation 7) separately for each DDS office and classify them as one of the following: "RD offices" if there is at least a 0.05 percentage point increase at the age thresholds $\left(\beta_{\mathrm{RD}} \geq 0.05\right)$ and the change in slope at age -6 does not exceed $0.001\left(\beta_{\text {Spline } 1}<0.001\right)$ when the application data is fitted under the equation (8); "Hybrid offices" if $\beta_{\mathrm{RD}} \geq 0.03$ and $\beta_{\text {Spline1 }} \geq 0.001$; "Spline offices" if $\beta_{\mathrm{RD}}<0.03$ and $\beta_{\text {Spline1 }}<0.001$. In the "AIC" method, we first collapse initial allowance rate by applicant age for each DDS office. We then run the following specifications on the collapsed data: "RD" (equation 2), "Spline" (equation 8), and "Hybrid" (equation 7) office. We assign the office type based on the specification that yields the minimum of Akaike information criterion (AIC). The "Alternative AIC" method is similar to "AIC," except that it chooses the simpler specification when the difference in AIC is small. In particular, if the difference in AIC values between simpler specification and minimum-AIC specification is less than 7, "Alternative AIC" chooses the simpler one, where "RD office" and "Spline office" specifications are considered simpler than "Hybrid office," and "RD office" specification is considered simpler than "Spline office" specification. In the "Visual Inspection" method, we classify DDS offices visually based on the binned scatter plots of initial allowance rate by applicant age.

Finally, we classify offices based on visual inspection and refer to this as the "Visual 
inspection method" below. For each DDS office, we create binned scatter plots of the initial allowance rate relative to applicant age at the initial decision date for applicants, where age is calculated as months from age 50 or age 55, whichever threshold is closer.

The classification results are consistent across methods, with approximately 20 percent of the offices "RD" offices, 40 percent "Spline" offices, and 40 percent "Hybrid" offices. Appendix Figure A2 compares IV estimates of the effect of disability benefits on financial outcomes using different classification methods. The IV point estimates and confidence intervals are similar.

\section{F Appendix: Calculating the Marginal Value of Public Funds}

We use our estimates, along with other estimates from the literature, to calculate the marginal value of public funds (MVPF) of disability programs, (Hendren, 2016, 2017). The MVPF is the ratio of the marginal benefits of a policy to its marginal cost. The MVPF of disability programs can be written as follows:

$$
\mathrm{MVPF}=\frac{\mathrm{WTP}+\eta_{E X} \mathrm{EX}}{1+\mathrm{FE}},
$$

where WTP is the recipient's willingness to pay for $\$ 1$ of the disability-program transfer; EX indicates the externalities of $\$ 1$ of disability benefits to third parties with an efficient welfare weight of $\eta_{E}$; and $\mathrm{FE}$ is the fiscal externality on the government's budget imposed by $\$ 1$ of disability transfer. The goal of the exercise is to compare the efficiency of disability programs when financial outcomes are considered versus when they are not, especially taking into account spillovers to third parties. This calculation will also facilitate the comparison of disability programs to other social-safety-net programs.

To start, we assume that WTP is one, as is the case for most cash programs, since recipients value $\$ 1$ of a transfer as $\$ 1 .{ }^{41}$ The second term in the numerator of equation (9) is EX, the positive externalities to non-recipients, which are not reflected in the cash transfer itself. To our knowledge, previous studies have not considered disability programs' externalities. Foreclosures lower the property values of nearby houses (Campbell et al., 2011; Anenberg and Kung, 2014), and so any evidence that disability programs deter foreclosures suggests that the program benefits third parties. We estimate that each disability allowance produces $\$ 2,472$ in spillover benefits to homeowners in the surrounding neighborhood. ${ }^{42}$

\footnotetext{
${ }^{41}$ WTP could be larger than one if, as we illustrate in the welfare discussion, benefits have an insurance value beyond their cash value. On the other hand, if we consider the value of health insurance provided by disability programs, WTP could be less than one. Finkelstein et al. (Forthcoming) find that non-disabled Medicaid recipients value the program far less than $\$ 1$-for- $\$ 1$.

${ }^{42}$ Campbell et al. (2011) extrapolate from their difference-in-difference estimates and forecasting models to calculate that each foreclosure lowers neighborhood property values from $\$ 148,000$ to $\$ 477,000$ during the
} 
The denominator of equation (9) represents the costs of disability programs that are not internalized by the recipient. In particular, the FE term reflects the net effect of disability programs on the government's budget. We consider effects on the government budget through the reduction in foreclosures and bankruptcies and the decrease in labor supply. Apgar et al. (2005) estimate that the median cost of a foreclosure to local governments is $\$ 5,000$ due to increased crime and fire risk. In addition, we calculate that each foreclosure costs the government on average $\$ 2,392$ in reduced taxes from the lender. ${ }^{43}$ We estimate that disability allowance reduces government costs by $\$ 132$ through higher property tax collections. ${ }^{44}$ For bankruptcy, we estimate a reduction in government costs of $\$ 135$ since lenders discharge debt in bankruptcy and deduct the discharged debt from taxable income. ${ }^{45}$ Finally, we calculate a $\$ 485$ decrease in tax revenues from reduced recipient earnings. ${ }^{46}$ Summing all three types of fiscal externalities yields a net increase in government cost of $\$ 218$.

Based on these calculations, and assuming that third parties have a social welfare weight that is 75 percent of the recipient's welfare weight, equation (9) suggests that disability programs have an MVPF of 1.04 when considering effects on foreclosure and bankruptcy. The ratio is smaller, 0.99, when we ignore these effects because of the large positive spillovers to third parties and to the government from reductions in foreclosures and bankruptcies. The MVPF is useful primarily to compare programs to each other. Hendren (2017) calculates the following MVPF ranges for other programs targeted at low-income populations: 0.88 for

Great Recession. We take the lower bound of this estimate and multiply it by our 3-year estimate of the reduction in foreclosure risk, 1.67 percentage points, to estimate $\$ 2,472$ in positive spillovers to neighboring households.

${ }^{43}$ For foreclosures where the remaining mortgage balance exceeds the auction price, lenders can deduct the discharged debt from their taxable income. U.S. Department of Housing and Urban Development (2010) reports the median price of existing homes sold in May 2010: \$179,400. Assume a 20-percent chance that foreclosure auctions cannot cover the remaining mortgage balance and one-third of this amount is discharged. Multiplying the discharged debt by a 20-percent corporate-income tax rate leads to a reduction in tax collections of $\$ 2,392$.

${ }^{44}$ As discussed above, foreclosures also lower nearby property values (Campbell et al., 2011; Anenberg and Kung, 2014), which reduce local property tax collections from that neighborhood. Property taxes are generally computed based on recent sales, and so will reflect an average of foreclosed houses and houses that were sold but not foreclosed upon. For this reason, we multiply the lower bound of the Campbell et al. (2011) estimate by 10 percent before multiplying by a property tax rate of 1.15 percent. This calculation yields $\$ 511$ in lost property taxes over 3 years. Since disability allowance reduces foreclosure rates by 1.67 percentage points, the reduction in foreclosure reduces government costs by $\$ 132$.

${ }^{45}$ On average, $\$ 167,576$ of debt is discharged in each bankruptcy based on authors' calculations using data from the Federal Judicial Center covering all consumer bankruptcies in the United States in 2008. We use $50 \%$ of this average amount to account for disability recipients having less access to credit and lower debt levels. We multiply this by a 20-percent corporate-income tax rate, and obtain a reduction in tax collections of $\$ 16,800$. Since disability programs reduce bankruptcies by 0.81 percentage points, the reduction in bankruptcy reduces government cost by $\$ 135$.

${ }^{46}$ From our estimates, we find that the initial disability-program allowance reduces annual earnings by $\$ 1,100$, or $\$ 3,300$ over 3 years. Assuming a 15 percent combined income and payroll tax rate, the reduction in recipient labor income increases government costs by $\$ 485$. 
an expansion of the Earned Income Tax Credit (EITC), 0.53-0.66 for an expansion of the Supplemental Nutrition Assistance Program (SNAP), 0-1.85 for job-training programs, and 0.79 for housing vouchers. Although most have a smaller MVPF than disability programs, these estimates do not incorporate the effects of these programs on financial outcomes. It is possible that considering reductions in financial events like bankruptcy and foreclosure would also increase the MVPF of these other programs.

\section{Table A3: Marginal Value of Public Funds (MVPF) Calculation}

Amount Notes

Spillover benefits to third parties (EX)

From reduction in foreclosure

Property value decline

Causal effect on foreclosure

Total spillovers from foreclosure reduction

Fiscal externalities (FE)

From reduction in foreclosure

Administrative cost of foreclosure to government

Taxes foregone on debt discharged by lenders

Local property tax decline from foreclosure

Causal effect on foreclosure

Total FE from foreclosure reduction

From reduction in bankruptcy

Taxes foregone on debt discharged by lenders

Causal effect on bankruptcy

Total FE from bankruptcy reduction

From reduction in recipient earnings

Reduction in recipient earnings

Total FE from earnings reduction

Total fiscal externalities
$\$ 148,000$ Lower bound from Campbell et al. (2011)

0.0167 Authors' 3-year estimates

$\$ 2,472$

$\$ 2,472 \times \eta_{E X}=\$ 1,854$ assuming $\eta_{E X}=0.75$

-\$5,000 Apgar et al. (2005)

$-\$ 2,392$ Assume $20 \%$ corporate income tax rate ${ }^{a}$

$-\$ 511$ Assume $1.15 \%$ property tax rate ${ }^{b}$

0.0167 Authors' 3-year estimates

$-\$ 132$

-\$16,758 Assume 20\% corporate tax rate ${ }^{c}$

0.0081 Authors' 3-year estimates

$-\$ 135$

\$3,231 Authors' 3-year estimates

$\$ 485$ Assume $15 \%$ income and payroll tax rate

$\$ 218$

$\$ 13,000$

Average annual disability cash transfer

1.04

MVPF of disability programs (with financial outcomes)

0.99

MVPF of disability programs (without financial outcomes)

${ }^{a}$ Calculation is based on $\$ 59,800$ debt discharged in each foreclosure, which is one-third of the median price of existing homes sold in May 2010 and assuming the amount recovered by auction are not sufficient to repay the remaining mortgage balance.

${ }^{b}$ Calculation is based on $\$ 44,400$, which is a total of three-year price drop of neighboring sold properties. Since property taxes are generally computed based on recently transacted homes, we use 10 percent of the lower bound estimates $(\$ 14,800)$ of nearby property values drop.

${ }^{c}$ Calculation is based on $\$ 83,800$ debt discharged in each bankruptcy, which is 50 percent of the average debt discharged in consumer bankruptcies in 2008.

Notes: This table presents the calculation of marginal value of public funds (MVPF) from equation (9), where we assume $\eta_{E X}=0.75$ for the relative social welfare weight of third parties. 


\section{G Appendix Figures and Tables}

Figure A.3: Steps of the Disability Determination Process

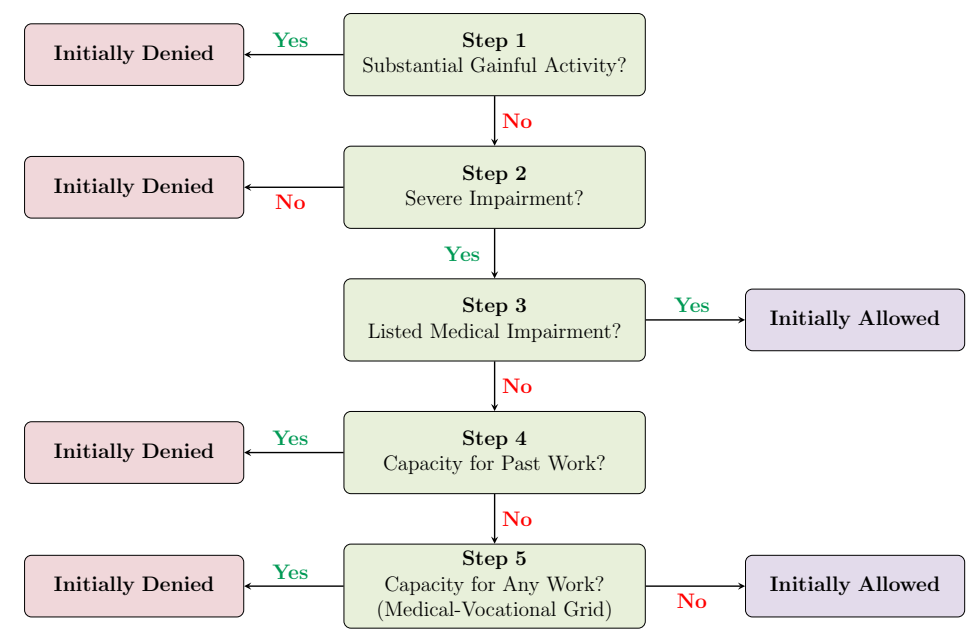

Notes: This figure presents the steps of the Social Security Administration's disability determination process. In step 1, disability-program applicants who are earning greater than substantial gainful activity levels $(\$ 1,170$ per month in 2017) are denied. In step 2, applicants who are determined to have a non-severe impairment are denied. In step 3, applicants whose diagnosis meets the medical listings are allowed. In step 4, applicants who are determined to have capacity for past work are denied. In step 5, applicants who are determined to have capacity for substantial gainful activity in any form are denied, while those determined not to have capacity for substantial gainful activity are allowed.

Figure A.4: Final Allowance Rate at Step 5 Relative to Applicant Age

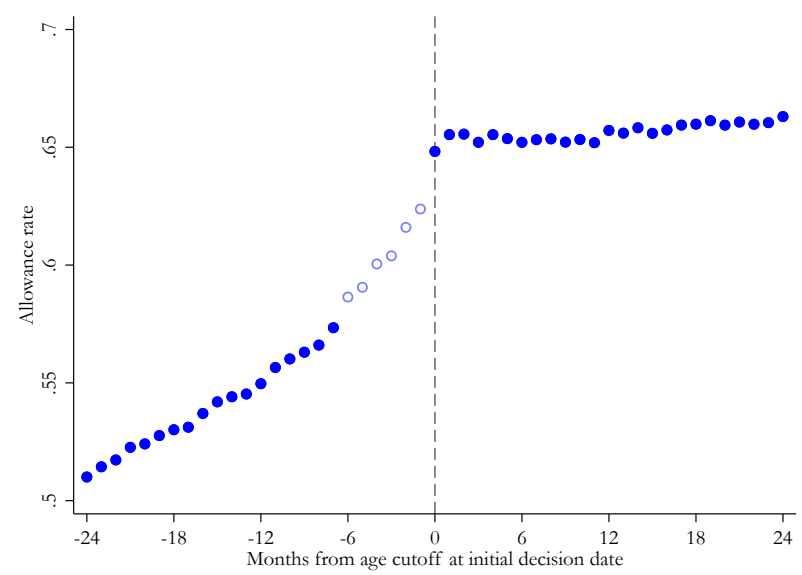

Notes: This figure plots the final allowance rate after all appeals relative to the disability-program applicant's age at the initial decision date for applicants in the home-purchase sample: disabilityprogram applicants who reach step 5 of the disability determination process, who have an initial decision date in 2000-2014, and whose ZIP Code of residence at application has an average of at least fifteen recorded home purchases per year during this period. Age is calculated as months from age 50 or age 55 , whichever threshold is closer. 
Figure A.5: Gross Home-Sale and Gross Home-Purchase Rates Relative to Applicant Age
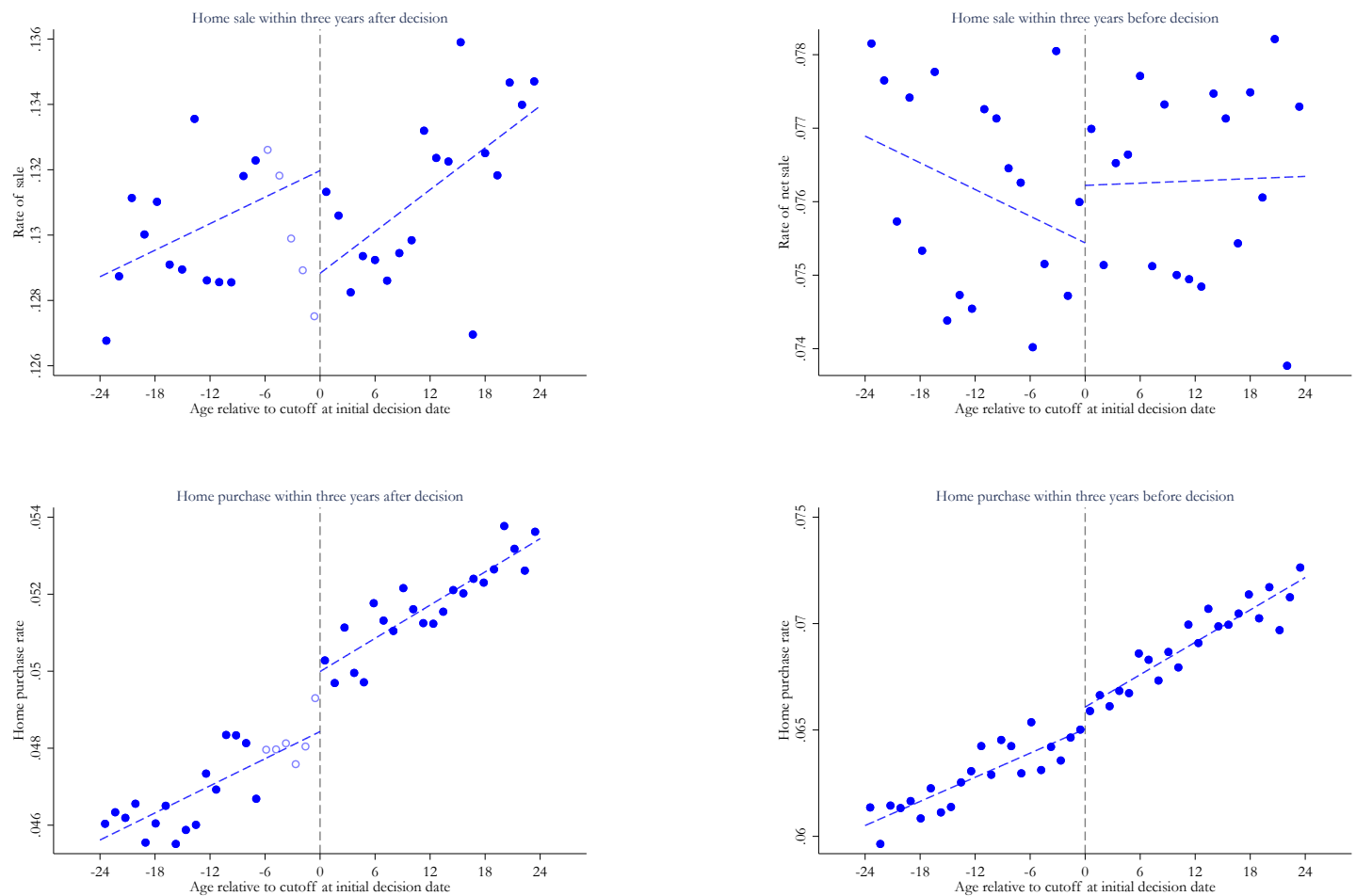

Notes: These figures plot the gross home-sale and gross home-purchase rates within three years after initial decision (left-hand side) and the gross home-sale and the gross home-purchase rates within three years before initial decision (right-hand side) relative to the disability-program applicant's age at the initial decision date. Age is calculated as months from age 50 or age 55, whichever threshold is closer. Figures are based on quantile spaced binning, which allow each bin to have the same number of observations. Dashed lines are fitted using a donut strategy, excluding the hollow markers that correspond to the borderline age period. The "home-sale sample" consists of disability-program applicants who appear in the deeds records (homeowners), who reach step 5 of the disability determination process, and who have an initial decision date in 2000-2014. The "home-purchase sample" consists of disability-program applicants who reach step 5 of the disability determination process and who have an initial decision date in 2000-2014. Each sample excludes ZIP Codes of residence at application that have an average of fewer than fifteen recorded events per year during the corresponding period. 
Figure A.6: Earnings Relative to Applicant Age
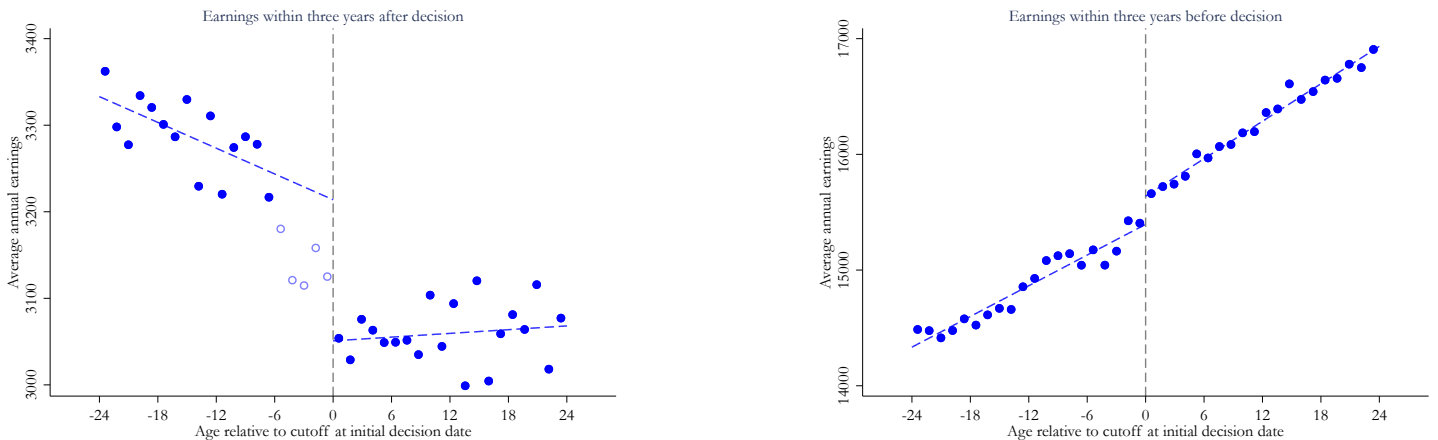

Notes: These figures plot the earnings within three years after initial decision (left-hand side) and the earnings within three years before initial decision (right-hand side) relative to the disabilityprogram applicant's age at the initial decision date. Age is calculated as months from age 50 or age 55, whichever threshold is closer. Figures are based on quantile spaced binning, which allow each bin to have the same number of observations. Dashed lines are fitted using a donut strategy, excluding the hollow markers that correspond to the borderline age period. This figure is based on the bankruptcy sample, disability-program applicants who reach step 5 of the disability determination process, who have an initial decision date in 2000-2009, and whose ZIP Code of residence at application has an average of at least five recorded bankruptcies per year during this period.

Figure A.7: Robustness Check of Estimation Strategies

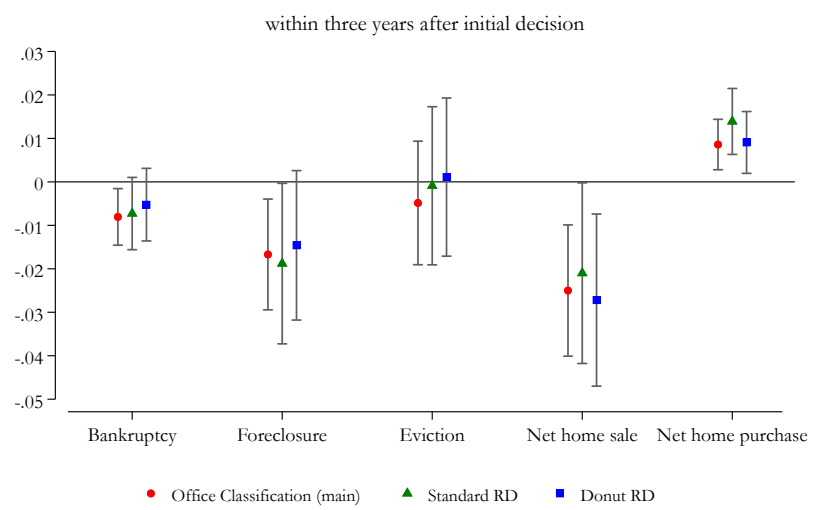

Notes: This figure presents instrumental-variable estimates of the effect of disability benefits on financial outcomes within three years of initial decision under the main specification by classifying types of DDS offices (equation 3), standard and donut RD specifications (equation 2). Donut RD regressions exclude applicants who are under age 50 or 55 by one to five months. 


\section{Figure A.8: Source of First Stage Attenuation}

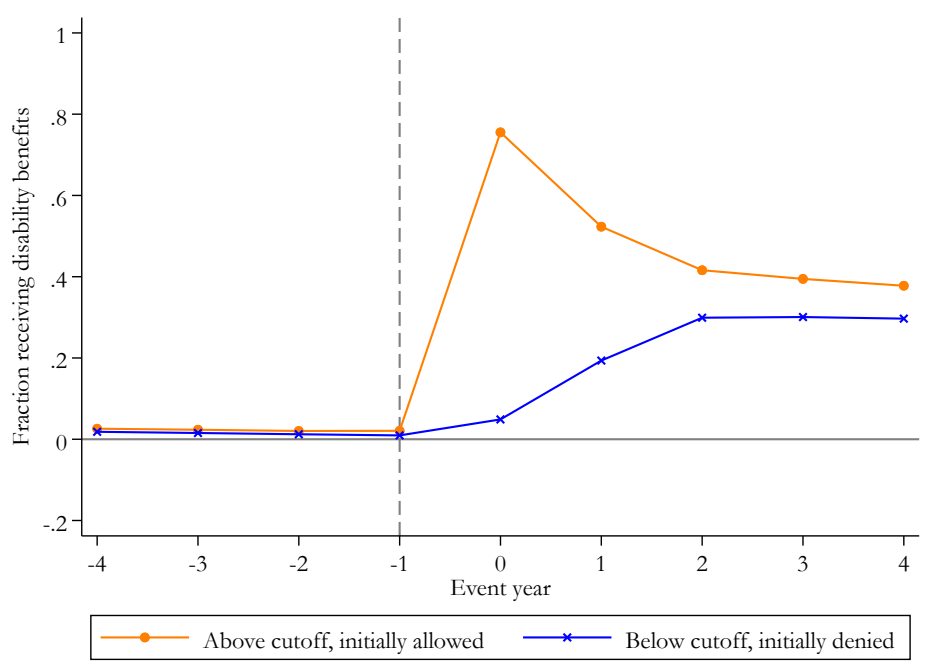

Notes: This figure plots the fraction of applicants receiving disability-program benefits relative to their initial decision date, for the bankruptcy sample. The "O" series plots fraction receiving disability-program benefits in each event year for individuals who are above 50 or 55 years (whichever threshold is closer) at the initial decision date and have a favorable initial decision. The "X" series plots fraction receiving disability-program benefits in each event year for individuals who are under 50 or 55 years (whichever threshold is closer) at the initial decision date and have an unfavorable decision. Sample is disability-program applicants who reach step 5 of the disability determination process, who have an initial decision date in 2000-2009, and whose ZIP Code of residence at application has an average of at least five recorded bankruptcies per year during this period.

Figure A.9: Household Consumption around Foreclosure and Bankruptcy from the PSID
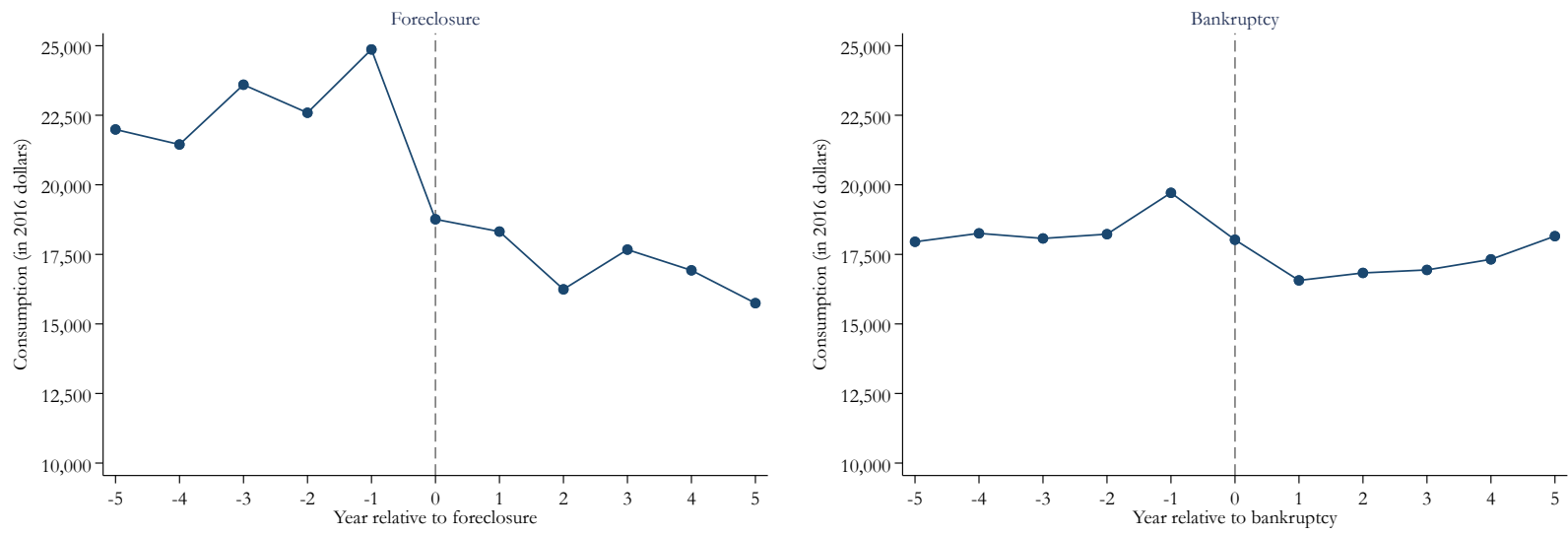

Notes: This figure plots the annual average of food and housing (mortgage and rent) expenses in 2016 dollars based on households that had gone through foreclosures (left) and bankruptcies (right) in the Panel Study of Income Dynamics (PSID). 
Table A.4: Covariate Balance Test - Eviction Sample

\begin{tabular}{|c|c|c|c|}
\hline & \multicolumn{3}{|c|}{ Eviction sample } \\
\hline & $\begin{array}{l}\text { Pt. Est. } \\
\text { (Std. Err.) }\end{array}$ & Mean & $\%$ of mean \\
\hline \multicolumn{4}{|l|}{ Covariate } \\
\hline Pre-application event & $\begin{array}{c}-0.000936 \\
(0.00139)\end{array}$ & 0.102 & $-0.9 \%$ \\
\hline Pre-app earnings & $\begin{array}{c}5.378 \\
(67.97)\end{array}$ & $\$ 11,146$ & $0.0 \%$ \\
\hline Years of education & $\begin{array}{l}-0.0217^{*} \\
(0.0124)\end{array}$ & 11.6 & $-0.2 \%$ \\
\hline Musculoskeletal & $\begin{array}{c}0.0136^{\text {*** }} \\
(0.00232)\end{array}$ & 0.442 & $3.1 \%$ \\
\hline Respiratory & $\begin{array}{c}0.000441 \\
(0.000856)\end{array}$ & 0.034 & $1.3 \%$ \\
\hline Cardiovascular & $\begin{array}{l}-0.00108 \\
(0.00129)\end{array}$ & 0.082 & $-1.3 \%$ \\
\hline Endocrine & $\begin{array}{l}-0.000746 \\
(0.000995)\end{array}$ & 0.046 & $-1.6 \%$ \\
\hline Neurological & $\begin{array}{c}-0.00200^{*} \\
(0.00112)\end{array}$ & 0.061 & $-3.3 \%$ \\
\hline Mental & $\begin{array}{c}-0.00684^{* * * *} \\
(0.00176)\end{array}$ & 0.174 & $-3.9 \%$ \\
\hline Special/other & $\begin{array}{l}-0.00114 \\
(0.00119)\end{array}$ & 0.070 & $-1.6 \%$ \\
\hline$p$-value on joint $F$-test & & 0.000 & \\
\hline Predicted event occurs & $\begin{array}{l}-0.000108 \\
(0.000104)\end{array}$ & 0.0995 & $-0.1 \%$ \\
\hline$N$ (in millions) & & 0.83 & \\
\hline
\end{tabular}

Notes: This table reports reduced-form estimates for the listed covariates for the eviction sample, where we put the covariate on the left-hand-side of the RD specification in equation (2) and report $\beta$ with standard errors in parentheses. The table reports the $p$-value on the $F$ test for the joint significance of all covariates. Pre-application earnings are average annual applicant earnings in the three years prior to the year of application, from the Master Earnings File. Years of education is self-reported years of education from the 831 Disability File. Body system codes (musculoskeletal, respiratory, cardiovascular, endocrine, neurological, mental, special/other) come from the 831 Disability File. "\% of mean" denotes point estimate as a percent of control mean, where control means are the average value of the variable for applicants who are under age 50 or 55 by 6 to 10 months. For "predicted adverse financial outcome," we first regress an indicator for having the adverse financial outcome prior to the initial decision date on a set of covariates (pre-application earnings, years of education, male, body system code dummies, and ZIP dummies). We then put "predicted adverse financial outcome" on the left-hand-side of the RD specification in equation (2) and report estimates of $\beta$. The eviction sample consists of disability-program applicants who reach step 5 of the disability determination process, who have an initial decision date in 2000-2009, and whose FIPS county code of residence at application that has an average of at least fifteen recorded events per year during this period. ${ }^{* * *} p<0.01,{ }^{* *} p<0.05,{ }^{*} p<0.1$. 
Table A.5: Covariate Balance Test - Net-home-sale and Net-home-purchase Samples

\begin{tabular}{|c|c|c|c|c|c|c|}
\hline & \multicolumn{3}{|c|}{ Net home-sale sample } & \multicolumn{3}{|c|}{ Net home-purchase sample } \\
\hline & $\begin{array}{c}\text { Pt. Est. } \\
\text { (Std. Err.) }\end{array}$ & Mean & $\%$ of mean & $\begin{array}{l}\text { Pt. Est. } \\
\text { (Std. Err.) }\end{array}$ & Mean & $\%$ of mean \\
\hline \multicolumn{7}{|l|}{ Covariate } \\
\hline Pre-application event & $\begin{array}{l}8.42 \mathrm{e}-05 \\
(0.00123)\end{array}$ & 0.147 & $0.1 \%$ & $\begin{array}{c}0.00232^{* * * *} \\
(0.000695)\end{array}$ & 0.174 & $1.3 \%$ \\
\hline Pre-app earnings & $\begin{array}{c}318.2^{* * *} \\
(74.06)\end{array}$ & $\$ 21,853$ & $1.5 \%$ & $\begin{array}{c}183.0^{* * *} \\
(32.58)\end{array}$ & $\$ 14,800$ & $1.2 \%$ \\
\hline Years of education & $\begin{array}{l}-0.00199 \\
(0.00856)\end{array}$ & 12.0 & $0.0 \%$ & $\begin{array}{c}-0.0137^{* * * *} \\
(0.00471)\end{array}$ & 11.7 & $-0.1 \%$ \\
\hline Musculoskeletal & $\begin{array}{c}0.00588^{* * * *} \\
(0.00174)\end{array}$ & 0.483 & $1.2 \%$ & $\begin{array}{c}0.00713^{* * *} \\
(0.000931)\end{array}$ & 0.440 & $1.6 \%$ \\
\hline Respiratory & $\begin{array}{c}0.000615 \\
(0.000663)\end{array}$ & 0.037 & $1.7 \%$ & $\begin{array}{c}0.000754^{* *} \\
(0.000385)\end{array}$ & 0.043 & $1.7 \%$ \\
\hline Cardiovascular & $\begin{array}{c}0.000590 \\
(0.00105)\end{array}$ & 0.098 & $0.6 \%$ & $\begin{array}{c}0.000734 \\
(0.000579)\end{array}$ & 0.104 & $0.7 \%$ \\
\hline Endocrine & $\begin{array}{c}-0.00254^{* * *} \\
(0.000723)\end{array}$ & 0.044 & $-5.8 \%$ & $\begin{array}{c}-0.00106^{* * *} \\
(0.000406)\end{array}$ & 0.047 & $-2.2 \%$ \\
\hline Neurological & $\begin{array}{c}0.000774 \\
(0.000908)\end{array}$ & 0.073 & $1.1 \%$ & $\begin{array}{c}0.000267 \\
(0.000459)\end{array}$ & 0.064 & $0.4 \%$ \\
\hline Mental & $\begin{array}{c}-0.00383^{* * *} \\
(0.00119)\end{array}$ & 0.135 & $-2.8 \%$ & $\begin{array}{c}-0.00519^{* * *} \\
(0.000691)\end{array}$ & 0.161 & $-3.2 \%$ \\
\hline Special/other & $\begin{array}{c}4.72 \mathrm{e}-05 \\
(0.000691)\end{array}$ & 0.041 & $0.1 \%$ & $\begin{array}{c}-0.000798^{*} \\
(0.000409)\end{array}$ & 0.050 & $-1.6 \%$ \\
\hline$p$-value on joint $F$-test & & 0.000 & & & 0.000 & \\
\hline Predicted event occurs & $\begin{array}{c}-0.000261^{* * *} \\
(8.88 \mathrm{e}-05)\end{array}$ & 0.143 & $-0.2 \%$ & $\begin{array}{c}0.000907^{* * *} \\
(0.000149)\end{array}$ & 0.166 & $0.55 \%$ \\
\hline$N$ (in millions) & & 1.45 & & & 5.12 & \\
\hline
\end{tabular}

Notes: This table reports reduced-form estimates for the listed covariates for the net-home-sale and nethome-purchase samples, where we put the covariate on the left-hand-side of equation (2) and report $\beta$ with standard errors in parentheses. The table reports the $p$-value on the $F$ test for the joint significance of all covariates. Pre-application earnings are average annual applicant earnings in the three years prior to the year of application, from the Master Earnings File. Years of education is self-reported years of education from the 831 Disability File. Body system codes (musculoskeletal, respiratory, cardiovascular, endocrine, neurological, mental, special/other) come from the 831 Disability File. "\% of mean" denotes point estimate as a percent of control mean, where control means are the average value of the variable for applicants who are under age 50 or 55 by 6 to 10 months. For "predicted adverse financial outcome," we first regress an indicator for having the adverse financial outcome prior to the initial decision date on a set of covariates (pre-application earnings, years of education, male, body system code dummies, and ZIP dummies). We then put "predicted adverse financial outcome" on the left-hand-side of equation (2), and report IV estimates. The outcome "net home-sale" is based on the home-sale sample: disabilityprogram applicants who appear in the deeds records (homeowners), who reach step 5 of the disability determination process, and who have an initial decision date in 2000-2014. The outcome "net homepurchase" is based on the home-purchase sample: disability-program applicants who reach step 5 of the disability determination process, and who have an initial decision date in 2000-2014. A "net" home sale is defined as a home sale that is not accompanied by a home purchase within six months before or after the sale, and analogously for net home purchase. Both samples exclude ZIP Codes of residence at application that have an average of fewer than fifteen recorded corresponding events per year during 2000-2014. ${ }^{* * *} p<0.01,{ }^{* *} p<0.05,{ }^{*} p<0.1$. 
Table A.6: Estimates of First Stage and Reduced-Form Effects - Bankruptcy and Foreclosure

\begin{tabular}{|c|c|c|c|c|c|}
\hline & \multicolumn{2}{|c|}{ First Stage } & \multicolumn{3}{|c|}{ Reduced Form } \\
\hline & $\begin{array}{c}\text { Initial allowance } \\
\text { Pt. Est. } \\
\text { (Std. Err.) }\end{array}$ & $\begin{array}{c}\text { Final allowance } \\
\text { Pt. Est. } \\
\text { (Std. Err.) }\end{array}$ & $\begin{array}{l}\text { Within } 1 \text { year } \\
\text { Pt. Est. } \\
\text { (Std. Err.) }\end{array}$ & $\begin{array}{c}\text { Within } 3 \text { years } \\
\text { Pt. Est. } \\
\text { (Std. Err.) }\end{array}$ & $\begin{array}{c}\text { Within } 5 \text { years } \\
\text { Pt. Est. } \\
\text { (Std. Err.) }\end{array}$ \\
\hline \multicolumn{6}{|l|}{ Bankruptcy ( $N$ : 3.07 million) } \\
\hline $\mathbb{1}\left\{{\text { Age } 50_{i}}_{i}>0\right\} \times$ TypeRD & $\begin{array}{c}0.0700^{* * *} \\
(0.00216)\end{array}$ & $\begin{array}{c}0.0298^{* * *} \\
(0.00269)\end{array}$ & $\begin{array}{l}-0.000217 \\
(0.000683)\end{array}$ & $\begin{array}{c}-0.000363 \\
(0.000982)\end{array}$ & $\begin{array}{r}-0.000106 \\
(0.00111)\end{array}$ \\
\hline 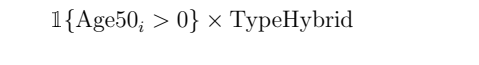 & $\begin{array}{c}0.0747^{* * *} \\
(0.00451)\end{array}$ & $\begin{array}{l}0.0271^{* * *} \\
(0.00541)\end{array}$ & $\begin{array}{l}-0.000552 \\
(0.00129)\end{array}$ & $\begin{array}{l}-0.00133 \\
(0.00182)\end{array}$ & $\begin{array}{l}-0.00194 \\
(0.00208)\end{array}$ \\
\hline 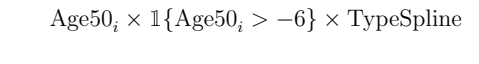 & $\begin{array}{l}0.0119^{* * *} \\
(0.000311)\end{array}$ & $\begin{array}{r}0.00395^{* * *} \\
(0.000374)\end{array}$ & $\begin{array}{l}-0.000124 \\
(8.53 \mathrm{e}-05)\end{array}$ & $\begin{array}{l}-0.000104 \\
(0.000122)\end{array}$ & $\begin{array}{l}-0.000115 \\
(0.000137)\end{array}$ \\
\hline 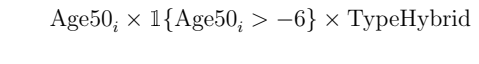 & $\begin{array}{l}0.00528^{* * *} \\
(0.000736)\end{array}$ & $\begin{array}{r}0.00314^{* * *} \\
(0.000918)\end{array}$ & $\begin{array}{l}-9.78 \mathrm{e}-05 \\
(0.000220)\end{array}$ & $\begin{array}{l}-0.000233 \\
(0.000310)\end{array}$ & $\begin{array}{l}-0.000201 \\
(0.000354)\end{array}$ \\
\hline Age $50_{i} \times \mathbb{1}\left\{{\left.\text { Age } 50_{i}>0\right\} \times \text { TypeSpline }}\right.$ & $\begin{array}{c}-0.0126 * * * \\
(0.000367)\end{array}$ & $\begin{array}{c}-0.00586^{* * *} \\
(0.000424)\end{array}$ & $\begin{array}{c}6.45 \mathrm{e}-05 \\
(9.78 \mathrm{e}-05)\end{array}$ & $\begin{array}{l}-3.71 \mathrm{e}-05 \\
(0.000139)\end{array}$ & $\begin{array}{l}-3.58 \mathrm{e}-05 \\
(0.000156)\end{array}$ \\
\hline Age $50_{i} \times \mathbb{1}\left\{\right.$ Age $\left.50_{i}>0\right\} \times$ TypeHybrid & $\begin{array}{c}-0.00592^{* * *} \\
(0.000738)\end{array}$ & $\begin{array}{c}-0.00492^{* * *} \\
(0.000912)\end{array}$ & $\begin{array}{c}4.62 \mathrm{e}-05 \\
(0.000220)\end{array}$ & $\begin{array}{c}0.000232 \\
(0.000309)\end{array}$ & $\begin{array}{c}0.000191 \\
(0.000352)\end{array}$ \\
\hline $\mathbb{1}\left\{{\left.\text { Age } 55_{i}>0\right\} \times \text { TypeRD }}>0\right.$ & $\begin{array}{l}0.132^{* * *} \\
(0.00280)\end{array}$ & $\begin{array}{c}0.0555^{* * *} \\
(0.00259)\end{array}$ & $\begin{array}{c}4.83 \mathrm{e}-05 \\
(0.000701)\end{array}$ & $\begin{array}{l}0.000484 \\
(0.00101)\end{array}$ & $\begin{array}{l}0.000286 \\
(0.00114)\end{array}$ \\
\hline 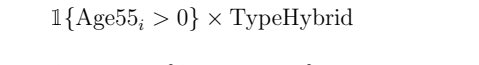 & $\begin{array}{c}0.0879^{* * *} \\
(0.00555)\end{array}$ & $\begin{array}{c}0.0390^{* * *} \\
(0.00511)\end{array}$ & $\begin{array}{r}-0.000878 \\
(0.00128)\end{array}$ & $\begin{array}{l}-0.00184 \\
(0.00178)\end{array}$ & $\begin{array}{c}-0.00144 \\
(0.00200)\end{array}$ \\
\hline Age $55_{i} \times \mathbb{1}\left\{\right.$ Age $\left.55_{i}>-6\right\} \times$ TypeSpline & $\begin{array}{l}0.0249 * * * \\
(0.000384)\end{array}$ & $\begin{array}{c}0.00895^{* * *} \\
(0.000345)\end{array}$ & $\begin{array}{c}-0.000251^{* * *} \\
(8.52 \mathrm{e}-05)\end{array}$ & $\begin{array}{c}-0.000310^{* *} \\
(0.000122)\end{array}$ & $\begin{array}{c}-0.000304^{* *} \\
(0.000137)\end{array}$ \\
\hline 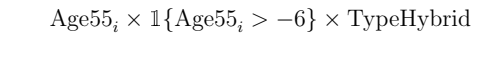 & $\begin{array}{l}0.00449^{* * *} \\
(0.000931)\end{array}$ & $\begin{array}{l}0.00213^{* *} \\
(0.000876)\end{array}$ & $\begin{array}{c}-2.38 \mathrm{e}-05 \\
(0.000217)\end{array}$ & $\begin{array}{c}-1.08 \mathrm{e}-05 \\
(0.000304)\end{array}$ & $\begin{array}{l}-0.000174 \\
(0.000341)\end{array}$ \\
\hline${\text { Age } 55_{i} \times \mathbb{1}\left\{\text { Age } 5_{i}>0\right\} \times \text { TypeSpline }}$ & $\begin{array}{l}-0.0286^{* * *} \\
(0.000445)\end{array}$ & $\begin{array}{l}-0.0122 * * * \\
(0.000385)\end{array}$ & $\begin{array}{c}0.000281^{* * *} \\
(9.73 \mathrm{e}-05)\end{array}$ & $\begin{array}{r}0.000318^{* *} \\
(0.000139)\end{array}$ & $\begin{array}{c}0.000316^{* *} \\
(0.000156)\end{array}$ \\
\hline Age $55_{i} \times \mathbb{1}\left\{\right.$ Age $\left.55_{i}>0\right\} \times$ TypeHybrid & $\begin{array}{c}-0.00802^{* * *} \\
(0.000929)\end{array}$ & $\begin{array}{c}-0.00531^{* * *} \\
(0.000869)\end{array}$ & $\begin{array}{l}1.21 \mathrm{e}-05 \\
(0.000217)\end{array}$ & $\begin{array}{l}2.59 \mathrm{e}-06 \\
(0.000302)\end{array}$ & $\begin{array}{c}0.000232 \\
(0.000339)\end{array}$ \\
\hline \multicolumn{6}{|l|}{ Foreclosure ( $N: 0.81$ million $)$} \\
\hline 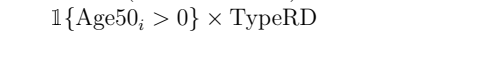 & $\begin{array}{c}0.118^{* * *} \\
(0.0102)\end{array}$ & $\begin{array}{c}0.0385^{* * *} \\
(0.0114)\end{array}$ & $\begin{array}{l}-0.00173 \\
(0.00418)\end{array}$ & $\begin{array}{r}-0.00970^{*} \\
(0.00581)\end{array}$ & $\begin{array}{l}-0.00656 \\
(0.00661)\end{array}$ \\
\hline 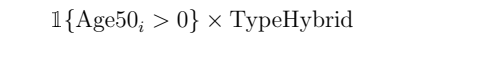 & $\begin{array}{c}0.0483^{* * *} \\
(0.00652)\end{array}$ & $\begin{array}{c}0.00973 \\
(0.00756)\end{array}$ & $\begin{array}{c}-0.000230 \\
(0.00256)\end{array}$ & $\begin{array}{c}0.00350 \\
(0.00359)\end{array}$ & $\begin{array}{c}0.00194 \\
(0.00401)\end{array}$ \\
\hline Age $50_{i} \times \mathbb{1}\left\{{\left.\text { Age } 50_{i}>-6\right\} \times \text { TypeSpline }}\right.$ & $\begin{array}{l}0.0172^{* * *} \\
(0.000691)\end{array}$ & $\begin{array}{c}0.00111 \\
(0.000876)\end{array}$ & $\begin{array}{l}-9.13 \mathrm{e}-05 \\
(0.000289)\end{array}$ & $\begin{array}{l}-0.000215 \\
(0.000413)\end{array}$ & $\begin{array}{c}0.000193 \\
(0.000459)\end{array}$ \\
\hline 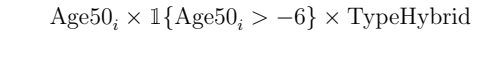 & $\begin{array}{c}0.0151^{* * *} \\
(0.00118)\end{array}$ & $\begin{array}{l}0.00270^{*} \\
(0.00146)\end{array}$ & $\begin{array}{l}-0.000389 \\
(0.000496)\end{array}$ & $\begin{array}{l}-0.00119^{*} \\
(0.000696)\end{array}$ & $\begin{array}{l}-0.000823 \\
(0.000776)\end{array}$ \\
\hline Age $50_{i} \times \mathbb{1}\left\{{\left.\text { Age } 50_{i}>0\right\} \times \text { TypeSpline }}\right.$ & $\begin{array}{c}-0.0171^{* * *} \\
(0.000747)\end{array}$ & $\begin{array}{c}-0.00441^{* * *} \\
(0.000896)\end{array}$ & $\begin{array}{c}2.82 \mathrm{e}-05 \\
(0.000293)\end{array}$ & $\begin{array}{c}7.96 \mathrm{e}-05 \\
(0.000419)\end{array}$ & $\begin{array}{c}-0.000299 \\
(0.000466)\end{array}$ \\
\hline Age $50_{i} \times \mathbb{1}\left\{\right.$ Age $\left.50_{i}>0\right\} \times$ TypeHybrid & $\begin{array}{c}-0.0153^{* * *} \\
(0.00113)\end{array}$ & $\begin{array}{c}-0.00632 * * * \\
(0.00137)\end{array}$ & $\begin{array}{c}0.000294 \\
(0.000464)\end{array}$ & $\begin{array}{c}0.00106 \\
(0.000650)\end{array}$ & $\begin{array}{c}0.000775 \\
(0.000724)\end{array}$ \\
\hline $\mathbb{1}\left\{\right.$ Age $\left.55_{i}>0\right\} \times$ TypeRD & $\begin{array}{c}0.115^{* * *} \\
(0.0103)\end{array}$ & $\begin{array}{c}0.0362^{* * *} \\
(0.00932)\end{array}$ & $\begin{array}{l}-0.00475 \\
(0.00361)\end{array}$ & $\begin{array}{l}-0.00319 \\
(0.00505)\end{array}$ & $\begin{array}{l}-0.00180 \\
(0.00561)\end{array}$ \\
\hline 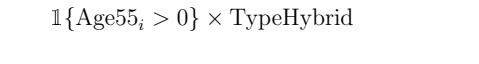 & $\begin{array}{c}0.0625^{* * *} \\
(0.00668)\end{array}$ & $\begin{array}{c}0.0274^{* * *} \\
(0.00578)\end{array}$ & $\begin{array}{c}-0.00456^{* *} \\
(0.00215)\end{array}$ & $\begin{array}{l}-0.00570^{*} \\
(0.00299)\end{array}$ & $\begin{array}{c}-0.00687^{* *} \\
(0.00334)\end{array}$ \\
\hline Age $55_{i} \times \mathbb{1}\left\{\right.$ Age $\left.55_{i}>-6\right\} \times$ TypeSpline & $\begin{array}{l}0.0314^{* * *} \\
(0.000776)\end{array}$ & $\begin{array}{c}0.00715^{* * *} \\
(0.000704)\end{array}$ & $\begin{array}{l}-0.000319 \\
(0.000249)\end{array}$ & $\begin{array}{l}-0.000362 \\
(0.000346)\end{array}$ & $\begin{array}{l}-0.000615 \\
(0.000385)\end{array}$ \\
\hline 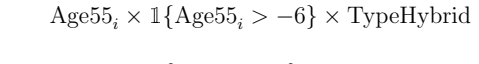 & $\begin{array}{c}0.0205^{* * *} \\
(0.00127)\end{array}$ & $\begin{array}{c}0.00373^{* * *} \\
(0.00115)\end{array}$ & $\begin{array}{c}0.000519 \\
(0.000418)\end{array}$ & $\begin{array}{c}0.000681 \\
(0.000579)\end{array}$ & $\begin{array}{c}0.000719 \\
(0.000646)\end{array}$ \\
\hline${\text { Age } 55_{i} \times \mathbb{1}\left\{\text { Age } 55_{i}>0\right\} \times \text { TypeSpline }}$ & $\begin{array}{l}-0.0348^{* * *} \\
(0.000814)\end{array}$ & $\begin{array}{r}-0.0114^{* * *} \\
(0.000708)\end{array}$ & $\begin{array}{c}0.000408 \\
(0.000254)\end{array}$ & $\begin{array}{c}0.000508 \\
(0.000354)\end{array}$ & $\begin{array}{r}0.000826^{* *} \\
(0.000392)\end{array}$ \\
\hline 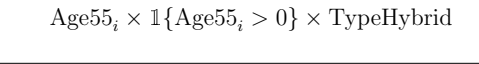 & $\begin{array}{c}-0.0237^{* * *} \\
(0.00119)\end{array}$ & $\begin{array}{c}-0.00808^{* * *} \\
(0.00106)\end{array}$ & $\begin{array}{l}-0.000425 \\
(0.000390)\end{array}$ & $\begin{array}{l}-0.000517 \\
(0.000540)\end{array}$ & $\begin{array}{l}-0.000535 \\
(0.000602)\end{array}$ \\
\hline
\end{tabular}

Notes: This table reports first stage and reduced-form estimates of the effect of being 50 years or older and 55 years or older at the initial decision date on the initial allowance rate, the final allowance rate after all appeals, and on reduced-form outcomes, specifically estimates of $\beta_{\mathrm{RD}_{j, T}}, \beta_{\mathrm{Spline}_{j, T}}$, and $\beta_{\mathrm{Spline}_{j, T}}$ from equation (3). The "bankruptcy" regressions are based on the bankruptcy sample: disability-program applicants who reach step 5 of the disability determination process and who have an initial decision date in 2000-2009. The "foreclosure" regressions are based on the foreclosure sample: disability-program applicants who appear in the deeds records (homeowners), who reach step 5 of the disability determination process, and who have an initial decision date in 2005-2014. Each sample excludes ZIP Codes of residence at application that have an average of fewer than five recorded events per year during the corresponding period. Standard errors in parentheses. ${ }^{* * *} p<0.01,{ }^{* *} p<0.05,{ }^{*} p<0.1$. 
Table A.7: Estimates of First Stage and Reduced-Form Effects - Eviction

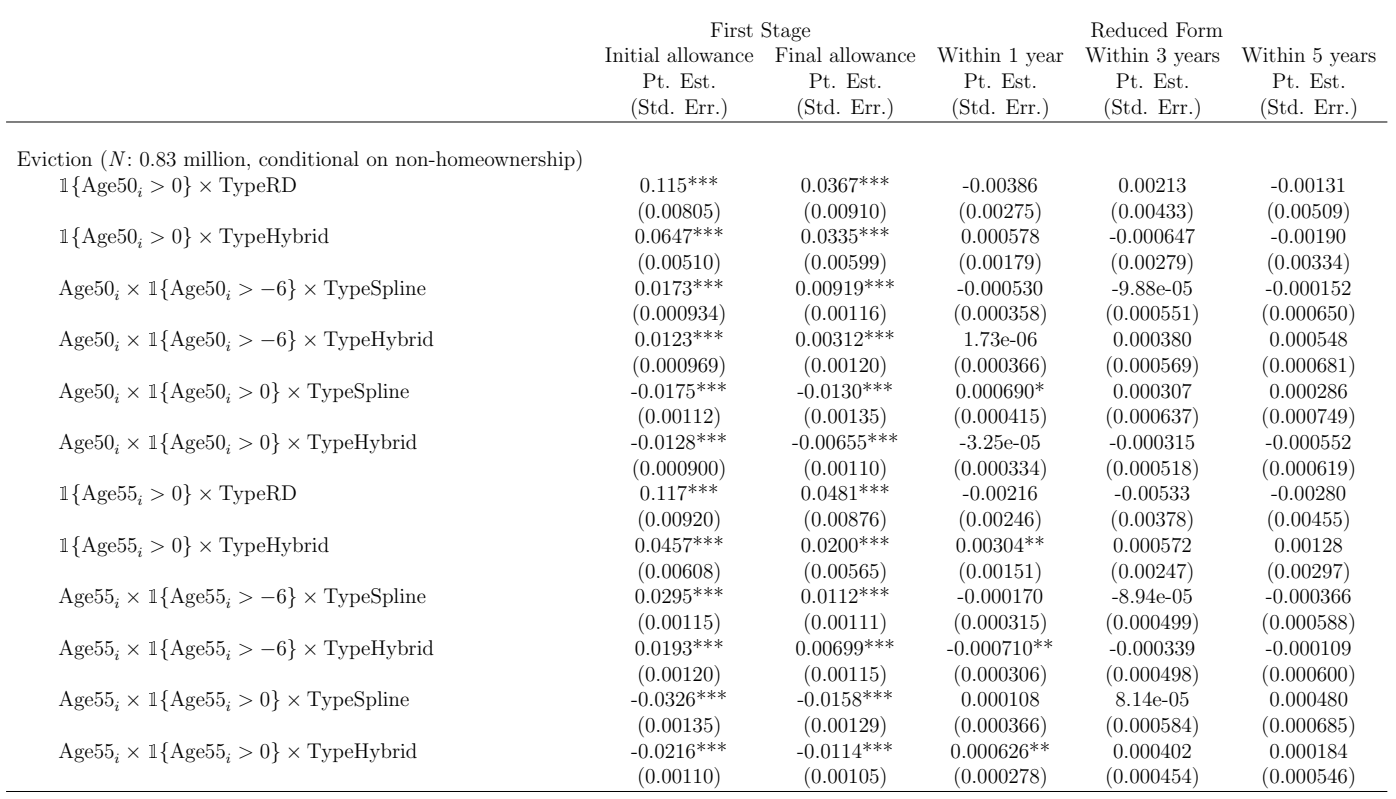

Notes: This table reports first stage and reduced-form estimates of the effect of being 50 years or older and 55 years or older at the initial decision date on the initial allowance rate, the final allowance rate after all appeals, and on reduced-form outcomes, specifically estimates of $\beta_{\mathrm{RD}_{j, T}}, \beta_{\mathrm{Spline}_{j, T}}$, and $\beta_{\mathrm{Spline}_{j, T}}$ from equation (3). The "eviction" regressions are based on the eviction sample: disability-program applicants who do not appear in the deeds records (non-homeowners), who reach step 5 of the disability determination process, who have an initial decision date in 2005-2014, and whose FIPS county code of residence at application that has an average of at least fifteen recorded events per year during this period. Standard errors in parentheses. ${ }^{* * *} p<0.01,{ }^{* *} p<0.05,{ }^{*} p<0.1$. 
Table A.8: Estimates of First Stage and Reduced-Form Effects - Net Home-sale and Net Home-purchase

\begin{tabular}{|c|c|c|c|c|c|}
\hline & \multicolumn{2}{|c|}{ First Stage } & \multicolumn{3}{|c|}{ Reduced Form } \\
\hline & $\begin{array}{c}\text { Initial allowance } \\
\text { Pt. Est. } \\
\text { (Std. Err.) }\end{array}$ & $\begin{array}{c}\text { Final allowance } \\
\text { Pt. Est. } \\
\text { (Std. Err.) }\end{array}$ & $\begin{array}{c}\text { Within } 1 \text { year } \\
\text { Pt. Est. } \\
\text { (Std. Err.) }\end{array}$ & $\begin{array}{l}\text { Within } 3 \text { years } \\
\text { Pt. Est. } \\
\text { (Std. Err.) }\end{array}$ & $\begin{array}{c}\text { Within } 5 \text { years } \\
\text { Pt. Est. } \\
\text { (Std. Err.) }\end{array}$ \\
\hline \multicolumn{6}{|c|}{ Net home-sale ( $N$ : 1.45 million, conditional on homeownership) } \\
\hline $\mathbb{1}\left\{{\left.\text { Age } 50_{i}>0\right\} \times \text { TypeRD }}\right.$ & $\begin{array}{l}0.105^{* * *} \\
(0.00653)\end{array}$ & $\begin{array}{c}0.0259^{* * *} \\
(0.00741)\end{array}$ & $\begin{array}{l}-0.00270 \\
(0.00334)\end{array}$ & $\begin{array}{r}-0.0108^{* *} \\
(0.00508)\end{array}$ & $\begin{array}{l}-0.00583 \\
(0.00588)\end{array}$ \\
\hline 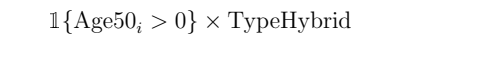 & $\begin{array}{c}0.0605^{* * *} \\
(0.00474)\end{array}$ & $\begin{array}{c}0.0221^{* * *} \\
(0.00561)\end{array}$ & $\begin{array}{l}-0.00113 \\
(0.00252)\end{array}$ & $\begin{array}{c}0.00360 \\
(0.00378)\end{array}$ & $\begin{array}{c}0.00258 \\
(0.00439)\end{array}$ \\
\hline${\text { Age } 50_{i} \times \mathbb{1}\left\{{\text { Age } 50_{i}}>-6\right\} \times \text { TypeSpline }}$ & $\begin{array}{l}0.0163^{* * *} \\
(0.000535)\end{array}$ & $\begin{array}{c}0.00107 \\
(0.000664)\end{array}$ & $\begin{array}{l}-0.000286 \\
(0.000282)\end{array}$ & $\begin{array}{l}-0.000805^{*} \\
(0.000430)\end{array}$ & $\begin{array}{l}-0.000585 \\
(0.000501)\end{array}$ \\
\hline 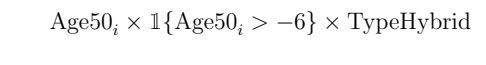 & $\begin{array}{l}0.0114^{* * *} \\
(0.000864)\end{array}$ & $\begin{array}{c}0.00103 \\
(0.00108)\end{array}$ & $\begin{array}{c}6.28 \mathrm{e}-05 \\
(0.000483)\end{array}$ & $\begin{array}{l}-0.000728 \\
(0.000724)\end{array}$ & $\begin{array}{l}-0.000264 \\
(0.000840)\end{array}$ \\
\hline${\text { Age } 50_{i} \times \mathbb{1}\left\{\text { Age } 0_{i}>0\right\} \times \text { TypeSpline }}$ & $\begin{array}{l}-0.0164^{* * *} \\
(0.000585)\end{array}$ & $\begin{array}{c}-0.00421^{* * *} \\
(0.000687)\end{array}$ & $\begin{array}{c}0.000384 \\
(0.000288)\end{array}$ & $\begin{array}{r}0.000897^{* *} \\
(0.000441)\end{array}$ & $\begin{array}{c}0.000711 \\
(0.000515)\end{array}$ \\
\hline 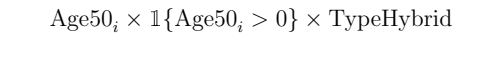 & $\begin{array}{r}-0.0119^{* * *} \\
(0.000820)\end{array}$ & $\begin{array}{c}-0.00460^{* * *} \\
(0.00101)\end{array}$ & $\begin{array}{l}-2.09 \mathrm{e}-05 \\
(0.000453)\end{array}$ & $\begin{array}{c}0.000628 \\
(0.000679)\end{array}$ & $\begin{array}{c}0.000299 \\
(0.000787)\end{array}$ \\
\hline $\mathbb{1}\left\{{\left.\text { Age } 55_{i}>0\right\} \times \text { TypeRD }}\right.$ & $\begin{array}{l}0.140^{* * *} \\
(0.00678)\end{array}$ & $\begin{array}{l}0.0449 * * * \\
(0.00601)\end{array}$ & $\begin{array}{l}-0.00404 \\
(0.00309)\end{array}$ & $\begin{array}{l}-0.00456 \\
(0.00469)\end{array}$ & $\begin{array}{l}-0.00715 \\
(0.00536)\end{array}$ \\
\hline $\mathbb{1}\left\{{\left.\text { Age } 55_{i}>0\right\} \times \text { TypeHybrid }}\right.$ & $\begin{array}{l}0.0698^{* * *} \\
(0.00510)\end{array}$ & $\begin{array}{c}0.0277^{* * *} \\
(0.00444)\end{array}$ & $\begin{array}{r}-0.000763 \\
(0.00225)\end{array}$ & $\begin{array}{l}0.000770 \\
(0.00338)\end{array}$ & $\begin{array}{l}0.00440 \\
(0.00391)\end{array}$ \\
\hline${\text { Age } 55_{i} \times \mathbb{1}\left\{\text { Age } 5_{i}>-6\right\} \times \text { TypeSpline }}$ & $\begin{array}{l}0.0305^{* * *} \\
(0.000599)\end{array}$ & $\begin{array}{l}0.00748^{* * *} \\
(0.000534)\end{array}$ & $\begin{array}{c}-0.000557^{* *} \\
(0.000252)\end{array}$ & $\begin{array}{c}-0.00108^{* * *} \\
(0.000387)\end{array}$ & $\begin{array}{c}-0.00161^{* * *} \\
(0.000451)\end{array}$ \\
\hline${\text { Age } 55_{i} \times \mathbb{1}\left\{\text { Age } 5_{i}>-6\right\} \times \text { TypeHybrid }}$ & $\begin{array}{l}0.0163^{* * *} \\
(0.000965)\end{array}$ & $\begin{array}{c}0.00332^{* * * *} \\
(0.000873)\end{array}$ & $\begin{array}{l}-0.000356 \\
(0.000429)\end{array}$ & $\begin{array}{l}-0.000879 \\
(0.000647)\end{array}$ & $\begin{array}{l}-0.00112 \\
(0.000747)\end{array}$ \\
\hline Age $55_{i} \times \mathbb{1}\left\{{\left.\text { Age } 55_{i}>0\right\} \times \text { TypeSpline }}\right.$ & $\begin{array}{l}-0.0338^{* * *} \\
(0.000634)\end{array}$ & $\begin{array}{l}-0.0115^{* * *} \\
(0.000542)\end{array}$ & $\begin{array}{c}0.000373 \\
(0.000258)\end{array}$ & $\begin{array}{c}0.000974^{* *} \\
(0.000399)\end{array}$ & $\begin{array}{l}0.00155^{* * *} \\
(0.000465)\end{array}$ \\
\hline 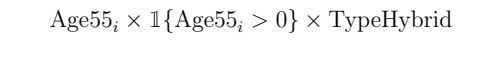 & $\begin{array}{l}-0.0191^{* * *} \\
(0.000907)\end{array}$ & $\begin{array}{c}-0.00711^{* * *} \\
(0.000811)\end{array}$ & $\begin{array}{c}0.000286 \\
(0.000403)\end{array}$ & $\begin{array}{c}0.000984 \\
(0.000606)\end{array}$ & $\begin{array}{c}0.00108 \\
(0.000700)\end{array}$ \\
\hline \multicolumn{6}{|l|}{ Net home-purchase ( $N: 5.12$ million) } \\
\hline $\mathbb{1}\left\{\right.$ Age $\left.0_{i}>0\right\} \times$ TypeRD & $\begin{array}{c}0.0934^{* * *} \\
(0.00302)\end{array}$ & $\begin{array}{c}0.0328^{* * *} \\
(0.00364)\end{array}$ & $\begin{array}{c}0.000276 \\
(0.000956)\end{array}$ & $\begin{array}{c}0.00141 \\
(0.00148)\end{array}$ & $\begin{array}{c}0.00148 \\
(0.00169)\end{array}$ \\
\hline 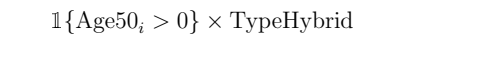 & $\begin{array}{c}0.0520 * * * \\
(0.00236)\end{array}$ & $\begin{array}{c}0.0194^{* * *} \\
(0.00288)\end{array}$ & $\begin{array}{l}0.00208^{* * *} * \\
(0.000744)\end{array}$ & $\begin{array}{c}0.00335^{* * *} \\
(0.00116)\end{array}$ & $\begin{array}{c}0.00335^{* *} \\
(0.00136)\end{array}$ \\
\hline Age $50_{i} \times \mathbb{1}\left\{{\left.\text { Age } 50_{i}>-6\right\} \times \text { TypeSpline }}\right.$ & $\begin{array}{l}0.0157^{* * *} \\
(0.000266)\end{array}$ & $\begin{array}{c}0.00354^{* * *} \\
(0.000339)\end{array}$ & $\begin{array}{c}5.64 \mathrm{e}-05 \\
(8.64 \mathrm{e}-05)\end{array}$ & $\begin{array}{l}-8.82 \mathrm{e}-05 \\
(0.000135)\end{array}$ & $\begin{array}{l}-0.000137 \\
(0.000157)\end{array}$ \\
\hline 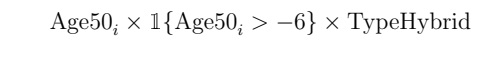 & $\begin{array}{l}0.0113^{* * *} \\
(0.000425)\end{array}$ & $\begin{array}{c}0.00324^{* * *} \\
(0.000548)\end{array}$ & $\begin{array}{l}-0.000236^{*} \\
(0.000141)\end{array}$ & $\begin{array}{c}-0.000456^{* *} \\
(0.000220)\end{array}$ & $\begin{array}{c}-0.000630^{* *} \\
(0.000257)\end{array}$ \\
\hline Age $50_{i} \times \mathbb{1}\left\{\right.$ Age $\left.50_{i}>0\right\} \times$ TypeSpline & $\begin{array}{r}-0.0156^{* * * *} \\
(0.000296)\end{array}$ & $\begin{array}{c}-0.00634^{* * *} \\
(0.000357)\end{array}$ & $\begin{array}{l}-6.42 \mathrm{e}-05 \\
(9.06 \mathrm{e}-05)\end{array}$ & $\begin{array}{c}0.000108 \\
(0.000142)\end{array}$ & $\begin{array}{c}0.000143 \\
(0.000166)\end{array}$ \\
\hline 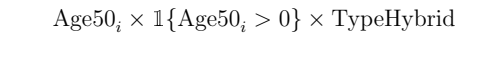 & $\begin{array}{l}-0.0113^{* * *} \\
(0.000405)\end{array}$ & $\begin{array}{c}-0.00619 * * * \\
(0.000513)\end{array}$ & $\begin{array}{c}0.000214 \\
(0.000133)\end{array}$ & $\begin{array}{c}0.000443^{* *} \\
(0.000207)\end{array}$ & $\begin{array}{c}0.000626^{* * *} \\
(0.000241)\end{array}$ \\
\hline $\mathbb{1}\left\{\right.$ Age $\left.5_{i}>0\right\} \times$ TypeRD & $\begin{array}{l}0.143^{* * * *} \\
(0.00365)\end{array}$ & $\begin{array}{c}0.0565^{* * *} \\
(0.00343)\end{array}$ & $\begin{array}{c}0.00240^{* *} \\
(0.00107)\end{array}$ & $\begin{array}{c}0.00104 \\
(0.00161)\end{array}$ & $\begin{array}{c}0.00214 \\
(0.00183)\end{array}$ \\
\hline $\mathbb{1}\left\{{\text { Age } 55_{i}}>0\right\} \times$ TypeHybrid & $\begin{array}{c}0.0646 * * * \\
(0.00288)\end{array}$ & $\begin{array}{l}0.0263^{* * *} \\
(0.00262)\end{array}$ & $\begin{array}{c}0.000198 \\
(0.000830)\end{array}$ & $\begin{array}{l}0.000849 \\
(0.00127)\end{array}$ & $\begin{array}{l}-0.00115 \\
(0.00147)\end{array}$ \\
\hline${\text { Age } 55_{i} \times \mathbb{1}\left\{\text { Age } 5_{i}>-6\right\} \times \text { TypeSpline }}$ & $\begin{array}{l}0.0299 * * * \\
(0.000334)\end{array}$ & $\begin{array}{c}0.00909 * * * \\
(0.000312)\end{array}$ & $\begin{array}{c}0.000321^{* * *} \\
(9.51 \mathrm{e}-05)\end{array}$ & $\begin{array}{c}0.000412^{* * *} \\
(0.000147)\end{array}$ & $\begin{array}{c}0.000424^{* *} \\
(0.000170)\end{array}$ \\
\hline Age $55_{i} \times \mathbb{1}\left\{\right.$ Age $\left.55_{i}>-6\right\} \times$ TypeHybrid & $\begin{array}{l}0.0166^{* * *} \\
(0.000537)\end{array}$ & $\begin{array}{c}0.00508^{* * *} \\
(0.000508)\end{array}$ & $\begin{array}{c}0.000126 \\
(0.000156)\end{array}$ & $\begin{array}{c}0.000204 \\
(0.000239)\end{array}$ & $\begin{array}{c}0.000667^{* *} \\
(0.000276)\end{array}$ \\
\hline Age $55_{i} \times \mathbb{1}\left\{\right.$ Age $\left.55_{i}>0\right\} \times$ TypeSpline & $\begin{array}{l}-0.0329^{* * * *} \\
(0.000360)\end{array}$ & $\begin{array}{c}-0.0131^{* * *} \\
(0.000322)\end{array}$ & $\begin{array}{c}-0.000306^{* * * *} \\
(0.000101)\end{array}$ & $\begin{array}{c}-0.000386^{* *} \\
(0.000157)\end{array}$ & $\begin{array}{c}-0.000361^{* *} \\
(0.000181)\end{array}$ \\
\hline 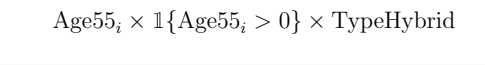 & $\begin{array}{l}-0.0191^{* * *} \\
(0.000507)\end{array}$ & $\begin{array}{c}-0.00895^{* * *} \\
(0.000474)\end{array}$ & $\begin{array}{l}-3.62 \mathrm{e}-05 \\
(0.000147)\end{array}$ & $\begin{array}{l}-0.000159 \\
(0.000225)\end{array}$ & $\begin{array}{c}-0.000563^{* *} \\
(0.000260)\end{array}$ \\
\hline
\end{tabular}

Notes: This table reports first-stage and reduced-form estimates of the effect of being 50 years or older and 55 years or older at the initial decision date on the initial allowance rate, the final allowance rate after all appeals, and on reduced-form outcomes, specifically estimates of $\beta_{\mathrm{RD}_{j, T}}, \beta_{\mathrm{Spline}_{j, T}}$, and $\beta_{\mathrm{Spline}_{j, T}}$ from equation (3). The "net home-sale" regressions are based on the home-sale sample: disabilityprogram applicants who appear in the deeds records (homeowners), who reach step 5 of the disability determination process, and who have an initial decision date in 2000-2014. The "net home-purchase" regressions are based on the home-purchase sample: disability-program applicants who reach step 5 of the disability determination process and who have an initial decision date in 2000-2014. A "net" home sale is defined as a home sale that is not accompanied by a home purchase within six months before or after the sale, and analogously for net home purchase. Each sample excludes ZIP Codes of residence at application that have an average of fewer than fifteen recorded events per year during the corresponding period. Standard errors in parentheses. ${ }^{* * *} p<0.01,{ }^{* *} p<0.05,{ }^{*} p<0.1$. 
Table A.9: Standard RD and Donut RD Estimates of First Stage and Reduced-Form Effects

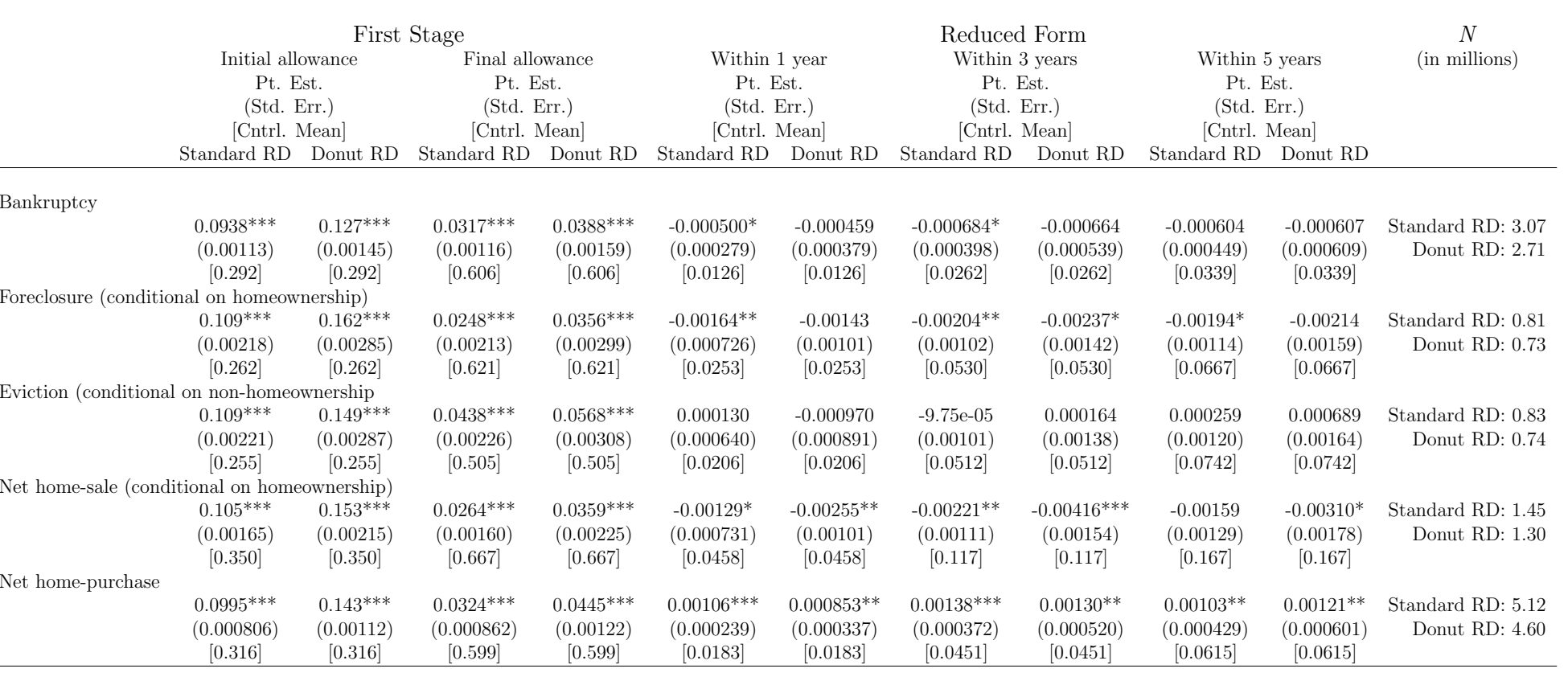

Notes: This table reports standard RD and donut RD first-stage estimates of the effect of being 50 years or older and 55 years or older at the initial decision date on the initial allowance rate, the final allowance rate after all appeals, and on reduced-form outcomes, specifically estimates of $\beta$ from equation (2). Donut RD regressions exclude applicants who are under age 50 or 55 by 1 to 5 months. The "bankruptcy" standard $\mathrm{RD}$ regressions are based on the bankruptcy sample: disability-program applicants who reach step 5 of the disability determination process, who have an initial decision date in 2000-2009. The "foreclosure" standard RD regressions are based on the foreclosure sample: disability-program applicants who appear in the deeds records (homeowners), who reach step 5 of the disability determination process, and who have an initial decision date in 2005-2014. The "eviction" standard RD regressions are based on the eviction sample: disability-program applicants who do not appear in the deeds records (non-homeowners), who reach step 5 of the disability determination process and who have an initial decision date in 2005-2014. The "net home-sale" standard RD regressions are based on the home-sale sample: disability-program applicants who appear in the deeds records (homeowners), who reach step 5 of the disability determination process, and who have an initial decision date in 2000-2014. The "net home-purchase" standard RD regressions are based on the home-purchase sample: disability-program applicants who reach step 5 of the disability determination process and who have an initial decision date in 2000-2014. A "net" home sale is defined as a home sale that is not accompanied by a home purchase within six months before or after the sale, and analogously for net home purchase. Samples involving "foreclosure" and "bankruptcy" outcomes exclude ZIP Codes of residence at application that have an average of fewer than five recorded events per year during the corresponding period; samples involving "eviction" outcomes exclude FIPS county codes of residence at application that have an average of fewer than fifteen recorded events per year during 2005-2014; samples involving "net home-sale" or "net home-purchase" outcomes exclude ZIP Code of residence at application that has an average of less than fifteen recorded corresponding events per year during 2000-2014. Standard errors in parentheses; control means in square brackets are the average value of the variable for applicants who are under age 50 or age 55 by 6 to 10 months or fewer. ${ }^{* * *} p<0.01,{ }^{* *} p<0.05,{ }^{*} p<0.1$. 
Table A.10: Instrumental Variable Estimates Using Standard RD and Donut RD Specification

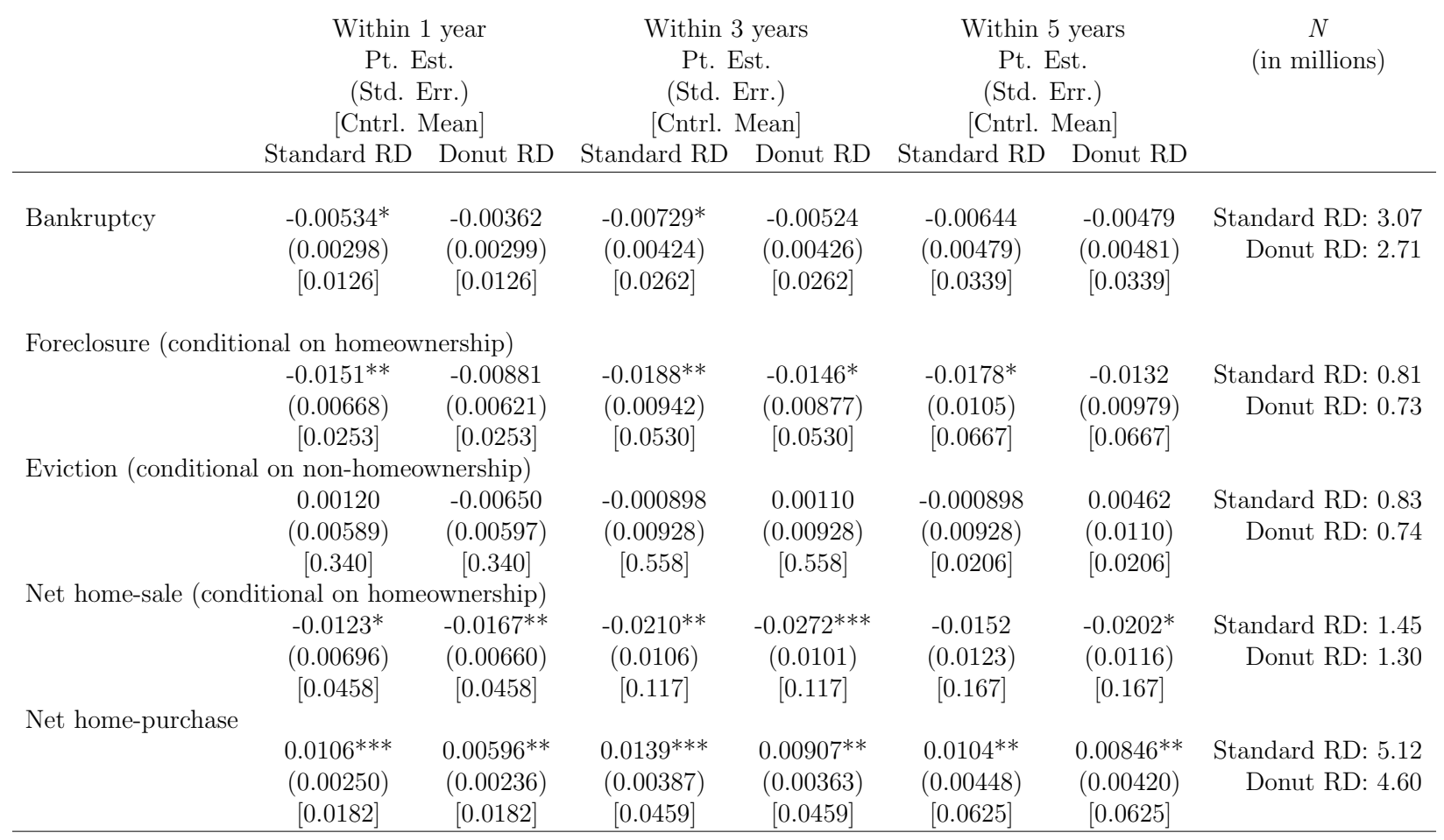

Notes: This table reports standard RD and donut RD instrumental-variable estimates of the effect of disability-program benefits on financial outcomes. Donut RD regressions exclude applicants who are under age 50 or 55 by 1 to 5 months. The "bankruptcy" regressions are based on the bankruptcy sample: disability-program applicants who reach step 5 of the disability determination process, who have an initial decision date in 2000-2009. The "foreclosure" regressions are based on the foreclosure sample: disabilityprogram applicants who appear in the deeds records (homeowners), who reach step 5 of the disability determination process, and who have an initial decision date in 2005-2014. The "eviction" regressions are based on the eviction sample: disability-program applicants who do not appear in the deeds records (nonhomeowners), who reach step 5 of the disability determination process, and who have an initial decision date in 2005-2014. The "net home-sale" regressions are based on the home-sale sample: disabilityprogram applicants who appear in the deeds records (homeowners), who reach step 5 of the disability determination process, and who have an initial decision date in 2000-2014. The "net home-purchase" regressions are based on the home-purchase sample: disability-program applicants who reach step 5 of the disability determination process and who have an initial decision date in 2000-2014. A "net" home sale is defined as a home sale that is not accompanied by a home purchase within six months before or after the sale, and analogously for net home purchase. Samples involving "foreclosure" and "bankruptcy" outcomes exclude ZIP Codes of residence at application that have an average of fewer than five recorded events per year during the corresponding period; samples involving "eviction" outcomes exclude FIPS county codes of residence at application that have an average of fewer than fifteen recorded events per year during 2005-2014; samples involving "net home-sale" or "net home-purchase" outcomes exclude ZIP Code of residence at application that has an average of less than fifteen recorded corresponding events per year during 2000-2014. Standard errors in parentheses; control means in square brackets are the average value of the variable for applicants who are under age 50 or 55 by 6 to 10 months or fewer. *** $p<0.01,{ }^{* *} p<0.05,{ }^{*} p<0.1$. 


\section{Table A.11: Instrumental Variable Estimates for Earnings and Income}

\begin{tabular}{|c|c|c|c|}
\hline & $\begin{array}{l}\text { Within } 1 \text { year } \\
\text { Pt. Est. } \\
\text { (Std. Err.) } \\
\text { [Cntrl. Mean] }\end{array}$ & $\begin{array}{l}\text { Within } 3 \text { years } \\
\text { Pt. Est. } \\
\text { (Std. Err.) } \\
\text { [Cntrl. Mean] }\end{array}$ & $\begin{array}{c}N \\
\text { (in millions) }\end{array}$ \\
\hline \multicolumn{4}{|l|}{ Earnings } \\
\hline \multirow{2}{*}{ Total Income } & $\begin{array}{c}-413.4^{* *} \\
(171.6) \\
{[\$ 2247]}\end{array}$ & $\begin{array}{c}-1,077^{* * *} \\
(148.2) \\
{[\$ 2144]}\end{array}$ & 3.02 \\
\hline & $\begin{array}{c}1,327 * * * \\
(146.7) \\
{[\$ 3387]}\end{array}$ & $\begin{array}{l}269.4^{*} \\
(139.0) \\
{[\$ 3124]}\end{array}$ & 1.65 \\
\hline
\end{tabular}

Notes: This table reports instrumental-variable estimates of the effect of disability-program benefits on average annual earnings after the initial decision and average annual earnings including disability-program benefit. Estimates here are based on the bankruptcy sample: disability-program applicants who reach step 5 in the disability determination process, who have an initial decision date in 2000-2009, and whose ZIP Code of residence at application that has an average of at least five recorded bankruptcies per year during this period. Standard errors in parentheses; control means in square brackets are the average value of the variable for applicants who are under age 50 or 55 by 6 to 10 months. ${ }^{* * *} p<0.01$, ** $p<0.05, * p<0.1$. 